\title{
Morally Injurious Experiences of Combat Exposed Veterans of Iraq and Afghanistan: Moderating Effects of Self-Forgiveness on Feelings of Shame and Guilt
}

Timothy Swiger

tswiger2@mix.wvu.edu

Follow this and additional works at: https://researchrepository.wvu.edu/etd

Part of the Counseling Psychology Commons

\section{Recommended Citation}

Swiger, Timothy, "Morally Injurious Experiences of Combat Exposed Veterans of Iraq and Afghanistan: Moderating Effects of Self-Forgiveness on Feelings of Shame and Guilt" (2020). Graduate Theses,

Dissertations, and Problem Reports. 7780.

https://researchrepository.wvu.edu/etd/7780

This Dissertation is protected by copyright and/or related rights. It has been brought to you by the The Research Repository @ WVU with permission from the rights-holder(s). You are free to use this Dissertation in any way that is permitted by the copyright and related rights legislation that applies to your use. For other uses you must obtain permission from the rights-holder(s) directly, unless additional rights are indicated by a Creative Commons license in the record and/ or on the work itself. This Dissertation has been accepted for inclusion in WVU Graduate Theses, Dissertations, and Problem Reports collection by an authorized administrator of The Research Repository @ WVU.

For more information, please contact researchrepository@mail.wvu.edu. 
Morally Injurious Experiences of Combat Exposed Veterans of Iraq and Afghanistan: Moderating Effects of Self-Forgiveness on Feelings of Shame and Guilt

Timothy Swiger

Follow this and additional works at: https://researchrepository.wvu.edu/etd

Part of the Counseling Psychology Commons 
Running head: MORAL INJURY, SHAME, GUILT, AND SELF-FORGIVENESS

\section{Morally Injurious Experiences of Combat Exposed Veterans of Iraq and Afghanistan: Moderating Effects of Self-Forgiveness on Feelings of Shame and Guilt}

Timothy A. Swiger, Ph.D.

Dissertation submitted to the College of Education and Human Services

at West Virginia University

in partial fulfillment of the

requirements for the degree of

Doctor of Philosophy

in

Counseling Psychology

Jeffrey Daniels, Ph.D., Chair

James Bartee, Ph.D.

Monica Leppma, Ph.D.

Christopher Scheitle, Ph.D.

Department of Counseling, Rehabilitation Counseling, and Counseling Psychology

Morgantown, West Virginia, 2020

Keywords: Veterans, Moral Injury, Self-Forgiveness, Shame, Guilt, Cognitive Dissonance Copyright 2018 by Timothy A. Swiger 


\section{ABSTRACT \\ Morally Injurious Experiences of Combat Exposed Veterans of Iraq and Afghanistan: Moderating Effects of Self-Forgiveness on Feelings of Shame and Guilt \\ Timothy Swiger}

Moral injury is a construct developed to explain a unique symptom profile of individuals who may have perpetrated, witnessed, or learned about events that transgress their held moral beliefs. Among combat exposed Veterans, particular attention has been focused on the ambiguous nature of recent military conflicts and the increased moral conflicts associated with more recent, unconventional combat tactics and strategies. This study examined the relationship between moral injury and feelings of shame and guilt among a large sample $(n=198)$ of Veterans who deployed in support of conflicts in Iraq and/or Afghanistan. Additionally, this study sought to examine self-forgiveness as a moderator of the well-studied and empirically supported association of moral injury and shame and guilt. This study considered demographic and exposure variables and found moral injury was positively correlated with feelings of shame, guilt, and with the combination of these two affective experiences. Also, self-forgiveness was found to moderate the relationship between shame and guilt. The results of this study further support the relationship between moral injury and feelings of shame and guilt, as identified in the past decade of moral injury literature. The results also suggest that self-forgiveness does significantly impact the strength of the relationship between moral injury and feelings of shame and guilt, which supports Litz et al.'s (2009) conceptual model. This study demonstrates a need for more research to examine self-forgiveness as a principle factor in moral injury treatment, which could improve the efficacy of moral injury treatments such as Adaptive Disclosure. 
MORAL INJURY, SHAME, GUILT, AND SELF-FORGIVENESS

\title{
DEDICATION
}

This study is dedicated to those who I had the distinct pleasure of serving with in the United

States military and who paid the ultimate sacrifice in defend our Freedoms. This study is also dedicated to those who survived combat but succumbed to their internal battles, as their war never ended. The following names, listed by rank, are true American heroes:

\author{
LCpl. Alberto Francesconi \\ LCpl. Jessie A. Cassada \\ LCpl. Julian T. Brennan \\ LCpl. Kevin T. Preach \\ LCpl. Daniel J. Geary \\ LCpl. Blaise A. Oleski \\ LCpl. Andrew P. Carpenter \\ Cpl. Michael W. Ouellette \\ Cpl. Anthony L. Williams \\ Cpl. Anthony B. Carden \\ PO2 Charles L. Milam \\ Sgt. David W. Wallace \\ Sgt. Trevor J. Johnson \\ SSgt. Daniel L. Hanson \\ Tech Sgt. Jason P. Swiger
}


MORAL INJURY, SHAME, GUILT, AND SELF-FORGIVENESS

\section{ACKNOWLEDGEMENTS}

I would like first to thank my committee chair, Dr. Jeff Daniels. Dr. Daniels was an integral part of my education and a faithful supporter of my academic and clinical career. His willingness to allow me to examine combat experiences among Iraq and Afghanistan Veterans enabled me the opportunity to inform my clinical practice through empirical research. Secondly, I would like to thank Dr. James Bartee. Dr. Bartee has been a trusted mentor who provided invaluable feedback throughout the course of writing this dissertation. I want to thank Vicki Railings for her assistance with all of the administrative procedures in completing my doctoral degree. I also want to thank the rest of my dissertation committee and those Veterans who participated in this study.

On a personal note, I would like to thank Dennis McCune. Mr. McCune is a fellow Marine who exemplifies the Marine Corps motto of "Semper Fidelis," as he is always faithful to the care of his fellow Marines. I want to thank my graduate cohort, without which I could not have completed this program. As this cohort will soon become practitioners in the field, each embodies the very essence of what it means to be mountaineers, in which they put the needs of others before themselves. Finally, I want to thank my wife and son for their unflagging support over the many years it has taken to complete my academic study. 


\section{TABLE OF CONTENTS}

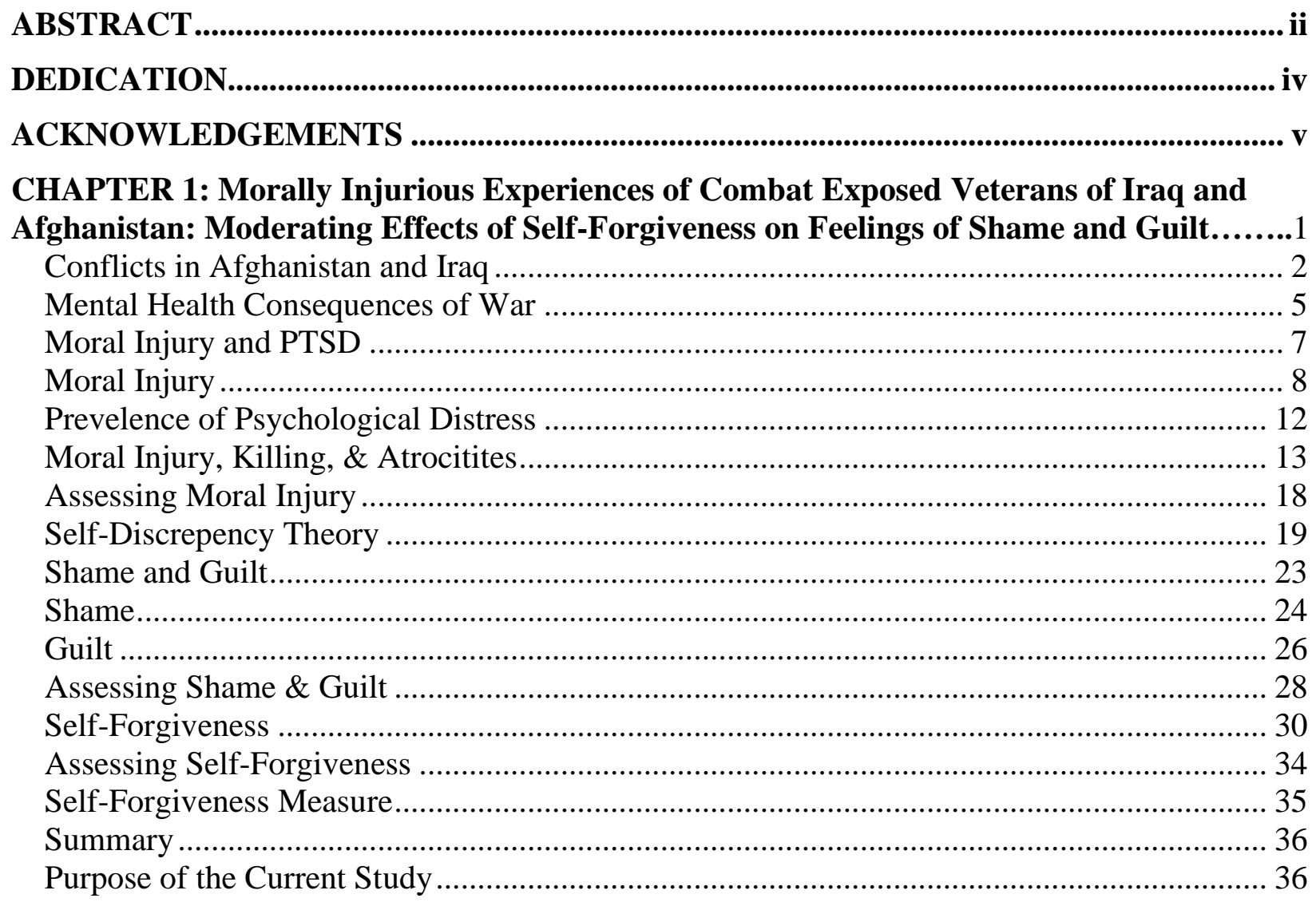

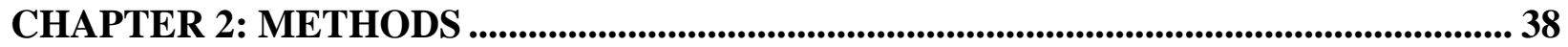

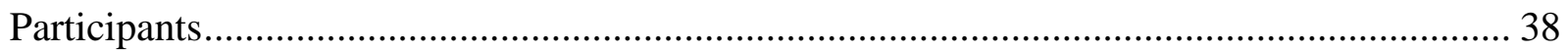

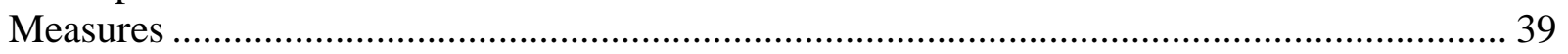

The Moral Injury Questionnaire- Military Version ............................................................. 39

The State Shame and Guilt Scale ..................................................................................... 42

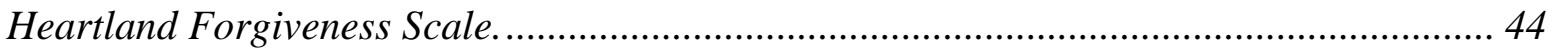

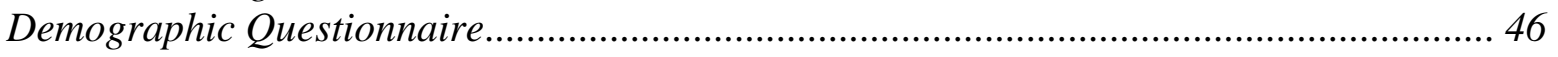

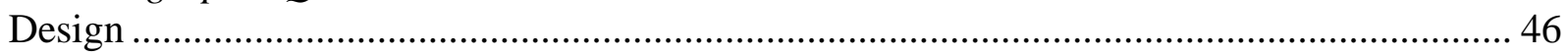

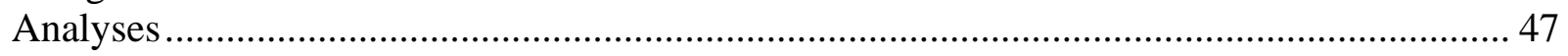

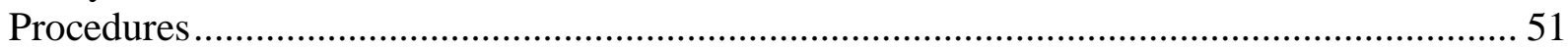

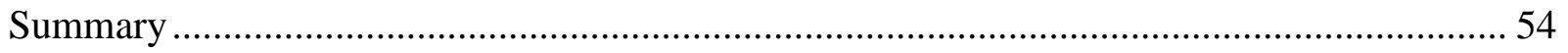

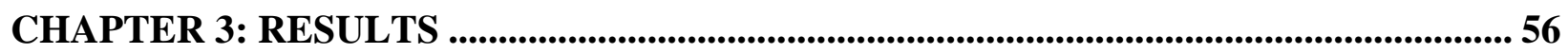

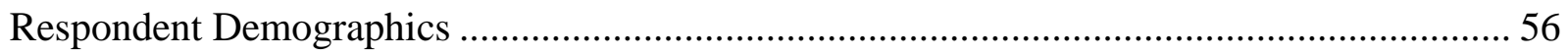

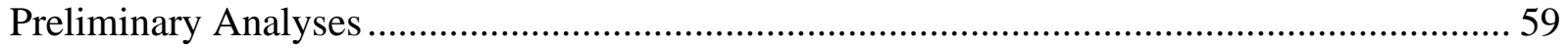

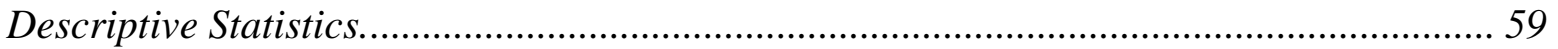

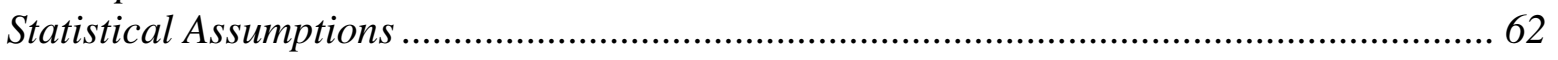




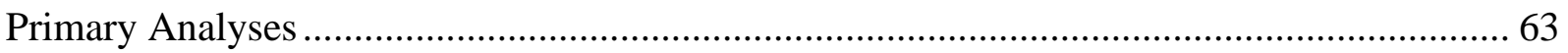

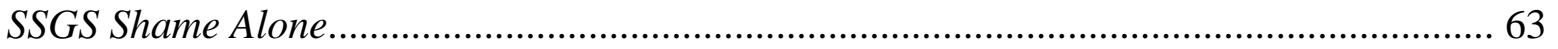

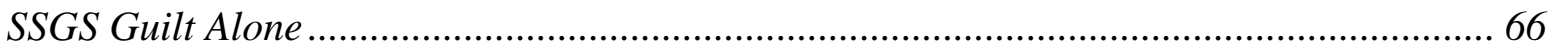

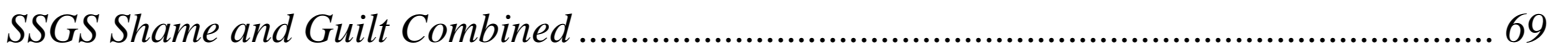

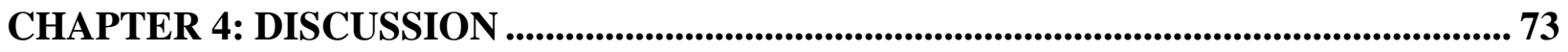

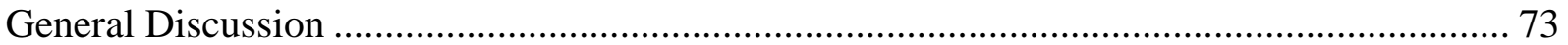

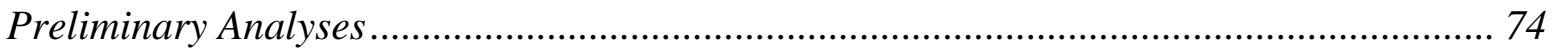

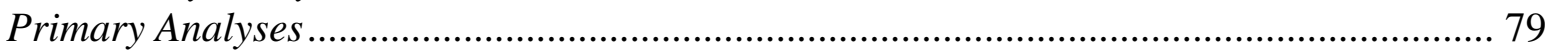

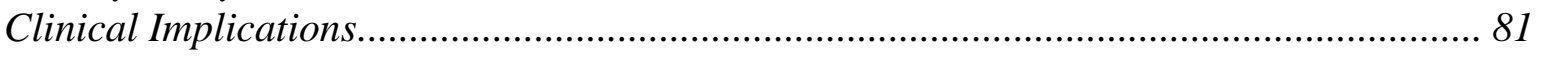

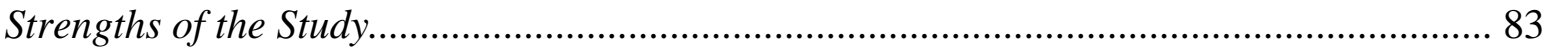

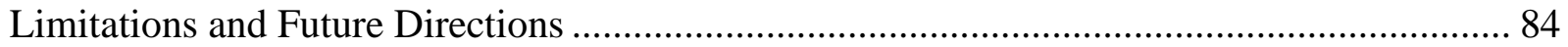

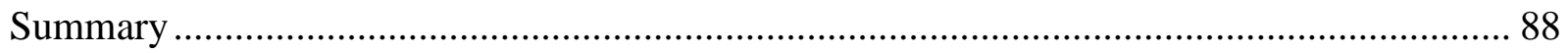

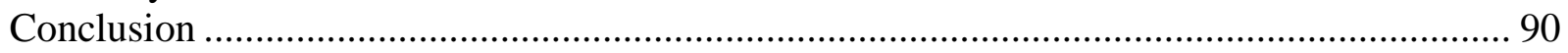

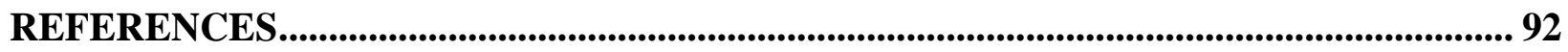

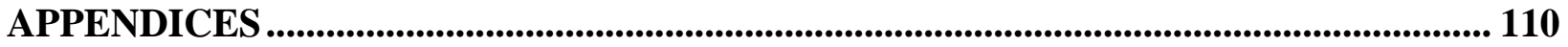

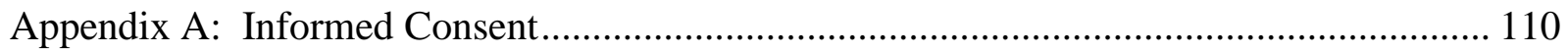

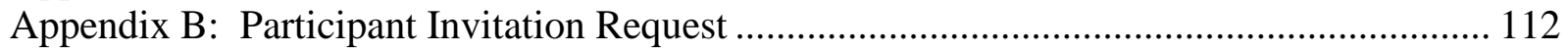

Appendix C: Debriefing Form ............................................................................... 113

Appendix D: Demographic Information Questionnaire .............................................. 114

Appendix E: IRB Approval .................................................................................... 116

Appendix F: Permission to Use the Moral Injury Question-Military Version ..................... 117

Appendix G: Moral Injury Questionnaire-Military Version Scale/Scoring Rubric............... 118

Appendix H: Permission to the State Shame and Guilt Scale ........................................ 120

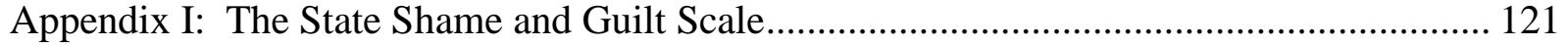

Appendix J: The State Shame and Guilt Scoring Rubric................................................... 122

Appendix K: Permission to Use the Heartland Forgiveness Scale ...................................... 124

Appendix L: The Heartland Forgiveness Scale/Scoring Rubric ...................................... 126

Appendix M: Statistical Assumptions ..................................................................... 129

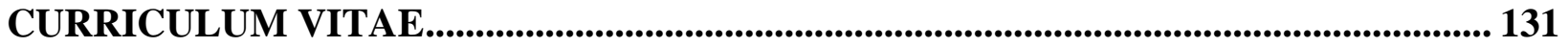


MORAL INJURY, SHAME, GUILT, AND SELF-FORGIVENESS

Morally Injurious Experiences of Combat Exposed Veterans of Iraq and Afghanistan: Moderating Effects of Self-Forgiveness on Feelings of Shame and Guilt

Combat exposure and aversive mental health consequences are well documented among Veterans of the campaigns in Afghanistan and Iraq (Bryan, Bryan, Morrow, Etienne, \& RaySannerud, 2014; Drescher et al., 2011; Jinkerson, 2016; Litz et al., 2009; Maguen, Vogt, King, King, Litz, \& Knight, 2010; Maguen et al., 2011; Maguen \& Litz, 2012; Schumacher, 2017). Moreover, posttraumatic stress disorder (PTSD) and depression have become widely understood as consequences of war (Possemato, Wade, Andersen, \& Ouimette, 2010). However, Shay (1994) and Litz et al. (2009) have proposed a newer construct known as moral injury to describe symptom manifestations that are not encompassed under the PTSD diagnostic label (e.g., feelings of shame, guilt, and self-condemnation). In psychological treatment, many combat Veterans face difficulties justifying and contextualizing their own, as well as others' actions in the field. This can result in an experience of internal discrepancy between the actual and idealized self, specifically between one's moral values and actions in combat that required killing, or other morally repugnant acts (Litz et al., 2009).

I sought to evaluate the role self-forgiveness might play in moderating the already established relationship between moral injury and feelings of shame and guilt (Schumacher, 2017). Researchers have suggested PTSD and moral injury can be comorbid (Jinkerson, 2016; Litz et al., 2009; Maguen \& Litz, 2012; Vogt et al., 2014), though there are outlined differences in their respective etiologies (Liz et al., 2009). Additionally, forgiveness research has found an inability to forgive is associated with aversive mental health outcomes (e.g., depression) (Witvliet, Phillips, Feldman, \& Beckham, 2004). As such, forgiveness research among Veterans with PTSD has discovered positive treatment effects related to PTSD symptom reduction 
MORAL INJURY, SHAME, GUILT, AND SELF-FORGIVENESS

(Karairmak \& Guloglu, 2014). However, self-forgiveness research with Veterans who report morally injurious experiences is limited. Moral injury is considered, by Litz et al. (2009), to be the result of a self-reflective process whereby one evaluates his or her individual experiences in the light of an internalized value system. Through the conceptual model of Litz et al. (2009), moral injury results from exposure to experiences such as perpetrating, failing to prevent, bearing witness to, or learning about acts that transgress an individual's personally held values and beliefs and expectations. Exposure, however, is not enough to result in moral injury. Litz et al. (2009) furthered their conceptual model to include "the individual also must be (or become) aware of the discrepancy between their morals and the experience (i.e., moral violation), causing dissonance and inner conflict” (p. 700). According to Litz et al. (2009), many Veterans will evaluate their roles related to exposures of potentially morally injurious events and who they are that may result in issues with psychological reconciliation, which may result in psychological distress or shame and guilt (Schumacher, 2017). The present study examined this gap in the literature.

\section{Conflicts in Afghanistan and Iraq}

"Mom, I am so sorry. My life has been hell since March of 2003 when I was part of the Iraq invasion.... I am freeing myself from the desert once and for all... I am not a good person. I have done bad things. I have taken lives. Now it's time to take mine." - U.S. Army Veteran Noah Pierce's final words (Alpert \& Kent, 2011, p. 4).

The final words of Noah Pierce represent more than just the experience of one Veteran returning from combat and they illustrate the harsh reality of surviving war. There are 18.5 million Veterans currently in the U.S., which represents a statistical minority among the American population (United States Census Bureau, 2017); however, as of 2015, only 
MORAL INJURY, SHAME, GUILT, AND SELF-FORGIVENESS

approximately 2.7 million of those Veterans have deployed in support of Operation Enduring Freedom (OEF), Operation Iraqi Freedom (OIF), and/or Operation New Dawn (OND) in and around Afghanistan and Iraq (Hautzinger et al., 2015). Specifically, the U.S. has used a small portion of the American population, approximately 1\% (Sayer, Carlson, \& Frazier, 2014), to fight in two of the most extensive campaigns in United States history (Jinkerson, 2016), and, as of this writing, American troops continue to be present in both regions. Although many Veterans return home and transition to civilian life without significant psychiatric conditions, a subset returns from the military with mental health concerns, similar to Noah Pierce, that require psychological services (Sayer et al., 2014). Many service members have been required to serve for at least one year, some deploying upwards of four or more years in combat zones (Frankfurt \& Frazier, 2016) to accommodate the demand for troops on the ground. Research indicates greater combat exposure and more acts of killing are directly linked with aversive mental health outcomes (e.g., posttraumatic stress disorder (PTSD), suicidality, and depression) (Bryan et al., 2014; Litz et al., 2009; Maguen et al., 2009; Maguen et al., 2010). The Veteran population has faced many of the burdens of these two conflicts on their own. Both engagements have brought an awareness to the American public about the consequences of extended conflicts as the Veteran suicide rate has been widely publicized following the report by Kemp and Bossarte (2012), which conveyed that 22 Veterans a day complete suicide. Some Veterans, much like Noah Pierce as quoted above, felt that they could no longer live with the person they believed they had become because of the actions they performed or observed in the field.

However, the duration of time spent in combat theaters is not the only significant factor contributing to the negative mental health outcomes of those engaged in modern warfare. Veterans of the Iraq and Afghanistan campaigns have been exposed to a variety of operational 
MORAL INJURY, SHAME, GUILT, AND SELF-FORGIVENESS

stressors not characteristic of conventional wars, including guerilla style attacks, terror tactics, and ambiguous civilian threats (Litz et al., 2009). Because of the combination of extended combat exposure and mission-critical-threats from unknown or unrecognized sources, Veterans of these two conflicts are more likely to experience potentially morally ambiguous situations that can increase the possibility of unintentional errors (e.g., loss of non-combatant life or betrayal by trusted peers or leadership) (Grossman, 2009; Litz et al., 2009). The inability to discriminate between combatants and civilians can contribute to combat-related trauma and moral injury (Drescher et al., 2011; Litz et al., 2009; Maguen \& Litz, 2012). Participants of these campaigns may witness intense human suffering and atrocities or engage in actions that may transgress their moral values (Drescher Foy, Kelly \& Leshner, 2011; Jinkerson, 2014; Litz et al., 2009; Nash \& Litz, 2013). Thus, service members who have been raised with the religiously based values such as "thou shalt not kill" may find themselves in situations that require them to do so as a prescription of war. Service men and women may also find themselves in situations where they must choose to take a life to save another. While the service member may follow the rules of engagement (ROE), they may struggle with the moral weight of their actions. It is this internal conflict and dissonance that characterizes the coined term moral injury (Litz et al., 2009, p. 696). Moral injury can be defined as the participating in or learning about actions that violate one's moral code (Litz et al., 2009), and those who struggle with morally injurious experiences may harbor feelings of shame and guilt (Drescher et al., 2011; Litz et al., 2009; Shay, 2003, 2010, 2012). Although moral injury has been associated with shame and guilt (Litz et al., 2009; Nash \& Litz, 2013; Schumacher, 2017), to my knowledge no research has yet examined selfforgiveness as a potential moderating variable between the relationship of moral injury and these feelings among combat-exposed Veterans of the conflicts in Iraq and Afghanistan. 
MORAL INJURY, SHAME, GUILT, AND SELF-FORGIVENESS

\section{Mental Health Consequences of War}

"Everyone who has ever deployed to a war zone is changed by his or her experiences; it would be abnormal not to be" (Hoge, 2010, p. 6).

Modern conflicts have seen increased survival rates due to technical advancements in such things as body armor, surgical battlefield care, and evacuations (Gawande, 2004). With improved survival rates, a significant number of Veterans are now exposed and re-exposed to potentially morally injurious experiences and the aftermath of grotesque violence that they will live with for the rest of their lives (Litz, 2007).

The conflicts in Afghanistan and Iraq have differed from conventional wars because those who served have had to struggle to differentiate the enemy from noncombatants, as mentioned above (Farnsworth et al., 2014; Litz et al., 2009). Exposure to guerrilla-style tactics (e.g., improvised explosive devices; IEDs) and extended conflicts have produced significant aversive health concerns within the Veteran community. As of 2016, Veterans of OIF and OEF campaigns, in and around Iraq and Afghanistan, have a documented PTSD and depression prevalence rate of 11-20\% in any given year (Department of Veteran Affairs, 2015). Those who served in these two conflicts are likely to have a comorbid condition of either alcohol or drug dependence (Seal et al., 2010). For instance, among those diagnosed with PTSD, according to McCauley et al. (2012), 46.4\% also met criteria for a substance use disorder (p. 284).

Although less than $20 \%$ of all Veterans utilize the VA health care system (Wisco et al., 2014), for those that do, the Department of Veteran Affairs has reported services for substance use disorder treatment in 2014 were as follows: (1) 78,575 Veterans receive care for alcohol dependence, (2) 60,010 received attention for nondependent abuse of drugs, and (3) 45,057 received care for drug dependence (Department of Veteran Affairs, 2014). While substance use 
MORAL INJURY, SHAME, GUILT, AND SELF-FORGIVENESS

disorders, PTSD and depression are reported at lower rates among Iraq and Afghanistan Veterans than other conflict eras (Department of Veteran Affairs, 2015; Fontana \& Rosenheck, 2004), alcohol use disorder remains the most prevalent issue reported among those who served in and around Iraq and Afghanistan (Calhoun, Elter, Jones, \& Straits-Troster, 2008).

In addition to PTSD and substance use disorders, Veterans also demonstrate high depression rates (Lapierre, Schwegler, \& LaBauve, 2007) and suicidal ideations (Hendin \& Haas, 1991). In an exploratory study of moral injury and suicidal ideations and attempts, Bryan et al. (2014) found those who report transgressions by others and also engaged in transgressions themselves reported a greater frequency of suicidal ideation, especially if they had a previous suicide attempt. Bryan et al. (2014) also discovered an individual's perceived transgressions were associated with more severe suicidal ideations. Since the beginning of the conflicts in Afghanistan and Iraq, suicide rates have increased 100\% among active duty personnel (U.S. Department of Defense, 2011) and more than 8,000 Veterans complete suicide in a given year (Kemp \& Bossarte, 2012). Examining suicide among these groups, Connor et al. (2013) investigated a sample of approximately three million Veterans who completed suicide and found $30.7 \%$ had a depression diagnosis, and another $11.7 \%$ had a PTSD diagnosis (Connor et al., 2013). Studies similar to Bryan et al. (2014) and Connor et al. (2013) suggest that individuals who act in ways that conflict with their moral values struggle to live with those actions. The notion that Veterans struggle to live with their war experiences is not a new concept. For instance, Hendin and Haas (1991) found suicidal ideations were related to various combat experiences (e.g., killing of women and children) among Vietnam Veterans similar to those outlined in Litz and colleagues' (2009) theoretical framework. As PTSD, depression, substance 
MORAL INJURY, SHAME, GUILT, AND SELF-FORGIVENESS

use, and suicidal ideations are all frequently reported among studies examining combat-trauma, differentiating moral injury and PTSD becomes a vital distinction.

\section{Moral Injury and PTSD}

Most of the current literature on combat trauma has centered on PTSD development with limited research being conducted on the role Veterans play in perpetrating, bearing witness to, learning about, or preventing violence (Litz et al., 2009). In the latest edition of The Diagnostic and Statistical Manual of Mental Disorders (5 ${ }^{\text {th }}$ ed.; DSM-5; American Psychiatric Association, 2013), PTSD has been moved as an anxiety disorder to be categorized as a Trauma-and-StressRelated Disorder. Additionally, PTSD no longer contains individual reactions to traumatic events (e.g., intense fear) (APA, 2013). However, PTSD research still focuses on fear conditioning and anxiety-related symptoms derived from traditional models (Vermetten \& Jetly, 2018). Some researchers have sought to expand the PTSD inclusion criteria to include severe feelings of shame and guilt (See Dearing \& Tangney, 2011) because many Veterans present in therapy with these intense negative emotions as primary issues with fear being a secondary or perhaps minimal to non-existent concern (Nazarov, Jetly, McNeely, Kiang, Lanius, \& McKinnon, 2015).

In addition, research has suggested that there is a high rate of comorbidity with PTSD and moral injury (Currier et al., 2015; Jinkerson, 2016; Litz et al., 2009; Maguen \& Litz, 2012; Vogt et al., 2014), as potentially morally injurious experiences and psychological trauma can result from similar contexts (e.g., combat) (Jinkerson, 2016). As PTSD and moral injury can develop from similar events, it is not remarkable that they are not mutually exclusive (Jinkerson, 2016; Litz et al., 2009; Shay, 1994). Litz et al.’s (2009) conceptual framework still identifies a sizeable gap in the literature on military combat trauma and treatment because the newest edition of the DSM-5 does not encompass the symptoms of moral injury (e.g., shame, guilt, and self- 
MORAL INJURY, SHAME, GUILT, AND SELF-FORGIVENESS

condemnation) or account for how those symptoms develop. It would appear from Litz et al. (2009) that moral injury is distinguishable from traditional fear-based PTSD presentations due to differing etiologies and symptom presentation (e.g., shame, guilt, and difficulties with selfforgiveness) (Gray et al., 2012). While the Veteran Health Administration provides programs that successfully diagnose disorders like PTSD and depression based on DSM-5 criteria, current treatment protocols may not adequately address those with moral injury as those criteria do not include moral injury and its associated mental health symptoms (Drescher et al., 2011; Litz et al., 2009). With low treatment utilization rates (Whealin et al., 2014), low treatment retention rates (Seal et al., 2010), and high endorsement of potentially morally injurious experiences (Bryan et al., 2014), moral injury is a possible contributor to the aversive mental health outcomes and selfreports of shame and guilt observed among the Veteran community. Empirical literature initially offered by Litz et al. (2009) presented moral injury as a dimensional problem. As research has continued to expand, researchers such as Jinkerson (2016), have stated that adequate research has been conducted to suggest moral injury is a syndrome. As researchers continue to examine moral injury, given etiological and symptom presentation differences, it has become clear that moral injury is a distinct construct from PTSD. However, as moral injury research is limited, gaps remain.

\section{Moral Injury}

As previously stated, moral injury is a relatively newer construct proposed to explain the war experiences of those who have served in situations that were potentially ethically and morally challenging. As a result, combat-exposed military personnel may develop negative emotional consequences (e.g., shame and guilt) (Litz et al., 2009; Shay, 2003, 2010, 2012). Stemming back to the early 1990's, Dr. Johnathan Shay wrote Achilles in Vietnam (1994). Shay 
MORAL INJURY, SHAME, GUILT, AND SELF-FORGIVENESS

intended to explain many of the war experiences of those who served in Vietnam by advocating that Homer's representation of combat in The Iliad, a tale of the Trojan War, may offer critical insights into the combat experiences of modern era Veterans. Shay expanded on Achilles in Vietnam by writing Odysseus in America (2003) to identify the struggles Veterans face when returning home from war. Both of these books were meant to infuse psychological principles and literary interpretations to aid the treatment of Veterans returning from war (Shay, 2010).

Shay is credited with coining the term "moral injury," and he defined moral injury as the psychological, physiological, and social outcomes of a person experiencing all three of the following criteria: (1) betrayal of "what's right" (2) by someone who holds legitimate authority (3) in a high-stakes situation (Shay, 1994, 2003, 2010, 2012). By definition, Shay's form of moral injury focuses on betrayal by others and results in symptoms not encompassed under the posttraumatic stress disorder (PTSD) diagnostic label (i.e., shame, guilt, and self-condemnation) (Shay, 2003, 2010, 2012). As noted by Shay (1994):

... Moral injury is an essential part of any combat trauma that leads to lifelong psychological injury. Veterans can usually recover from horror, fear, and grief once they return to civilian life, so long as "what's right" has not been violated. (p. 20)

Litz et al. (2009) built upon Shay's definition to suggest a betrayal of "what's right" could also come from oneself. Litz and colleagues' working definition of moral injury expanded the effects of potentially morally injurious experiences to include emotional consequences resulting from "Perpetrating, failing to prevent, bearing witness to, or learning about acts that transgress deeply held moral beliefs and expectations” (p. 700). Litz et al. (2009) described moral transgressions as acts of commission (e.g., killing) or omission (e.g., failing to prevent war 
MORAL INJURY, SHAME, GUILT, AND SELF-FORGIVENESS

atrocities) that create cognitive dissonance (See also: Festinger, L., 1962) for the individual as he/she struggles to incorporate information from their war experiences with their own selfconcepts. If potentially morally injurious acts are viewed by the Veteran as being contextdependent, external, and not stable, then the Veteran can likely integrate the experiences over time (Litz et al., 2009; Stein et al., 2012); however, more severe manifestations of moral injury can produce greater levels of cognitive dissonance and feelings of shame and guilt (Litz et al., 2009; Maguen \& Litz, 2012). As a result of intense, unremitting guilt and shame, Veterans may participate in self-punishing behaviors (e.g., isolation, substance use, self-handicapping behaviors [e.g., self-sabotaging relationships], and parasuicidal thoughts) that can mimic PTSDlike symptoms (e.g., numbing or withdrawal) (Litz et al., 2009). Litz et al. (2009) suggested other presentations of moral injury may include demoralization or self-condemnation (e.g., "I am a bad person"). Moral injury leads to cognitive dissonance, and a vast array of other psychological problems (e.g., anxiety, depression, or intrusive thoughts) (Stein et al., 2012). According to Schumacher (2017), potentially morally injurious experiences can be produced by either definition outlined by Litz et al. (2009) or Shay (1994), and both are intrinsically linked to violations of moral or ethical beliefs by oneself or others.

Researchers have already examined combat-related stressful events (e.g., Rubin, Dennis, \& Beckham, 2011) and shame and guilt among combat Veterans with a PTSD diagnosis (Robinaugh \& McNally, 2010). While PTSD and moral injury research demonstrate a high rate of comorbidity (Currier et al., 2015; Jinkerson, 2016; Litz et al., 2009; Maguen \& Litz, 2012; Vogt et al., 2014), moral injury has been proposed as a theoretically distinct construct from PTSD (Litz et al., 2009). While PTSD is a recognized mental health disorder, leading to a categorical diagnosis, moral injury is a dimensional problem with no set threshold (Maguen \& 
MORAL INJURY, SHAME, GUILT, AND SELF-FORGIVENESS

Litz, 2012). Moral injury symptom presentations can involve re-experiencing painful memories, avoidance symptoms (e.g., isolation), and increased suicide risk (Hendin \& Haas, 1991;

Jinkerson, 2016; Maguen et al., 2012; Stein et al., 2012), similar to PTSD. Litz et al. (2009) outlined the etiological differences between moral injury and PTSD, with PTSD being mostly physiological in nature based on a fear response. Moral injury, however, is an evaluation of an event and attribution of moral responsibility to oneself that may result in inconsistency of one's actions with one's own moral code (Litz et al., 2009).

The empirical literature on moral injury is limited due to the relative newness of this recently proposed construct. According to Schumacher (2017), the majority of moral injury literature has focused on exploratory studies, assessment of potentially morally injurious experiences, and potential treatment protocols, but is limited in scope. According to Maguen and Litz (2012), the initial validation of the construct of moral injury occurred in 2011. In 2011, an exploratory study was conducted to attempt to categorize war-zone events that could potentially identify situations aiding in the development of moral injury (Drescher et al., 2011). Drescher et al. (2011) interviewed 23 health and religious professionals treating service members of Iraq and Afghanistan. The study found betrayal (e.g., leadership failures or failure to live up to own moral code), disproportionate violence (e.g., acts of revenge), incidents involving noncombatants (e.g., harm or killing of civilians), and within-rank violence (e.g., friendly fire) as themes associated with the development of moral injury (Drescher et al., 2011). Furthermore, the study also identified signs and symptoms of moral injury (e.g., social problems, psychological symptoms, spiritual issues, and self-deprecation) (Maguen \& Litz, 2012), which is consistent with the conceptual framework outlined by Litz and colleagues (2009). 
MORAL INJURY, SHAME, GUILT, AND SELF-FORGIVENESS

\section{Prevalence of Psychological Distress}

To further validate the moral injury construct Vargas, Hanson, Kraus, Drescher, Division, and Foy (2013) examined the National Vietnam Veterans' Readjustment Study (NVVRS). The NVVRS was a congressionally-initiated epidemiological study conducted in the 1980's with a total sample of 3,016 that included men and women that who served between August 5, 1964, and May 7, 1975, 1,200 of whom served in Vietnam or surrounding areas. The NVVRS study results indicated a $30.9 \%$ lifetime prevalence rate of PTSD for male study participants and a 26.9\% rate for female participants who served during the Vietnam era (Gradus, 2007). Vargas et al. (2013) reviewed NVVRS archival data of 100 conflict-exposed Veterans and 200 non-combat exposed male Veteran's responses through random stratified sampling. In reviewing the 100 conflict-exposed Veterans, the researchers found that 14 of the 100 evaluated responses were consistent with moral injury themes, signs, and symptoms. While prevalence rates cannot be inferred from these results, moral injury themes among combat personnel warranted additional examination. Conway (2013) replicated the work of Vargas et al. (2013) with combat theater nurses. Conway (2013) found 55\% of item responses were correlated with signs and symptoms of moral injury. Furthermore, $62 \%$ of the sample described moral injury symptoms (Conway, 2013).

Examining more recent data, Wisco et al. (2017) analyzed the National Health and Resilience in Veterans Study (NHRVS) data. Of the 564 combat Veterans in the NHRVS sample, Wisco et al. (2017) found a total of $10.8 \%$ of those Veterans acknowledged actions that transgressed their own moral code and $25.5 \%$ reported transgressions by others. Additionally, $25.5 \%$ of those combat Veterans also endorsed items of betrayal. These researchers found significant correlations between transgressions by oneself and reported betrayal by others with 
MORAL INJURY, SHAME, GUILT, AND SELF-FORGIVENESS

current mental health disorders, suicidal ideations, and suicide attempts (Wisco et al., 2017). With potentially morally injurious experiences, signs, and symptoms reported among both Vietnam and Gulf War era Veterans, critical examination of the contributing factor of moral injury has begun.

\section{Moral Injury, Killing, and Atrocities}

According to researchers it is self-evident that combat exposure and experiences of trauma, losses, and military operational difficulty contribute to the development of PTSD and other mental health concerns (Drescher et al., 2011; Stein et al., 2012). Specifically, Maguen and Litz (2012) identified killing in combat as a leading contributor to moral injury development and the emergence of general mental health concerns. Service men and women deployed in Iraq and Afghanistan have operated in conflicts where morally ambiguous situations present themselves because of unknown civilian threats and guerilla-style warfare. Unlike classical moral reasoning dilemmas such as Kohlberg's 1969 scenario in which a gentleman must decide whether to steal a lifesaving drug for his dying wife because he cannot afford it, these men and women must make split-second decisions that can result in a lifetime of questioning. Furthermore, Veterans may develop moral injury as part of actions that may lie within the current rules of engagement (e.g., killing an enemy combatant) or outside of those rules (e.g., retaliation or torture) (Shay, 1994). Regardless of whether the action is deemed legal by the rules of engagement (ROE), some scholars (e.g., Farnsworth et al., 2014; Litz et al., 2009) have contended those actions can nevertheless be potentially morally injurious (e.g., taking a life) (Frankfurt \& Frazier, 2016). The ROEs are particularly relevant in the context of unclear civilian threats in modern conflict because many Veterans may report hesitation in their decision to act while in combat for fear of punishment through the uniformed code of military justice. As such, Veterans may be left with 
MORAL INJURY, SHAME, GUILT, AND SELF-FORGIVENESS

feelings of guilt or shame for a failure to act quickly enough so that harm or death resulted (Litz et al., 2009), or they may have acted too rapidly because of previous experiences where others may have been harmed or killed because they or someone else failed to respond (Farnsworth et al., 2014).

Researchers have outlined circumstances in which individuals can act in ways inconsistent with their own moral beliefs and values such as killing in combat (Maguen et al., 2009; Maguen et al., 2010). The processes by which Veterans morally disengage from those actions are outlined by Bandura (1999, 2002). Specifically, Bandura (1999) identified moral agency as a dual process in which individuals act in ways that inhibit inhumane behaviors and proactive processes that support acting humanly. Bandura (2002) identified these two aspects of moral agency as contributing to moral actions, both positive and negative, that contribute to the moral heroism (e.g., soldiers protect villagers from Taliban forces even though there is great risk to their lives) or moral disengagement (e.g., soldiers slaughter a village or dehumanize their enemies). According to Drescher et al. (2011), service men and women are required to act in such ways as a means of survival or mission accomplishment that may require the harming or killing of others. Maguen, Metzler, Litz, Seal, Knight, and Marmar (2009) examined the relationship between killing and mental health and functional outcomes among a small subsample of the NVVRS data $(n=259)$ and found killing was associated with PTSD symptoms, functional impairment, violent behaviors, and dissociation. According to Maguen and Litz (2012), the association with those aversive health outcomes was prominently strengthened if the person killed was a noncombatant. In 2012, Maguen and colleagues found similar results with Veterans who reported killing experiences (i.e., killing enemies, prisoners, or civilians), and those Veterans had twice the likelihood of endorsing suicidal thoughts than those who did not. 
MORAL INJURY, SHAME, GUILT, AND SELF-FORGIVENESS

Both of these studies built upon and replicated the findings of Fontana and Rosenheck (1999), which divided the NVVRS data into two random subsamples and found killing or injuring others was statistically associated with posttraumatic stress symptoms when controlling for general combat exposure.

Studies examining killing among Veterans of Iraq and Afghanistan have produced similar results. Hoge and colleagues (2004) studied a sample of 3,671 Veterans after they had returned home from deployment. Hoge et al. (2004) found that 52\% of those Veterans reported firing at the enemy and $32 \%$ believed they were responsible for the death of a combatant. Furthermore, many of those Veterans (i.e., 60-65\%) reported seeing dead bodies and witnessing ill/wounded noncombatants. Hoge and colleagues (2004) found correlations between those who killed and witnessed combat aftermath with aversive health concerns (e.g., PTSD, generalized anxiety, and depression); however, moral injury was not examined in this sample. More recently, Maguen, Vogt, et al. (2011) examined a sample of 317 Iraq and Afghanistan Veterans, and found that 11\% of those Veterans who reported killing while in combat endorsed posttraumatic stress symptoms, and frequency and quantity of alcohol use and abuse were greater for those Veterans. Although killing is not a variable of interest in the present study, killing is conceptually outlined as a contributor to the development of moral injury (Litz et al., 2009; Shay, 2003; 2012). As such, killing is delineated to clarify the operational demands required of those who serve in combat settings which result in aversive health consequences (e.g., shame and guilt).

While killing is correlated with many of the maladaptive health outcomes identified among the Veteran community (Hoge et al., 2004; Maguen et al., 2012; Maguen, Vogt, et al., 2011), some discussion of war atrocities seems warranted in the present context. Drescher et al. (2011) described the ability of people to act in ways that are inconsistent with their moral values 
MORAL INJURY, SHAME, GUILT, AND SELF-FORGIVENESS

and beliefs to kill enemy combatants. It is reasonable to suggest the same morally disengaging process can occur when committing war atrocities. War atrocities are categorized in this paper as actions that constitute egregious violations of the laws of war (e.g., intentionally killing civilians, torture, rape, or killing of war prisoners). Currier, McCormick, and Drescher (2015) identified cultural and relational circumstances in which Veterans acknowledged dehumanization of enemies and civilians alike. While war atrocities may infrequently be noted among combat Veterans, incidents such as the My Lai Massacre of Vietnam (Greiner, 2009) or 2007 Shinwar shooting of Afghanistan (Talton \& Naylor, 2008) do occur and demonstrate that acts of excessive violence and revenge do take place.

Incidents such as the My Lai Massacre have been examined by writers (e.g., Bandura, 2002) to illuminate the morally disengaging process of those who slaughtered civilians. Bandura (2002) also identified a young pilot, H. J. Thompson, who used his helicopter as a barricade between his fellow countrymen and the villagers of My Lai as a means to protect the Vietnamese from the onslaught of U.S. troops. In fact, Thompson gave an order to kill American servicemen if they attacked the helicopter, which Bandura (2002) identified as moral heroism. Both actions, killing civilians and protecting them, are outlined by Bandura (2002) as a way to illustrate the power situations can exert over individuals during combat. Conducting interviews with health professionals who have treated Veterans, Drescher et al. (2011) identified exposure to or perpetuating of disproportionate violence is a contributor to moral injury development. Beckham and colleagues (1998) examined a small sample of 151 Vietnam Veterans with chronic PTSD and found exposure to atrocities (e.g., unnecessary or inappropriate harming of civilians, mistreatment of enemies, disproportionate violence, and acts of revenge) were significantly correlated with posttraumatic stress symptoms. 
MORAL INJURY, SHAME, GUILT, AND SELF-FORGIVENESS

In another study, researchers reanalyzed NVVRS data and found $16 \%$ of those Veterans reported participating in atrocities in Vietnam, while another 35\% reported observing such acts (Currier, Holland, \& Sheu, 2014). Both killing and exposure to war atrocities align with behaviors defined by both Shay (1994) and Litz et al. (2009) as contributing to moral injury development. Furthermore, these behaviors are theoretically linked to feelings of shame and guilt produced by carrying out orders that violate an individual's moral code or failing to prevent others from committing such atrocities (Drescher et al., 2011; Litz et al., 2009). To articulate the perceived changes in a person's morality, Currier et al. (2015) interviewed Veterans about their war zone experiences, and one Veteran stated:

Part of it was probably the moral aspects of things.... and then feeling that I betrayed all those values by hurting people and embracing the other part of anger and hate... I went over and became the enemy. I felt like I became the enemy and what I went there for was to take out the enemy. We are doing our job at one point... and over time and seeing things... everything starts being clouded, and you start becoming somebody different. Sometimes you just do not know it because it's just so easy to do it. I was just wondering more of why I did it. What caused me to do it, to get this far, when I always thought that I was mentally stronger than other people? ... especially when it came to my morals and my upbringing... I don't know... things change. (p. 114)

Individuals who engage in these actions may experience incongruences between their own selfconcepts and are unable to resolve those self-discrepancies regardless of the appropriateness of their behaviors according to the rules of engagement. 
MORAL INJURY, SHAME, GUILT, AND SELF-FORGIVENESS

\section{Assessing Moral Injury}

According to Schumacher (2017), the majority of moral injury literature has focused on three areas (i.e., exploratory studies, assessment of potentially morally injurious experiences, and potential treatment protocols), but the relevant research is narrow and sparse. To date, only two measures have been developed to assess exposure to potentially morally injurious events. The Moral Injury Events Scale (MIES; Nash et al., 2013) was the first to be developed and assesses committing or witnessing transgressive acts, as defined by Litz et al. (2009), and perceived betrayal by others, as defined by Shay (1994). Secondly, the Moral Injury Questionnaire Military version (MIQ-M; Currier et al., 2015) was developed to gather more data on moral injury development. The MIQ-M collects information on committing or witnessing transgressive acts and betrayal, but it also includes causes and effects and differentiates between acts that do and do not violate the rules of engagement (Frankfurt \& Frazier, 2016). Both measures are limited because they do not distinguish between exposure to potentially morally injurious experiences and the development of morally injury, but these are the only two psychometrically validated measures currently available.

The MIQ-M was selected for this study because it is a standard measurement of assessing Veterans' exposure to and experience of moral stress in combat (Currier et al., 2015). The MIQM and MIES were significantly positively correlated with measures of distress, according to Frankfurt and Frazier (2016). Additionally, the current study seeks to replicate the work of Schumacher (2017), which used the MIQ-M to examine moral injury and suicidal ideations of Veterans who reported feelings of shame and guilt. The MIQ-M was also selected because it has good incremental and convergent validity (Schumacher, 2017), and the MIQ-M has a unidimensional structure designed to assess potentially morally injurious experiences (Currier et 
MORAL INJURY, SHAME, GUILT, AND SELF-FORGIVENESS

al., 2015). Finally, the MIQ-M has been validated and normed on the recently returned cohort of Iraq and Afghanistan campaign Veterans through both qualitative (Currier, McCormick, \& Drescher, 2015) and quantitative approaches (Currier, Holland, and Malott, 2015; Schumacher, 2017).

\section{Self-Discrepancy Theory}

In addition to the theory of moral injury, a second theoretical framework for the proposed study is based on Self-Discrepancy Theory developed by E. Tory Higgins (1987). The idea that people experience cognitive dissonance (see also Festinger, 1957) when integrating life happenings (e.g., potentially morally injurious combat experiences) that conflict with their sense of self and the world around them is not a new concept. In social psychology, discomfort and inconsistency among beliefs have been examined (See also Heider, 1958). Higgins (1987) presented self-discrepancy theory as a tripartite explanation for individual discrepancies through self and affect, which attempts to explain (1) various types of discomfort people experience when holding incompatible beliefs, (2) emotional vulnerabilities, in relation to system demands, that people possess and contribute to their self-beliefs, and (3) the available and accessible discrepancy differences individuals possess can result in cognitive dissonance. Higgins (1987) posited that the self consists of three domains: (1) the representation of a person's perception of their actual attributes, known as actual self, (2) the description of what the person wishes to be ideally, known as the ideal self, and (3) the representation of the qualities a person or others believe that person should have, known as the ought self. Higgins (1987) also identified the combinations of the real, ideal, and ought selves among six internalized standards or "selfguides" that, in conjunction with the theory as a whole, propose the differences and needs among 
MORAL INJURY, SHAME, GUILT, AND SELF-FORGIVENESS

persons vary compared to the needs they seek to meet. As a result, self-guides are individually specific.

Higgins (1987) identified two types of self-discrepancy standpoints (i.e., self and other) that can be applied to those who have been exposed to potentially morally injurious experiences through self-guides. In particular, two of Higgins's (1987) self-guides can be used directly to potentially morally injurious event processes and consequences as outlined by Litz et al. (2009). First, actual/own versus ideal/other is the notion that one's attributes do not match the ideal self that the person believes others wish for them to possess, which can result in shame or downcast feelings. Feelings of downcast can result because the Veteran feels as though he or she has lost standing or esteem in the opinion of others (e.g., fellow soldiers). The loss of esteem or standing is described by Higgins (1987) as the other standpoint of self, as the Veteran's view is based on what they believe others think of them. For instance, those who believe that they have been betrayed by their command or trusted others by being placed in compromising situations (Shay, 2012) may have performed actions that diminish their sense of themselves as moral actors (Currier, Holland, \& Mallott, 2015; Jinkerson, 2016; Litz et al., 2009). Through their selfperceptions, the Veteran may view the standpoints of others (e.g., fellow soldiers, family, and friends) as observing them negatively (e.g., "I acted this way and they think I'm now a bad soldier") which can result in the dissonance between their actions and what they think others will think of them for performing those actions. Higgins (1987) described the actual/own versus ideal/other self-guide as one in which an individual's view is absent of positive outcomes because their actual and ideal attributes do not match, resulting in dejection-related emotions (i.e., shame, embarrassment, and feeling downcast). 
MORAL INJURY, SHAME, GUILT, AND SELF-FORGIVENESS

The other self-guide identified by Higgins (1987) is the actual/own versus ought/own self-discrepancy, which suggests that personal perspective doesn't match with the "duty" they seek to fulfill (Higgins, 1987). The second self-discrepancy identified here targets the selfcondemnation behaviors that are reported by Veterans who have conducted, observed, or learned about operations in which a civilian was harmed or killed, or performed an action themselves that is counter to their moral ideals (Litz et al., 2009). Higgins (1987) identified self-contempt as a result of the latter self-discrepancy. In such cases of war, which can be highly negative and unpredictable, Veteran experiences can influence their attributions of the meaning of war experiences (Currier, Holland, \& Mallott, 2015) and other routine life events (e.g., returning to civilian life). Such experiences can result in the loss of trust demonstrated by many combat Veterans with PTSD and who have sustained moral injury (Litz et al., 2009; Vogt et al., 2014). Reflections, needless worries, and compulsive attempts at evading similar situations in the future are likely outcomes (Berntsen \& Rubin, 2006), such as PTSD-like isolation seen among combat Veterans who report moral injury (Jinkerson, 2016). Colby (1968) identified wishful and valued beliefs (e.g., hindsight bias), which can be seen in Veterans who have experienced combat trauma (e.g., "I wish I could have saved his life" or "I ought to have been a better Marine") resulting in self-discrepancies between the actual and ideal self (Higgins, 1987). As these discrepancies are rehearsed through autobiographical memories, which may or may not account for situational circumstances, they may become central to the Veteran's self-narrative (e.g., "I am a bad person”) (Berntsen \& Rubin, 2006; Litz et al., 2009). According to Higgins (1987), persons who identify with the actual/own versus ought/own self-guide are subject to the presence of negative emotions related to self-dissatisfaction (i.e., guilt, self-contempt, and uneasiness) 
MORAL INJURY, SHAME, GUILT, AND SELF-FORGIVENESS

which are similar to those described by other researchers (Drescher et al., 2011; Litz et al., 2009).

Self-discrepancy theory provides a helpful rationale for the development of cognitive dissonance related to a person's actions and their beliefs connected to self-perception of those actions and how they believe others will view them (Higgins, 1987). Higgins (1987) described self-discrepancies as producing emotional vulnerabilities similar to other theorists (see Festinger, 1957; Heider, 1958). However, self-discrepancy theory went beyond previous theories by assigning precise emotions (e.g., shame and guilt) to specific types of self-discrepancies (Higgins, 1987). Through Litz et al.'s (2009) conceptual model of potentially morally injurious events and Drescher et al.'s (2011) identification of morally injurious symptom manifestations, Higgins (1987) provided a theoretical basis for examining actions performed, observed, witnessed, or learned about by Veterans serving in Iraq and Afghanistan that have resulted in cognitive dissonance and feelings of shame and guilt. While shame and guilt, among psychological measures, have been correlated to clinical conditions such as depression and PTSD (Tangney et al., 1992), there remains a need to understand the relationship between potentially morally injurious experiences, shame, and guilt. By examining these variables in my study, I hope to validate the relationship proposed by Schumacher (2017) between moral injury and feelings of shame and guilt among Veterans who endorse maladaptive self-concepts (e.g., "I'm a bad person"). This study can also expand on previous research by investigating the moderating effects of self-forgiveness on negative emotional consequences (e.g., shame, guilt, isolation, and self-condemnation) resulting from self-discrepancies following engagement in the conflicts of Afghanistan and Iraq. 
MORAL INJURY, SHAME, GUILT, AND SELF-FORGIVENESS

\section{Shame and Guilt}

According to Vermetten and Jetly (2018), the recent reintroduction of morally injurious experiences among combat-related literature has been focused on the psychological consequences of combat incidents that result in guilt, shame, and inner conflict. Fontana and Rosenheck (2004) examined mental health service utilization among combat Veterans with PTSD and found those Veterans reported their primary reason for seeking psychological services were feelings of shame and guilt over-and-above fear-based and anxiety-related symptoms. However, research on shame and guilt has been scarce among combat Veterans (Nazarov et al., 2015), even though shame and guilt have been identified as chronic issues among those who report acts of omission and commission during a war (Kubany, 1994).

According to Nazarov and colleagues (2015), shame and guilt have been habitually used interchangeably; however, they embody unique psychological constructs, but both can develop through exposure to or from perpetrating moral wrongdoings. Shame and guilt have often been depicted as "self-conscious emotions," because the occurrence of shame and guilt involves negative evaluations of the global self and specific actions performed (Tangney \& Dearing, 2002). The primary distinction between the two concepts of negative evaluations is that the experience of shame involves a negative self-evaluation that is global, stable, and uncontrollable (e.g., "I am a bad person") and guilt develops through the negative evaluation of a particular transgressing behavior (e.g., "I did a bad thing”) (Lewis, 1971; Tangney \& Dearing, 2002). Both emotions can be psychologically distressing (Wilson, Drozdek, \& Turkovic, 2006) and warrant more careful differentiation within the Veteran population because they are both identified as contributors to suicidal ideations and attempts (Bryan et al., 2014; Conner, 2013). Shame and guilt are also identified symptoms of those who experience morally injurious events (Drescher et 
MORAL INJURY, SHAME, GUILT, AND SELF-FORGIVENESS

al., 2011; Litz et al., 2009) with a clear relationship between greater morally injurious event exposure and reported feelings of shame and guilt (Schumacher, 2017).

\section{Shame.}

According to Wilson et al. (2006), shame is a more complex intrapsychic process than guilt due to core attributional dimensions related to the self, identity, ego processes, and personality. Again, shame is conceptualized in this study as a negative self-evaluation that is global, stable, and uncontrollable (e.g., "I am a bad person") related to one's self-concept (Tangney \& Dearing, 2002). Specifically, shame is an internal sense of self-violation of one's own true nature, regardless of how accurate or inaccurate an individual's self-perceptions may be (e.g., actual/own versus ought/own or actual/own versus ideal/other self-discrepancies) (Higgins, 1987; Wilson et al., 2006). In situations in which shame results, the Veteran loses a sense of selfworth (Wilson et al., 2006), which is similar to Litz et al.'s (2009) concept of eroded moral beliefs about themselves or others. When Veterans perpetrate, witness, fail to prevent, or learn about actions that transgress their moral beliefs, the resulting shame can cause a temporary or permanent loss of the Veteran's sense of virtue, wholeness, and moral integrity (Wilson et al., 2006).

Fenichel (1945) once wrote, "I feel ashamed" which means "I do not want to be seen" (p. 139). In other words, shame is an excessively self-conscious awareness of oneself as having been revealed in a less than desirable light by one's own action or as seen by others in a manner that conflicts with an individual's ideal self-concept (Litz et al., 2009; Wilson et al., 2006). Additionally, shame can develop with or without spectators being present (Wilson et al., 2006). As Veterans have performed actions that are not characteristic of their moral values, they may be left with a negative self-appraisal (Tangney \& Dearing, 2002). Veterans who experience shame 
MORAL INJURY, SHAME, GUILT, AND SELF-FORGIVENESS

may encounter decreased internal empathy (Leith \& Baumeister, 1998). Shame can also reduce interactions with one's social network (i.e., isolation) (Keltner \& Harker, 1998). Shame has been linked with various mental health outcomes such as PTSD and depression (Nazarov et al., 2015; Tangney, Wagner, \& Gramzow, 1992). Shame has also been connected to suicidal ideations (Bryan et al., 2014; Bryan et al., 2013). Conceptually, suicidal thoughts can be understood as the need to escape or obliterate the Veteran's cognitive dissonance (Wilson, 2005).

Robinaugh and McNally (2010) identified the process of shame endorsement as being capable of eliciting intrusive and distressing memories, similar to those reported by Veterans with posttraumatic stress symptoms, especially if the Veteran's memories become central to his/her identity (e.g., "I am a bad person, and now I'm unforgivable"), which is the antithesis of optimal posttraumatic growth (Wilson, 2005). As Drescher et al. (2011) identify avoidance and isolation behaviors as possible outcomes of moral injury, shame may be a contributing factor. In the original model outlined by Litz et al. (2009), shame was identified as the core emotion in moral injury development because of its significant relationship with adverse mental health outcomes, similar to the findings of adjective checklist measures assessing shame with depression and posttraumatic stress symptoms (Tangney, Wagner, \& Gramzow, 1992). For Veterans who encounter potentially morally injurious experience, shame may play a role in the inability to make meaning of their war experiences (Currier et al., 2015). Shame may also contribute to a shattered worldview (Frankfurt \& Frazier, 2016) resulting in maladaptive behaviors (e.g., substance abuse, suicidal ideations/attempts, anhedonia and dysphoria, and poor self-care) (Drescher et al., 2011; Litz et al., 2009; Shay, 2012; Wisco et al., 2017). Wilson and colleagues (2006) noted that shame is more incapacitating and painful than guilt, but both emotions cause psychological distress. Furthermore, they indicate that while feelings of shame 
MORAL INJURY, SHAME, GUILT, AND SELF-FORGIVENESS

and guilt possess distinct psychological dimensions, they can coexist depending on the circumstances in which the maladaptive emotions develop during trauma (Wilson et al., 2006).

\section{Guilt.}

While shame is considered the inner emotion of moral injury (Litz et al., 2009), guilt has been researched concerning specific actions or failed behavioral enactments (e.g., failing to prevent atrocities) in which a person feels responsible (Wilson et al., 2006). Lewis (1971) viewed guilt as an internal evaluation which arises from a specific action (e.g., a single transgression), which differs from shame as a negative evaluation of the whole self (Tangney \& Dearing, 2002). Precisely, guilt develops through the negative evaluation of a particular transgressing behavior (e.g., "I did a bad thing”) (Tangney \& Dearing, 2002). Guilt is a common response to trauma that has been connected to poor psychological functioning (Browne, Trim, Myers, \& Norman, 2015). While research on guilt's contribution to negative psychological outcomes is inconclusive due to some studies reporting no relationship except when paired with shame (Tangney, Stuewig, \& Mashek, 2007), others suggest a strong involvement (Browne et al., 2015; Clifton, Feeny, \& Zoellner, 2017; Nazarov et al., 2015).

As guilt seldom involves self-other comparisons, it is more focused on individual actions that can impact a persons' moral code or duties (Wilson et al., 2006), similar to the transgressive acts outlined by Litz et al. (2009). The notion of Veterans failing to act in accordance with their "duty" is believed to adversely affect a core identity (Kubany et al., 1997). Wilson and colleagues (2006) described guilt as emphasizing moral beliefs and values that comprise an individual's core identity and as a process by which a person creates a sense of control for the purpose of meaning development and reconciliation. However, maladaptive guilt is a process by which the Veteran's perpetrations or failed actions are viewed as wrongdoings, and those actions 
MORAL INJURY, SHAME, GUILT, AND SELF-FORGIVENESS

are self-perceived as preventable by acting differently (Lindsay-Hartz, 1984). Contrasted with shame, guilt is not deemed an internal evaluation of the self's goodness or badness but, instead, an evaluation of the role a person plays (Tangney \& Dearing, 2002). Referring back to Drescher et al. (2011), the role military personnel are required to fill while deployed in combat zones does require those individuals to perform actions that may be counter to their moral beliefs (e.g., killing), and those actions may result in feelings of guilt (Litz et al., 2009; Maguen et al., 2009; Shay, 2014).

Wilson and colleagues (2006) identified various types of guilt, such as bystander guilt and death guilt. Both forms of guilt were defined as self-recrimination processes for failed actions that resulted in the occurrence of immoral actions which resulted in substantial harm or death, similar to the notion of failing to prevent, bearing witness to, or learning about actions that conflict with one's moral code (Litz et al., 2009). Death guilt, also known as survivors' guilt, has been found to produce various symptoms among Veterans (e.g., emotional numbing, tension, and regret) (Browne et al., 2015). Shay (1994) identified "survivors' guilt" as a personal responsibility by the Veteran for the death of another, even if the Veteran was not present at the time of the death, which results in feelings of worthlessness (p. 146). As such, for those Veterans who possess feelings of worthlessness, those Veterans may report shame, guilt, and selfcondemnation due to a perceived (Drescher et al., 2011; Litz et al., 2009) failure to have protected fellow service personnel. For some Veterans, they endorse irrational bystander guilt as they believe they "should have" or "could have" been able to prevent the experience (i.e., death or harm) from occurring, which is not always possible (Browne et al., 2015). The presence of guilt has long been documented among combat Veterans and shows strong positive correlations with re-experiencing and avoidance symptoms (Henning \& Frueh, 1998). Guilt has also 
MORAL INJURY, SHAME, GUILT, AND SELF-FORGIVENESS

continued to be reported among Veterans of recent campaigns (Fontana \& Rosenheck, 2004). Guilt has a moral foundation related to the failure to act in a manner that is authentically congruent with the personal values of the Veteran (Wilson et al., 2006). For some Veterans, irreversibility of their actions produces cognitive dissonance due to those actions resulting in inhumane or lethal consequences (Browne et al., 2015; Wilson et al., 2006).

Tangney and Dearing (2003) found guilt proneness was not as reliable an indicator of Veteran community mental health concerns as shame proneness. Nonetheless, guilt and shame are both hypothesized to be the fundamental pathological bases of the majority of combat-related mental health concerns (Bryan et al., 2013; Litz et al., 2009; Wilson et al., 2006). As Kim et al. (2011) found shame was more predictive of depressive symptoms than was guilt, but shame and guilt were equally as predictive in identifying posttraumatic stress symptoms (Browne et al., 2015).

\section{Assessing Shame and Guilt}

Prior research has shown that shame and guilt distinctly contribute to evaluations of oneself and actions that result in cognitive dissonance and self-discrepancies that produce varying types of symptom manifestations for Veterans when returning from war. These selfconscious emotions are difficult to assess as they are typically used interchangeably (Nazarov et al., 2015). Various measures have been developed to assess shame (State Shame Measure; SSM; Bonner, Greenbaum, \& Quade, 2017), guilt (Trauma Related Guilt Inventory; TRGI; Kubany et al., 1996), or both shame and guilt (Test of Self-Conscious Affect 3-Modified; TOSCA-3; Rodriguez, Young, Neighbors, Tou, \& Lu, 2016). For a more comprehensive list of measures assessing shame and guilt see Robins, Noftle, and Tracy (2007). For this study, the State Shame and Guilt scale (SSGS) (Marschall, Sanftner, \& Tangney, 1994) was selected as a brief 
MORAL INJURY, SHAME, GUILT, AND SELF-FORGIVENESS

statement-based measure of assessing both feelings of shame and guilt among combat Veterans of Iraq and Afghanistan. The SSGS measures shame, guilt, and pride, but only subscales for shame and guilt were used for this study.

Tangney and Dearing (2002) noted that assessing and differentiating shame and guilt at the state level is difficult, but research has demonstrated the SSGS measure can be used with Veterans who report morally injurious experiences and feelings of shame and guilt (Schumacher, 2017). The SSGS measure is psychometrically sound (Marschal et al., 1994; Tangney \& Dearing, 2002) among adolescents (Tilghman-Osborne, Cole, Felton, \& Ciesla, 2014), college students (Tangney \& Dearing, 2002), and Veterans (Schumacher, 2017), with internal inconsistency Cronbach's alpha coefficients ranging from .82 to .89 (Tangney \& Dearing, 2002). In a comparison of the SSGS (i.e., state shame and guilt scale) and, more commonly used, TOSCA-A measures (i.e., trait shame and guilt scale), researchers have found internal consistencies to be comparable (Tilghman-Osborne et al., 2014) in assessing two different types of shame and guilt (i.e., endorsement of state shame and state guilt versus shame and guilt proneness). As moral injury is proposed to alter the self-concept of the Veteran (Litz et al., 2009; Shay, 2003), and the lasting effects of combat have been documented from previous conflict eras (e.g., Vietnam), the SSGS was selected to assess the perpetual shame and guilt related to the docile nature of Veterans to their war experiences.

Despite the high face validity associated with the SSGS (Tangney, 1996), it was selected for this study because of its strong psychometric properties, and the initial rationale for conducting the study was to replicate the findings of Schumacher (2017), who used the SSGS scale with Veterans who reported feelings of shame and guilt when prompted to think about their military service. The SSGS has been used to examine complex traumatic experiences of 
MORAL INJURY, SHAME, GUILT, AND SELF-FORGIVENESS

substance users with PTSD (Held, Owens, \& Anderson, 2015) and those who have engaged in unethical behaviors (Gino, Aval, \& Ariely, 2013). Through the conceptual framework of Litz et al. (2009), moral injury is identified as potentially developing through unethical actions or behaviors that conflict with one's own moral beliefs, and the SSGS measure has demonstrated an ability to capture the resulting feelings of shame and guilt (Schumacher, 2017).

According to Woodyatt and Wenzel (2013) and Witvliet et al. (2004), an inability to forgive oneself can result in aversive mental health concerns among Veterans with combat related trauma. Hence, researchers suggest that self-forgiveness is a part of the healing process for Veterans who experience morally injurious symptoms (i.e., shame and guilt) and maladaptive self-discrepancies as a result of exposures to potentially morally injurious experiences. Selfforgiveness and moral injury have been examined in one small sample $(n=40)$ of Veterans being treated for PTSD (Snider, 2015). In this study Snider split the sample into a control and treatment group in which self-forgiveness was incorporated with cognitive processing therapy, and they found the treatment group did demonstrate a minor reduction in reported feelings of shame. Snider (2015) also identified the small sample as a limitation of the study and called for greater research to be conducted but noted that self-forgiveness may be the inverse to feelings of shame, guilt, and self-condemnation. However, to this writer's knowledge, self-forgiveness has not been examined as a moderator of the relationship between moral injury and feelings of shame and guilt (see Schumacher, 2017) among combat Veterans of Iraq and Afghanistan.

\section{Self-Forgiveness}

According to Worthington and Langberg (2012), self-condemnation is a central problem expressed by those who serve in war and who subsequently seek psychotherapy. They defined self-condemnation as criticism and disapproval of oneself due to the Veterans' perceived (1) 
MORAL INJURY, SHAME, GUILT, AND SELF-FORGIVENESS

moral wrongdoings, (2) failure to act in a manner consistent with their moral values, or (3) failure to live up to their own expectations (Worthington \& Langberg, 2012). As Veterans of Iraq and Afghanistan were placed in situations that were morally ambiguous and ethically challenging (Drescher et al., 2011; Litz et al., 2009), those Veterans may have violated their own moral beliefs through witnessing or engaging in unethical behaviors that resulted in self-condemnation and feelings of shame and guilt. For these Veterans, such violations may fragment their central beliefs about humanity and goodness in the world (Drescher et al., 2011). To compound the problem of their eroded worldview, Veterans who experienced trauma may experience shame and guilt that result in excessive, intermittent or unrelenting contempt for themselves (Maguen \& Litz, 2012) and leaves the Veteran with the belief that they are unforgivable. In addition, as Veterans struggle with their own self-forgiveness, they may also struggle with forgiving others (e.g., their command) or receiving forgiveness from others related to their war experiences, known as the forgiveness triad (Enright and the Human Development Study Group, 1996). Baskin and Enright (2004) described forgiveness as the "willful giving up of resentment in the face of another's (other's) considerable injustice and responding with beneficence to the offender even though that offender has no right to the forgiver's moral goodness" (p. 80). Additionally, Enright (2001) identified forgiveness as, "foregoing resentment or revenge" not because the perpetrator deserves it, but instead giving the perpetrator "mercy, generosity, and love." These two descriptions of forgiveness can apply to the morally compromising behaviors exhibited by a Veteran's peers or chain of command (e.g., those that betray the Veteran) (Shay, 2003). However, Veterans that suffer from morally injurious experiences may struggle to engage in forgiveness when the perpetrator is the Veteran themselves (Litz et al., 2009). Worthington and Langberg (2012) suggested that self-forgiveness consists of two distinct types (i.e., 
MORAL INJURY, SHAME, GUILT, AND SELF-FORGIVENESS

decisional and emotional). Decisional self-forgiveness is a process by which the Veteran consciously decides not to act with malice, self-blame, and self-condemnation and views himself/herself with equal appraisals (i.e., self-worth) as others (Worthington, 2006). Whereas emotional self-forgiveness is the emotional substitution of unforgiving emotions, such as shame and guilt, with more adaptive positive emotions like empathy, sympathy, compassion, love, and understanding (Worthington \& Langberg, 2012).

Enright (2001) noted that forgiveness requires a transgression or act that is perceived as violating the assumptions of that individual's "ought world" and those actions be viewed as unjust or unfair, and the process of recognition does not nullify the behavior. Shay's (1994) statement bears repeating in this context:

... moral injury is an essential part of any combat trauma that leads to lifelong psychological injury. Veterans can usually recover from horror, fear, and grief once they return to civilian life, so long as "what's right" has not been violated. (p. 20)

Enright (2001) went on to explain that the forgiver recognizes the behavior as deserving of punishment but decides to release resentment and engage in an act of mercy (i.e., forgiving), so the forgiver becomes the one who receives the benefit. More specifically, Enright (2001) stated that forgiveness is not condoning or excusing actions that occurred (e.g., disproportionate violence towards civilians or enemy combatants or killing) and reconciliation is not required for forgiveness to be achieved. In other words, Veterans who may have performed irreconcilable actions (e.g., killing) can still forgive themselves or others through an internal process. The process of self-forgiveness is described as the Veteran accepting that they're flawed in a way they had not previously been able to admit (e.g., the Veteran's capability to perform inhuman 
MORAL INJURY, SHAME, GUILT, AND SELF-FORGIVENESS

actions such as war atrocities or killing) (Worthington \& Langberg, 2012). Recognition of these flaws can result in anger and other adverse health outcomes (Drescher et al., 2011) and is a reasonable response to trauma (Enright, 2001).

Enright's model of forgiveness consists of four stages. First, the Veteran must acknowledge the behaviors he/she or others performed that conflicted with their moral beliefs have resulted in anger or self-condemnation. Secondly, the Veteran must decide to make a conscious effort to forgive himself/herself or others. Thirdly, one must develop a tangible plan to forgive, and, finally, Veterans must discover the emotions (e.g., shame and guilt) related to their morally injurious experiences and release them to move on with their lives (Enright, 2001). The final stage guides the wronged one to find new life meaning (Enright 2001; Worthington \& Langberg, 2012).

Currier and colleagues (2015) explored meaning-making as a moderating variable for morally injurious effects on posttraumatic stress and depressive symptoms and suicidal risk. They further highlighted the need to be able to interpret and make meaning of the events that had transpired for those Veterans. However, through Enright's (2001) conceptualization of forgiveness and Currier et al.'s (2015) meaning making study, an inability to forgive could inhibit a Veteran from developing meaning or deal with feelings of shame and guilt associated with their war experiences.

It is hypothesized that self-forgiveness could promote symptom reduction among morally injured Veterans who report feelings of shame and guilt, which could in turn support their capacity to develop new life meaning. As previously mentioned, PTSD and moral injury do share some aspects of comorbidity, and research has found that forgiveness was significantly related to lower levels of PTSD among Turkish Veterans (Karairmak \& Guloglu, 2014). Veterans who 
MORAL INJURY, SHAME, GUILT, AND SELF-FORGIVENESS

encounter death, atrocities and the demands of war may struggle to view the world as trustworthy and just. Thus, they may be unable to forgive themselves for actions they performed in the line of duty, regardless of environmental circumstances that led to the transgression, and those transgressions may leave the Veteran feeling hopeless and alone (Currier, Holland, \& Malott, 2015; Litz et al., 2009). Maguen and Litz (2012) identified forgiveness as a possible factor that could alter poor mental health outcomes for morally injured Veterans, and they suggested that forgiveness could alleviate symptoms of guilt, shame, and self-condemnation. Maguen and Litz (2012) also identified successful treatment interventions for those who reported killing in combat as incorporating elements of self-forgiveness in cognitive processing of war experiences for those who've struggled with possible self-discrepancies.

Gassin, Enright, and Knutson (2005) offered forgiveness as a process that is based on the strength of the individual forgiver and is not described as weakness or vulnerability because the forgiver is the beneficiary of forgiveness. Moreover, the forgiver does not have to reconcile or verbalize their forgiveness, because forgiveness is a gift to themselves (Enright, 2001). Baskin and Enright (2004) conducted a meta-analysis of nine published studies $(n=330)$ and found positive correlations between forgiveness and reductions in anger, anxiety, and depressive symptoms that are commonly reported among Veterans with moral injury, similar to other studies examining forgiveness (e.g., Fehr, Gelfand, \& Nag, 2010).

\section{Assessing Self-Forgiveness}

In this study, I hypothesized that Veterans develop self-discrepancies between the persons they were before the war and the self-concept they possess following potentially morally injurious experiences. These Veterans return home with feelings of shame and guilt that can result in maladaptive behaviors (e.g., self-harm or self-sabotaging relationships) (Drescher et al., 
MORAL INJURY, SHAME, GUILT, AND SELF-FORGIVENESS

2011), and they generally identify with a sense of unforgivableness (Litz et al., 2009). As research on moral injury, shame, and guilt is limited, the proposed study seeks to examine this gap in the literature by investigating the relationship between moral injury and feelings of shame and guilt, while also probing the moderating effects of self-forgiveness among combat-exposed Veterans of Iraq and Afghanistan. Litz et al. (2009) identified moral injury in a conceptual framework that encompassed the transgressor as being the individual themselves, beyond betrayal by others as outlined by Shay (2003). Because self-discrepancies related to warzone actions can result in shame and guilt (Drescher et al., 2011; Litz et al., 2009; Tangney et al., 2007), I sought to examine Veterans' ability to self-forgive in this study.

\section{Self-Forgiveness Measure.}

The Heartland Forgiveness Scale (HFS) was developed to assess forgiveness of self, others, and situations but only the self-forgiveness subscale was used in the present study. Veterans may transgress their own moral beliefs through perpetrating, bearing witness to, learning about, or failing to prevent incongruent acts (Litz et al., 2009). Thus, the self-reflective process can result in great inner conflict related to those experiences (Drescher et al., 2011). The HFS self-forgiveness subscale produced an internal consistency reliability coefficient of .72 during initial development (Thompson et al., 2005). The HFS self-forgiveness subscale internal consistently reliability coefficient represents a moderate internal consistency; however, the HFS has been widely used among Veterans with combat trauma (e.g., Bryan, Theriault, \& Bryan, 2015; Karairmak \& Guloglu, 2014; Schuettler \& Boals, 2011). Additionally, the HFS selfforgiveness subscale provides a brief measure of self-forgiveness comparative to other longer measures such as The State Self-Forgiveness Scale (Wohl, DeShea \& Wahkinney, 2008). Provided with the conceptual identification of moral injury as an internal conflict between 
MORAL INJURY, SHAME, GUILT, AND SELF-FORGIVENESS

actions and moral beliefs and values, the HFS self-forgiveness measure is a brief measure to be used to assess the dispositional self-forgiveness of the Veteran completing this study survey.

\section{Summary}

Combat Veterans of Afghanistan and Iraq have been placed in morally ambiguous and ethically challenging situations due to unclear civilian threats, the use of guerilla style tactics, and perceived failures by those in command, which have increased the likelihood of unintentional operational and combat-derived errors (e.g., loss of noncombatant life) (Grossman, 2009; Litz et al., 2009). According to self-discrepancy theory, individuals who experience morally compromising situations, such as combat Veterans, may develop inner conflict related to their specific actions and dissonance around their self-concept. As such, moral injury is a result of experiences that conflict with an individual's personally held values and beliefs that can result in feelings of shame and guilt (Schumacher, 2017). To this writer's knowledge, self-forgiveness has not yet been examined as a moderator between the proposed relationship between moral injury and feelings of shame and guilt.

\section{Purpose of the Current Study.}

Current researchers on moral injury call for increased attention to forgiveness and Veteran war experiences (Currier et al., 2015; Drescher et al., 2011; Litz et al., 2009; Maguen \& Litz, 2012; Schumacher, 2017). In addition, there is limited published research specifically examining self-forgiveness among Veterans who convey moral injury and report distressing internalized reactions such as feelings of shame and guilt. The purpose of this study was to explore the relationship between moral injury and feelings of shame and guilt among combat exposed Veterans of Iraq and Afghanistan previously identified by Schumacher (2017). Furthermore, this study investigated the moderating effects of self-forgiveness on the identified 
MORAL INJURY, SHAME, GUILT, AND SELF-FORGIVENESS

relationship, which can have clinical implications. This study may contribute to the literature on moral injury through the use of assessment measures that examine the current theoretical models to test the following four hypotheses: (1) It is hypothesized self-forgiveness moderates the relationship between moral injury and shame alone, (2) It is hypothesized self-forgiveness moderates the relationship between moral injury and guilt alone, (3) It is hypothesized that moral injury is positively correlated with feelings of shame and guilt, and (4) It is hypothesized that self-forgiveness moderates the relationship between moral injury and feelings of shame and guilt. 
MORAL INJURY, SHAME, GUILT, AND SELF-FORGIVENESS

\section{CHAPTER II: METHODS}

In this study, I sought to replicate and extend earlier research that supported a relationship between morally injurious experiences and feelings of shame and guilt among Iraq and Afghanistan Veterans. In addition, I wanted to determine if self-forgiveness moderated the relationship between moral injury and feelings of shame and guilt. I tested the hypotheses that moral injury would be positively associated with feelings of shame and guilt among Iraq and Afghanistan Veterans in the preliminary analysis, such that greater levels of self-reported morally injurious experiences would be associated with greater levels of self-reported current feelings of shame and guilt. Further, it was hypothesized that self-forgiveness would moderate the relationship between moral injury and feelings of shame and guilt among Iraq and Afghanistan Veterans, such that higher levels of reported self-forgiveness would moderate the relationship between moral injury and shame and guilt as examined together and independently. Specifically, I hypothesized higher levels of self-forgiveness would be inversely related to reported feelings of shame/guilt.

\section{Participants}

An a priori statistical power analysis was performed for sample size estimation using G*Power software (Faul, Erdfelder, Buchner, \& Lang, 2009). To establish the statistical significance of the multiple correlation coefficient $\left(R^{2}\right)$, the F-statistic was used. The effect size

(ES) hypothesized in the proposed study was a medium effect $\left(f^{2}=.15\right)$, with an alpha $(\alpha)$ level of .05 and statistical power of $(1-\beta=.80)$. The power level of .80 was selected for the present study because given the nature of the statistical instruments, and the constructs under investigation, setting power at .80 allowed a reasonable, but not over estimation of the chance of finding the hypothesized correlation, if, in fact, it exists (Cohen, 1992). The estimated sample size needed 
MORAL INJURY, SHAME, GUILT, AND SELF-FORGIVENESS

for this effect, calculated using $\mathrm{G}^{*}$ Power software (Faul et al., 2009), was $n=68$ for this crosssectional study. I recruited a convenience sample of 198 via social media (i.e., Facebook) to compensate for any incomplete data and to increase the statistical power of this study.

Compensation for participation in this study was provided through the opportunity to enter a drawing for one of four \$20.00 Amazon gift cards. Total monetary cost for this research study was $\$ 80.00$. The use of social media provides the opportunity to potentially access both Veterans who do and do not seek VA medical services, as the VA usage rate among Iraq and Afghanistan Veterans is low (Seal et al., 2010; Whealin et al., 2014).

Inclusion criteria were Veteran status and recent deployment history. Specifically, to be eligible to participate in this study, participants must have served in the United States armed forces for no less than two years. Also, because this study sought to examine Veterans of Iraq and Afghanistan campaigns exclusively, participants had to have completed no less than one deployment to a combat zone in or around Iraq or Afghanistan during the Gulf War Era II campaigns (Operation Enduring Freedom (OEF), Operation Iraqi Freedom (OIF), or Operation New Dawn (OND); 2001- Present). A convenience sample $(n=198)$ was collected.

\section{Measures}

\section{The Moral Injury Questionnaire - Military Version (MIQ-M; Currier, Holland,}

Drescher, \& Foy, 2015). The MIQ-M is a standardized measurement of self-reported exposure to potentially morally injurious experiences (MIEs), which is defined as the extent to which service members experience moral stress from war-zone experiences that develop into adverse psychological symptom constellations (i.e., shame and guilt) (See Appendix G). The MIQ-M was developed to examine the following six domains, as outlined by Drescher et al. (2011), that empirically contribute to moral injury development: (1) acts of betrayal; (2) acts of 
MORAL INJURY, SHAME, GUILT, AND SELF-FORGIVENESS

disproportionate violence; (3) circumstances resulting in the harm or death of noncombatants; (4) within rank violence; (5) situations where death or suffering were obvious; and (6) ethical and moral conflicts (Currier et al., 2015). Any or all of these outcomes can result from various means (i.e., Veteran has perpetrated, witnessed, failed to prevent, or learned about events that violate his/her moral beliefs and expectations) (Liz et al., 2009). The MIQ-M consists of 19-items related to witnessing (e.g., "I saw/was involved in the death(s) of an innocent"), participating in (e.g., "I did things that betrayed my personal values"), or failing to prevent situations that result in Veterans experiencing cognitive dissonance as a result of transgressing their moral codes (e.g., “I feel guilt for surviving when others didn't").

All items on the MIQ-M are rated on a 4-point Likert-type scale ranging from 1 (never) to 4 (often). The total score is derived by adding the points across all items, with possible scores ranging from 19 to 76 (Currier et al., 2015). Higher scores indicate higher exposure to potentially morally injurious experiences (PMIEs) and greater diversity and frequency within those experiences. Currier et al.'s (2015) initial psychometric development and validation of the MIQM consisted of a community sample of 131 Iraq and Afghanistan Veterans and a clinical sample of 82 Iraq and Afghanistan Veterans. Currier et al. (2015) found Veterans among the clinical sample reported statistically significantly higher scores than the community sample. The researchers conducted a factor analysis and found a unidimensional structure.

The MIQ-M demonstrated strong convergent validity with combat exposure, posttraumatic stress symptoms, depression, and social and functional impairments among both samples (Currier et al., 2015). Additionally, researchers examined the hypothesized relationship between the observed variables and their underlying latent construct of moral injury and found strong data fit for both samples. Currier et al. (2015) reported the community sample model fit 
MORAL INJURY, SHAME, GUILT, AND SELF-FORGIVENESS

from their confirmatory factor analysis as follows: $\chi 2(72)=115.30, p<.001$; Root Mean Square Error of Approximation $($ RMSEA $)=.07,90 \%$ Confidence Interval $(\mathrm{CI})=.04-.09 ;$ Standardized Root Mean Square Residual $(\mathrm{SRMR})=.04$; Comparative Fit Index $(\mathrm{CFI})=.90 ; \Delta \chi 2(2)=30.94$, $p<.001$. The clinical sample mode fit was reported as follows: $\chi 2(72)=75.97, p=.35$; RMSEA $=.03,90 \%$ C.I $=.00-.07 ; \mathrm{SRMR}=.05 ; \mathrm{CFI}=.98$. Currier et al. $(2015)$ allowed for correlated errors for items 7 and 9, as well as items 1 and 15, due to wording of the questions that contributed to correlations between items. For instance, items 7 and 9 both begin with "I feel guilt" and measure forms of survivors' guilt and error terms were permitted due to wording. Additionally, items 1 and 15 were also correlated but also shared similar wording "betrayed or let-down." After allowing these items to correlate, Currier et al. (2015) found improved model fits, reported above, for both community and clinical samples. According to MacCallum, Brown, and Sugawara (1996), RMSEA between .05 and .01 demonstrate good and excellent model fit. The RMSEAs for both community and clinical samples were .04 and .03 which demonstrates a close concentration of data points to the line of best fit for each model and fall between the good to excellent range statistically. The SRMR is another measure of fit calculated for each of the above models. The SRMR for both community and clinical samples were .05 and .04, respectively. Currier et al.'s (2015) SRMR results indicate good fit according to Hu and Bentler (1999), who report a value less than .08 demonstrates good fit. These "good" model fits indicate that the MIQ-M is assessing exposure to potentially morally injurious experiences and those associated symptoms outlined in the Litz et al. (2009) model and, thus, was selected for this study.

As only one other measure has been established to assess potentially morally injurious experiences among those who've served in the military, Currier et al.'s (2015) statistical analyses 
MORAL INJURY, SHAME, GUILT, AND SELF-FORGIVENESS

were vital in establishing the MIQ-M as a measure based on the construct of moral injury. The purpose of the present study was to examine moral injury and feelings of shame and guilt related to war experiences. As such, the MIQ-M is designed to specifically examine those experiences among military samples.

Furthermore, Currier et al.’s (2015) preliminary analyses consisted of statistically significant bivariate correlations between MIQ-M scores and psychological impairment, social functioning, PTSD, and depression $(p<.001)$ after controlling for demographics, deploymentrelated factors, and exposure to combat-related life threat stressors. MIQ-M scores were statistically significantly higher for Active Duty Army $(p=.012)$ and Marines $(p=.011)$ compared to other branches $(p=.012)$, which was expected, as those two service branches tend to see and experience greater degrees of combat compared to other service branches. The MIQM was chosen for this study based on strong incremental and convergent validity and adequate psychometric properties, validation with military service members and community and clinical Veteran samples, and applicability to participants at various stages of reintegration.

The State Shame and Guilt Scale (SSGS; Marschal, Sanftner, \& Tangney, 1994). The SSGS is a standardized measure of self-reported feelings of shame, guilt, and pride (See Appendix I). The SSGS consists of 15-items (e.g., "I feel good about myself" and "I feel like apologizing, confessing") rated on a 5-point Likert-type scale, ranging from 1 (Not feeling this way at all) to 5 (Feeling this way very strongly). Total scores are formed by summing all points across all items, with possible scores ranging from 5 to 25 . Higher scores represent more persistent and severe feelings of shame, guilt, and pride.

The SSGS was initially developed as a manipulation check for shame induction in an experimental study of shame and empathy (Marschall et al., 1994). The scale is divided into 
MORAL INJURY, SHAME, GUILT, AND SELF-FORGIVENESS

three subscales (i.e., shame, guilt, and pride), each of which consist of five items. The shame scale is designed to measure (state) feelings of shame by asking shame related questions (e.g., "I want to sink into the floor and disappear"). The guilt subscale is designed to measure (state) feelings of guilt by asking guilt related questions (e.g., "I feel remorse, regret" and "I feel like apologizing, confessing"). The other SSGS scale is the pride subscale which measures (state) feelings of pride experiences (e.g., "I feel good about myself," and "I feel capable, useful"). Marschall and colleagues (1994) examined a university sample $(n=142)$, and they reported that internal consistency estimates of the three subscales of the SSGS (5-items per scale) produced strong internal consistency reliabilities, with Cronbach's alpha coefficients as follows: (1) shame $=.89,(2)$ guilt $=.82$, and (3) pride $=.87$ (Marschall et al., 1994; Tangney \& Dearing, 2002). As such, the alpha coefficients for shame and guilt, presented by Marschall et al. (1994), were deemed adequate for this study. For this study, I only used the shame and guilt subscales because the purpose of this study was to directly examine moral injury's relationship with feelings of shame and guilt, and to replicate previous research (e.g., Schumacher, 2017), as such, although the pride scale does demonstrate strong psychometric properties, the construct of pride is beyond the aim of the current study.

The SSGS has been used with Veterans of Iraq and Afghanistan (see Schumacher, 2017) to explore morally injurious experiences and feelings of shame and guilt. The SSGS has been used to investigate self-conscious emotions correlated with unethical and ethical actions (Gino, Aval, \& Ariely, 2013), and it has been used in studies examining complex traumatic experiences (see Held, Owens, \& Anderson, 2015). The SSGS was chosen for this study because the SSGS instrument has proven to be psychometrically sound (Marschal et al., 1994; Tangney \& Dearing, 
MORAL INJURY, SHAME, GUILT, AND SELF-FORGIVENESS

2002), although the measure has high face validity (Tangney, 1996), and its applicability with Veterans of recent conflicts.

Heartland Forgiveness Scale (HFS; Thompson et al., 2002). The HFS is a standardized self-report measurement of dispositional forgiveness, measuring the extent to which an individual can forgive oneself, others, and situations (Thompson et al., 2002) (See Appendix K). The HFS consists of 18-items related to forgiving oneself (e.g., "although I feel bad at first when I mess up, over time I can give myself some slack"), forgiving others (e.g., "I continue to be hard on others who have hurt me”), or forgiving situations (e.g., "If I am disappointed by uncontrollable circumstances in my life, I continue to think negatively about them"). The HFS is rated on a 7-point Likert-type scale, ranging from 1 (almost always false of me) to 7 (almost always true of me), indicating self-reported responses to negative situations described. The HFS consists of nine items that are positively worded to assess forgivableness and nine items that are worded negatively to assess unforgivableness. Total scores are formed by summing all of the positively worded questions and reverse scoring the negative questions. All scores are then summed for a total score, with possible scores ranging from 9 to 63 . Higher scores indicate higher self-reported likelihood of forgiving oneself, others, and situations. The HFS was chosen for this study based on acceptable psychometric properties (Thompson et al., 20002), validation with military and Veteran samples, and applicability to participants at various stages of military transition.

In the initial development and validation of the HFS, Thompson and colleagues (2005) reported that total score internal consistency estimates yielded Cronbach's alpha coefficients ranging between .86 and .87 . Thompson et al. (2005) performed three studies on college students to validate the HFS, sample sizes included 499, 1,111, and 504, respectively. Factor analysis was 
MORAL INJURY, SHAME, GUILT, AND SELF-FORGIVENESS

conducted and found question wording accounted for systematic variability in item responses (e.g., positively or negatively worded items), and the forgiveness factors (i.e., self, others, and situation) were significantly correlated. The factor analysis divided the self, other, and situation factors from the positively and negatively worded items and input them as indictors. The self, other, and situations were loaded as first-order factors while language (positive or negative) was loaded as a second-order factor. The factor analysis produced a strong data fit with CFI $=.96$, RMSEA $=.44$, and RMSEA CI $=.04-.05$. The forgiveness factors were significantly correlated (i.e., self and other, $r=.31$, self and situation $r=.78$, and other and situation $r=.54$ ). As such, Thompson and colleagues noted that forgiveness is composed of three separate constructs. This study examined only the construct of self-forgiveness, and Thompson et al. (2005) reported internal consistencies of HFS self-forgiveness subscale among the three initial validation studies as (1) .75, (2) .76, and (3) .72, respectively. Thompson et al. (2005) reported these alpha coefficients demonstrate acceptable rates of internal consistency. In recent studies examining forgiveness among college students, the HFS internal consistencies were reported as comparable to the initial validation and development findings of the HFS (Yao, Chen, Yu, \& Sang, 2016). As the HFS measures forgiveness in the context of transgressions, studies have found that the HFS self-forgiveness subscale among combat-exposed Veterans with PTSD Cronbach's alpha coefficients .84 (Bryan et al., 2015) and .92 (Kashdan, Julian, Merritt, \& Uswatte, 2006) demonstrate the empirical utility of the HFS and its subscales.

Correlational coefficients between the HFS and three measures of dispositional forgiveness (i.e., Forgiveness of Self and Forgiveness of Others scales (Mauger, Perry, Freeman, Grove, McBride, \& McKinney, 1992), and the Multidimensional Forgiveness Inventory (Tangney, Boone, \& Dearing) were calculated (Thompson et al., 2002). The HFS self-subscale 
MORAL INJURY, SHAME, GUILT, AND SELF-FORGIVENESS

was significantly correlated with the Maguer et al. Forgiveness of Self and Multidimensional Forgiveness Inventory self-subscales, according to Thomson et al., 2005). Additionally, the HFS other subscale (i.e., forgiveness of others) was also correlated with Mauger et al.'s (1992) Forgiveness of Others and Multidimensional Forgiveness Inventory other subscale (i.e., $t$ (273) 5 5.1, $p<.001, t(273) 53.9, p<.001)$ (Thompson et al., 2002). Though forgiveness research among Veterans is sparse, the HFS has been used with the Iraq and Afghanistan cohort of Veterans in previous studies (e.g., Bryan et al., 2015; Karairmak \& Guloglu, 2014).

Demographic Questionnaire. A forced-choice sociodemographic and military service characteristics questionnaire included 11items (See Appendix D). Veterans were asked to provide information about age, sex, ethnicity, education level, military discharge, service branch, highest rank earned, deployment status, number of deployments, deployment locations, and if they are currently receiving VA mental health services. The demographic questions were used to provide descriptive information about the collected sample.

\section{Design}

This study is correlational in nature. I explored the influence of self-forgiveness (subscale score on the HFS) on the relationship between moral injury (total score on the MIQ-M) and feelings of shame and guilt (total score on the SSGS) among U.S. combat Veterans of OEF/OIF/OND campaigns. This study was a quantitative, cross-sectional, correlational, surveystyle design. A cross-sectional survey-style design can be conducted at one time through the use of a developed questionnaire to examine variables of interest (Lindell \& Whitney, 2001). One predictor variable (Moral Injury), one moderating variable (forgiveness), and three criterion variables (shame alone, guilt alone, and shame and guilt combined) were analyzed in this study. 
MORAL INJURY, SHAME, GUILT, AND SELF-FORGIVENESS

\section{Analyses}

Data were analyzed using Statistical Package for Social Sciences (SPSS Version 25) statistical software (International Business Machines (IBM), 2013). Descriptive statistics means and standard deviations, and scale internal consistency reliabilities were calculated on all measures providing aid in data interpretation. The data were assessed for normality, potential covariates derived from participant demographics, and statistical assumption violations (e.g., linear relationship, multivariate normality, and homoscedasticity) which are reported in the Results section. Statistically significant relationships among demographic and exposure variables were entered into the regression models to account for their contributions in explained variance. No validity check questions were included in the survey material.

In this study all participants received identical survey material with random variation in survey order. All participants first completed the demographic question and the MIQ-M, then secondary measures (SSGS and HFS Self-Forgiveness subscale) were randomly ordered via Qualtrics survey randomizer. No comparison group was included. To ensure data integrity, I included exclusionary criteria of the data through Qualtrics (e.g., less than $80 \%$ completion of Qualtrics survey or completed survey in less than 3 minutes were removed).

To account for missing data, study variable means were used for incomplete items. To test the hypothesis that feelings of shame and guilt are a function of exposure to potentially morally injurious experiences, and more specifically whether self-forgiveness moderated the relationship between moral injury and feelings of shame alone, guilt alone, or shame and guilt combined, a series of hierarchical multiple regressions were conducted to address the following hypotheses: 
MORAL INJURY, SHAME, GUILT, AND SELF-FORGIVENESS

H1: It is hypothesized self-forgiveness moderates the relationship between moral injury and shame alone. For hypothesis one, the relationship between moral injury, derived from the total score on the MIQ-M, and feelings of shame alone (measured by the SSGS shame subscale score) were hypothesized to be moderated by self-forgiveness (HFS - self-forgiveness subscale score). SPSS was used to create a new variable using the centered MIQ-M scores and centered self-forgiveness scores, accounting for multicollinearity, to examine the moderating effects of self-forgiveness and will be referenced as the interaction term (Self-forgiveness = MIQ-M, centered x Self-Forgiveness subscale, centered). To avoid potentially problematic high multicollinearity between the component variables of the interaction term, they were centered by subtracting the respective means from the relevant scores on the MIQ-M and HFS selfforgiveness subscale.

This model accounted for statistically significant demographic and exposure variables (e.g., gender, combat exposure, rank, type of discharge, and use of VA mental health services) by entering them into the first model of each regression to account for their explained variance. For this regression, the three predictors, moral injury, self-forgiveness, and the interaction term, created in SPSS, were entered in subsequent order to examine the hypothesized relation and is outlined in Figure 1. I entered moral injury as the first predictor variable, as shame alone was entered as the criterion variable, followed by scores on the HFS representing self-forgiveness and then the interaction term was entered as the third predictor. It was hypothesized that selfforgiveness would moderate the relationship between moral injury and shame alone. 


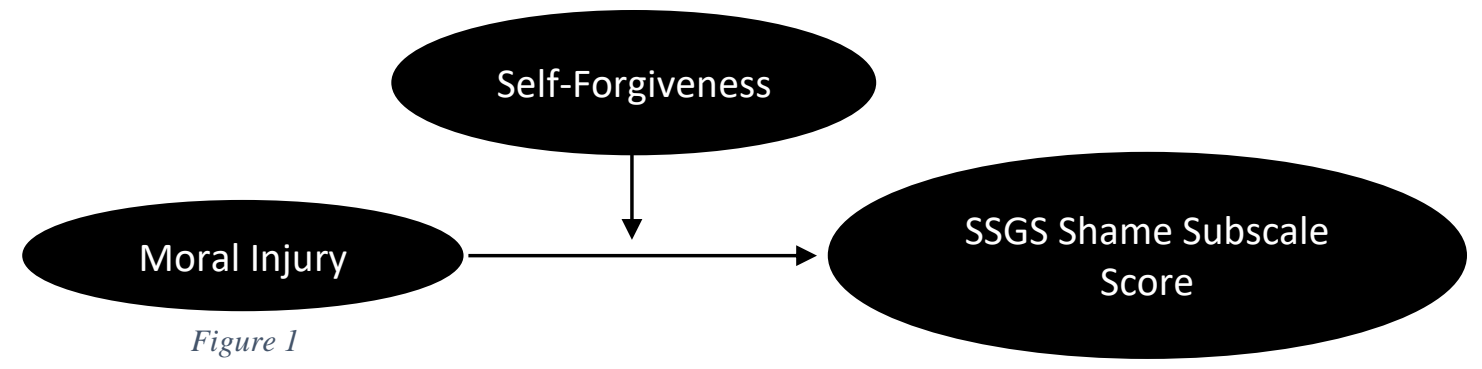

$\mathrm{H} 2$ : It is hypothesized self-forgiveness moderates the relationship between moral injury and guilt alone. Similar to the previous regression, this model accounted for selected statistically significant demographic and exposure variables and entered three predictor variables (i.e., moral injury, self-forgiveness, and the interaction term). I entered guilt alone (measured by the SSGS guilt subscale scores), as the criterion variable as outlined in Figure 2. I then entered moral injury (MIQ-M) as the first predictor variable, followed by scores on the HFS representing selfforgiveness, and the interaction term was entered as the third predictor. It is hypothesized that self-forgiveness would moderate the relationship between moral injury and guilt alone.

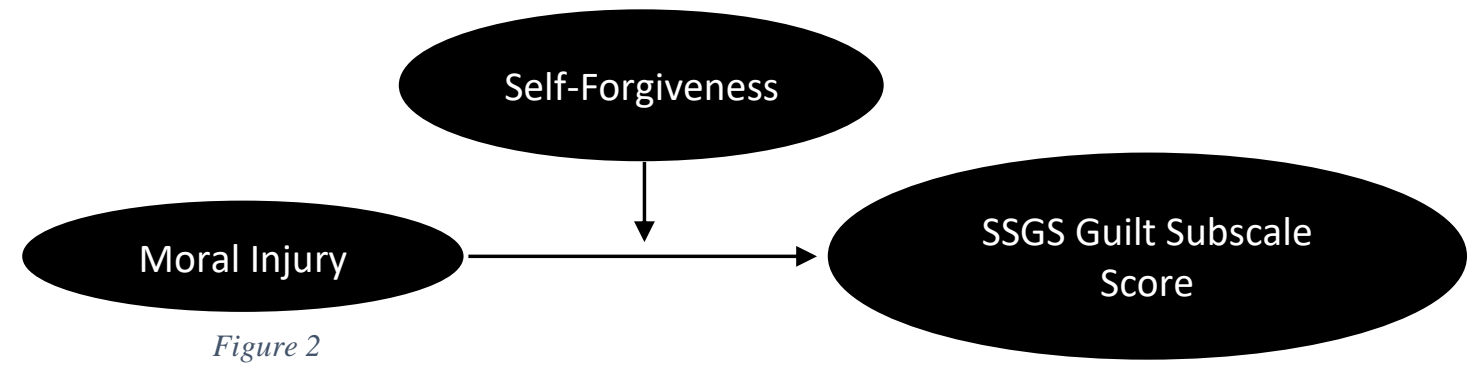

H3: It is hypothesized that moral injury is positively correlated with feelings of shame and guilt. In the first model of this regression statistically significant demographic and exposure variables were entered. Then two predictors, moral injury and self-forgiveness, were entered against a criterion variable derived from the combined SSGS guilt and shame subscale scores. Moral injury was hypothesized to account for a significant amount of variance and be positively 
MORAL INJURY, SHAME, GUILT, AND SELF-FORGIVENESS

correlated with reported levels of shame and guilt among combat exposed Veterans of the Iraq and Afghanistan conflicts, as outlined in Figure 3. Self-forgiveness was entered as the second variable in the hierarchical linear regression model in combination with moral injury. I hypothesized that self-forgiveness would show a significant, but negative correlation with feelings of shame and guilt combined. The primary function of the third hypothesis was to examine the relationships among moral injury, self-forgiveness, and feelings of shame and guilt combined, thus, providing a foundation for the moderator variable to be examined in a subsequent regression.

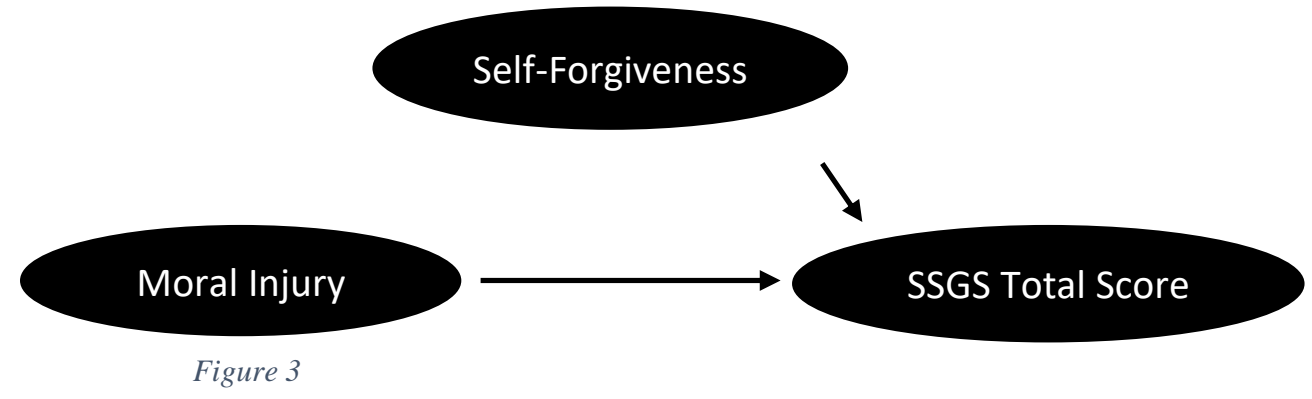

H4: It is hypothesized that self-forgiveness moderates the relationship between moral injury and feelings of shame and guilt. This model contained demographic and exposure variables of statistical significance and three predictors, moral injury, self-forgiveness, and the interaction of the latter two represented by the new variable created in SPSS. I entered moral injury (MIQ-M) as the first predictor variable, followed by scores on the HFS representing selfforgiveness, and then the interaction term was entered as the third predictor. The criterion variable was the combined shame and guilt subscale scores on the SSGS. This regression is modeled in Figure 4. This three-parameter model was analyzed to determine if moral injury and self-forgiveness interact in a statistically significant manner to predict feelings of shame and 
guilt over-and-above moral injury alone and to examine if self-forgiveness moderated this hypothesized relationship. The two models were then compared to determine how the predictors of moral injury and self-forgiveness impact feelings of shame and guilt in the target population and assisted in determining the explanatory power over-and-above their independent contributions. Significance level for this model was $p=.05$.

\section{Self-Forgiveness}

Moral Injury

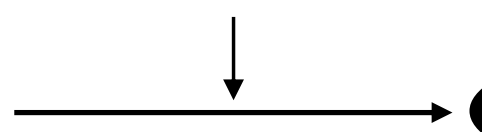

\section{SSGS TOTAL SCORE}

Figure 4

\section{Procedures}

This study was submitted to the Institutional Review Board (IRB) at West Virginia University (WVU). Following IRB approval, participants were initially recruited through convenience sampling using Amazon Mechanical Turk (M-Turk) survey database. All study measures were uploaded into a Qualtrics survey and then uploaded to the M-Turk database. MTurk survey posting included an outline of the eligibility criteria (i.e., discharged from the military, completion at least one deployment to a combat zone, a member of the Gulf War II era cohort, possess Veteran status, and completed no less than two years of military service), completion time, and contact information of the investigator. M-Turk survey posting also included the recruitment script (See Appendix B). However, after three days of the survey being posted via Amazon Mechanical Turk, all completed surveys $(n=40)$ were invalid. Invalid surveys included reported military rank unachievable to period of enlistment (e.g., E-8 after only 
MORAL INJURY, SHAME, GUILT, AND SELF-FORGIVENESS

serving in the military for two years), impossible deployment to service length ratios (e.g., completed four or more deployments within a two-year enlistment), and survey completion under three minutes. As a result of invalid data, the survey was removed from Amazon Mechanical Turk and all completed surveys were not utilized for this study.

I developed a secondary recruitment strategy that was submitted to the Institutional Review Board (IRB) at West Virginia University (WVU). Following IRB approval, participants were recruited through convenience sampling using social media (i.e., Facebook). A sharable Facebook post was disseminated via the researcher's social media (i.e., Facebook) account. Additionally, the Qualtrics survey link was shared with organized social media groups (e.g., Veterans of Foreign Wars- an online community of Veterans who have deployed, Veterans of WVU - an online Veteran students organization affiliated with West Virginia University, and The War They Brought Home - an online social support group for combat Veterans). Participants were able to view the link to the study on Qualtrics where they were provided with the inclusion criteria again. Individuals were able to share or post the link to the study on their personal Facebook pages.

All study measures were uploaded into the Qualtrics survey. The social media survey posting included an outline of the eligibility criteria (i.e., discharged from the military, completion of at least one deployment to a combat zone, a member of the Gulf War II era cohort, possess Veteran status, and completed no less than two years of military service), estimated completion time, and contact information of the investigator. Study survey posting was also included as part of the recruitment script (See Appendix B).

Veterans who agreed to participate in this study clicked on the Qualtrics survey link provided via sharable Facebook post. Before beginning the survey, participants were instructed 
MORAL INJURY, SHAME, GUILT, AND SELF-FORGIVENESS

to read the informed consent document (See Appendix A) on the opening screen of the Qualtrics survey, which detailed the rights of the participant (i.e., right to discontinue at any point, right to anonymity, and the right to an explanation of the potential risks and benefits of participation).

The informed consent was provided on the initial screen to ensure all participants understood the risks and benefits of this study. The page also described confidentiality and informed participants that any report derived from this study will use de-identified data. Participants were not able to begin the survey until they agreed to the informed consent. By agreeing to the informed consent, participants indicated that they had read the informed consent document and agree to participate in this study. Participants were provided the contact information of the investigator so if they had any questions regarding the study or were interested in receiving a summary of the findings at the conclusion of the survey, they would know who to contact.

After obtaining consent, participants were directed to the measures of the study, which included The Moral Injury Questionnaire (MIQ-M; Currier et al., 2015), the Heartland Forgiveness Scale (HFS; Thompson et al., 2005), The State Shame and Guilt Scale (SSGS; Marschall et al., 1994), and a brief demographic questionnaire. First, participants were prompted to complete the brief eleven-item demographic questionnaire (Appendix D). Any items that were endorsed under the exclusion criteria (e.g., not a Veteran) sent participants to the end of survey screen via the skip-logic function on Qualtrics to prohibit them from completing the survey. Once participants completed the demographic questionnaire, they were directed to the core measures of this study. The remaining measures were randomly counterbalanced to account for order effects. All participants received the same survey material.

At the completion of the survey, participants were presented with a closing window. The participants were thanked for their participation and provided the researcher's contact 
MORAL INJURY, SHAME, GUILT, AND SELF-FORGIVENESS

information once more should they have had questions or concerns about the study, their rights as a participant, or would like a copy of the results once completed. No additional incentives were included in this study. After completion of the study, participants were redirected to a separate distinct link to collect email addresses for the Amazon gift cards drawing to safeguard anonymity and privacy for those participants who wanted to enter the drawing for a chance to win.

In order to choose the recipients of the gift card incentives this researcher randomly choose four participant emails using a random number generator (Random.org, 2019). The participants who chose to provide an email address were assigned a number and those numbers were chosen via the random number generator. The winners were emailed an electronic link for a gift card. All emails collected were kept separate from study materials to ensure confidentiality of participants. Winning email addresses were forwarded their Amazon gift card with no other information included in the email to ensure no link could be made between their participation and the awarded Amazon gift card.

\section{Summary}

The current body of literature is limited in addressing the role of self-forgiveness as a moderating variable of the previously well-established relationship between moral injury and feelings of shame and guilt. I sought to replicate and extend this literature and provide evidence for the relationship between morally injurious experience and adverse feelings of shame and guilt and the moderating effects forgiveness. I employed a cross-sectional quantitative survey design and solicited participants who have served in and around Iraq and Afghanistan during Gulf-Era II campaigns (i.e., OEF/OIF/OND). Participants were recruited through the use of social media (i.e., Facebook) who met the qualifications for this study. Participants were asked to 


\section{MORAL INJURY, SHAME, GUILT, AND SELF-FORGIVENESS}

provide demographic information, and complete the study measures (i.e., MIQ-M, SSGS, and HFS). A pilot study was conducted with five combat Veterans that established the estimated completion time to be between 5-10 minutes. All collected data and hypotheses were analyzed using SPSS software. The findings of this study bridge the gap between empirical work outlining proposed conceptual models and hold treatment implications for combat Veterans. 
MORAL INJURY, SHAME, GUILT, AND SELF-FORGIVENESS

\section{CHAPTER III: RESULTS}

\section{Respondent Demographics}

All participants completed the online survey using Qualtrics. Eligibility criteria, which were provided in the social media recruitment listing and on the introduction page of the survey, stated that the participant must have Veteran status and have deployed in support of conflicts in or around Iraq and Afghanistan after 2001. Two hundred fifty-two surveys were submitted. Survey responses were removed for participants who did not meet the eligibility criteria or completed less than $80 \%$ of the questionnaire, which resulted in a removal of 54 surveys. Specifically, 28 participants indicated they were still on active duty and, thus, have not obtained Veteran status from the military. Additionally, incomplete surveys $(n=26)$ of participants who did not complete $80 \%$ of the survey items were listwise deleted. As such, the total sample size for the study was 198, which demonstrated a 78.6\% completion rate. Participants included 163 Veterans with combat exposure (82.32\%) and 35 non-combat Veterans (17.68\%). Deployment locations for Veterans in this study were Afghanistan with 69 Veterans who only deployed to that country (34.85\%), 85 Veterans who deployed only to Iraq (42.93\%), and 44 Veterans who deployed to both Iraq and Afghanistan (22.22\%). Participant ages were broken into categories

for this study, but their ages ranged from 25 to 66 with a mean of 36.68 and standard deviation of 6.83. The ethnic diversity of this study sample is reported as follows: Caucasian American or White $(n=166 ; 83.84 \%)$, African American or Black $(n=7 ; 3.54 \%)$, Latino/a $(n=7 ; 3.54 \%)$, Asian ( $n=6 ; 3.03 \%)$, Biracial or Multiracial $(n=7 ; 3.54 \%)$, Native American/Alaska Native $(n$ $=3 ; 1.52 \%)$, and Other $(n=2 ; 1.01 \%)$.

While a small sample of this study $(n=21 ; 10.61 \%)$ had a high school or equivalent education, a sizeable portion of the collected sample had at least some higher education $(n=67$; 
MORAL INJURY, SHAME, GUILT, AND SELF-FORGIVENESS

$33.84 \%)$. Another subset of this sample had completed a higher-level education beyond a twoyear degree or equivalent $(n=40 ; 20.20 \%)$. The remaining study participants had completed a 4year degree or greater $(n=70 ; 35.36 \%)$. Participants of this study were comprised primarily of Veterans with honorable discharges $(n=186 ; 93.94 \%)$. Other discharges comprised a small portion of this sample $(n=12 ; 6.07 \%)$. There were no dishonorable discharges reported. Veterans in this sample were more likely to be enlisted $(n=193 ; 97.47)$ with officers representing $2.54 \%(n=5)$ of the overall sample. Veterans in this study were also more likely to have served via active duty in the United States Marine Corps $(n=105 ; 53.03 \%)$ or Army $(n=$ $50 ; 25.25 \%)$. Service branch identification for Veterans in this study have been further broken down in Table 1.

The majority of Veterans in this study have deployed more than once $(n=127 ; 64.14 \%)$. Seventy-one Veterans in this study reported one deployment (35.86\%). More Veterans reported two deployments $(n=78 ; 39.39 \%)$. Another group of Veterans reported three deployments in support of conflicts in Iraq and/or Afghanistan $(n=27 ; 13.64 \%)$. Finally, a small sample reported four or more deployments since $2001(n=22 ; 11.11 \%)$. Of note, among the sample as a whole, the use of VA mental health services was relatively split; however, more Veterans reported not using mental health service $(n=108 ; 54.82 \%)$. Table 1 indicates the representation of participant demographics.

Table 1 Participant Demographics

\begin{tabular}{lcc}
\hline Variable & Number of Participants & $\%$ \\
\hline Deployment Location & & \\
Afghanistan & 69 & $34.85 \%$ \\
Iraq & 85 & $42.93 \%$ \\
Both & 44 & $22.22 \%$ \\
Combat Exposure & & \\
Yes & 163 & $82.32 \%$ \\
No & 35 & $17.68 \%$
\end{tabular}


MORAL INJURY, SHAME, GUILT, AND SELF-FORGIVENESS

\begin{tabular}{|c|c|c|}
\hline \multicolumn{3}{|l|}{ Age } \\
\hline 18 to 29 & 22 & $11.10 \%$ \\
\hline 30 to 39 & 123 & $62.10 \%$ \\
\hline 40 to 49 & 43 & $21.70 \%$ \\
\hline 50 and Above & 10 & $0.51 \%$ \\
\hline \multicolumn{3}{|l|}{ Gender } \\
\hline Male & 185 & $93.43 \%$ \\
\hline Female & 11 & $5.56 \%$ \\
\hline Gender Fluid & 1 & $0.51 \%$ \\
\hline Transgender & 1 & $0.51 \%$ \\
\hline \multicolumn{3}{|l|}{ Race/Ethnicity } \\
\hline Native American/Alaska Native & 3 & $1.52 \%$ \\
\hline Asian & 6 & $3.03 \%$ \\
\hline African American (Black) & 7 & $3.54 \%$ \\
\hline Latino/a & 7 & $3.54 \%$ \\
\hline European-American (Caucasian) & 166 & $83.84 \%$ \\
\hline Bi-Racial/Mixed Ethnicity & 7 & $3.54 \%$ \\
\hline Other & 2 & $1.01 \%$ \\
\hline \multicolumn{3}{|l|}{ Highest Education Level } \\
\hline High School or Equivalent (GED) & 21 & $10.61 \%$ \\
\hline Some College & 67 & $33.84 \%$ \\
\hline $\begin{array}{l}\text { 2-Year College Degree or Technical } \\
\text { School Graduate }\end{array}$ & 40 & $20.20 \%$ \\
\hline 4-Year College Degree & 40 & $20.20 \%$ \\
\hline Some Graduate School & 11 & $5.56 \%$ \\
\hline Graduate or Professional Degree & 19 & $9.60 \%$ \\
\hline \multicolumn{3}{|l|}{ Type of Military Discharge } \\
\hline Honorable & 186 & $93.94 \%$ \\
\hline $\begin{array}{l}\text { General Discharge Under Other than } \\
\text { Honorable Conditions }\end{array}$ & 9 & $4.55 \%$ \\
\hline Other than Honorable (OTH) & 1 & $0.51 \%$ \\
\hline Bad Conduct & 2 & $1.01 \%$ \\
\hline \multicolumn{3}{|l|}{ Military Service Branch } \\
\hline U.S. Army & 50 & $25.25 \%$ \\
\hline U.S. Army Reserves & 4 & $2.02 \%$ \\
\hline U.S. Army National Guard & 16 & $8.08 \%$ \\
\hline U.S. Air Force (Active) & 4 & $2.02 \%$ \\
\hline U.S. Marine Corps (Active) & 105 & $53.03 \%$ \\
\hline U.S. Marine Corps (Reserve) & 4 & $2.02 \%$ \\
\hline U.S. Navy (Active) & 13 & $6.57 \%$ \\
\hline U.S. Navy (Reserve) & 1 & $0.51 \%$ \\
\hline Other & 1 & $0.51 \%$ \\
\hline \multicolumn{3}{|l|}{ Rank Upon Discharge } \\
\hline $\mathrm{E}-1$ to $\mathrm{E}-4$ & 105 & $53.03 \%$ \\
\hline$E-5$ to $E-7$ & 82 & $41.41 \%$ \\
\hline
\end{tabular}


MORAL INJURY, SHAME, GUILT, AND SELF-FORGIVENESS

\begin{tabular}{lcc}
\hline E-8 to E-9 -1 to O-4 & 6 & $3.03 \%$ \\
O-1 & 3 & $1.52 \%$ \\
O-5 to O-7 & 1 & $0.51 \%$ \\
W-1 to W-2 & 1 & $0.51 \%$ \\
Number of Deployments & & \\
1 & 71 & $35.86 \%$ \\
2 & 78 & $39.39 \%$ \\
3 & 27 & $13.64 \%$ \\
4 or More & 22 & $11.11 \%$ \\
Using VA Mental Health Service & & \\
Yes & 89 & $45.18 \%$ \\
No & 108 & $54.82 \%$ \\
\hline
\end{tabular}

Note. $N=198$.

\section{Preliminary Analyses}

Descriptive statistics. Moral Injury, as measured by the MIQ-M, had a mean score of 39.48 (Range $=19$ to $64, \mathrm{SD}=10.21)$. The MIQ-M score for this study is consistent with MIQM questionnaire development means and standard deviations. Currier et al. (2015) reported the MIQ-M community sample scores as a mean of $33.5(\mathrm{SD}=17.99)$ and clinical sample mean of $52.44(\mathrm{SD}=20.59)$. Shame Alone, as measured by the SSGS Shame subscale, had a mean of 10.61 (Range $=5$ to $25, \mathrm{SD}=5.68)$, which is slightly elevated in comparison to Schumacher (2017) who reported an SSGS shame mean score of 7.28 (SD = 3.68) among a Veteran sample. Guilt Alone, as measured by the SSGS Guilt subscale, had a mean of 11.16 (Range $=5$ to 25 , SD $=5.51$, which was also slightly elevated in comparison to Schumacher's (2017) who reported an SSGS guilt mean score of 8.63 (SD = 4.44). Finally, self-forgiveness, as measured by the HFS Self-Forgiveness subscale, had a mean of 25.78 (Range $=6$ to 42, SD =6.92). This study's HFS self-forgiveness mean and standard deviation constitutes a lower than average level of selfforgiveness, according to Thompson et al. (2005). During the psychometric development of the HFS self-forgiveness scale, a mean of 30.99 (SD = 6.17) was reported. 
MORAL INJURY, SHAME, GUILT, AND SELF-FORGIVENESS

Cronbach's alpha coefficients were calculated to measure the internal consistency reliability of each instrument. Internal consistency results for the MIQ-M in this study $(\alpha=0.87)$ were consistent with Braitman et al. (2018) results of a Cronbach's alpha $(\alpha=0.92)$ for the MIQM. The HFS-SF internal consistency for this study $(\alpha=0.73)$ was lower than the initial reported internal consistency by Thompson and colleagues $(2005)(\alpha=0.86)$, but the HFS-SF internal consistency for this study is in the acceptable range (Cohen, 1988). The SSGS internal consistencies for this study are as follows: Shame Subscale $(\alpha=0.90)$, SSGS Guilt Subscale $(\alpha=$ 0.90), and SSGS Total Scale $(\alpha=0.94)$. Theses scores reflect similar scores to those of the original validation study as Marschall et al. (1994) reported internal consistency for shame and guilt as follows: shame ( $\alpha=0.89)$, and guilt $(\alpha=0.82)$. All of this study's internal consistency outcomes fall within the acceptable to excellent range for internal consistency (Cohen, 1988).

Table 2 demonstrates the results of bivariate correlations indicating the associations among predictor, outcome, and demographic and exposure study variables. All demographic variables for this study are categorical, as age was divided into four categories. 
MORAL INJURY, SHAME, GUILT, AND SELF-FORGIVENESS

Table 2

Bivariate Correlations Between Study Variables

\begin{tabular}{|c|c|c|c|c|c|c|c|c|c|c|c|c|c|c|c|c|}
\hline & 1 & 2 & 3 & 4 & 5 & 6 & 7 & 8 & 9 & 10 & 11 & 12 & 13 & 14 & 15 & 16 \\
\hline 1) Not Male & -- & .04 & -.07 & .08 & -.07 & $.20 * *$ & .08 & -.02 & .04 & $.14^{*}$ & -.02 & -.09 & $.21 * *$ & $.19 * *$ & $.20 * *$ & $-.26 * *$ \\
\hline 2) Age Range & & -- & -.03 & .11 & $-.25 * *$ & .13 & $.30 * *$ & .09 & $.37 * *$ & -.10 & .01 & $-.20 * *$ & -.11 & -.08 & -.14 & .04 \\
\hline 3) Ethnicity & & & -- & .03 & -.04 & -.01 & -.05 & -.01 & -.04 & -.09 & .12 & .02 & .05 & .06 & .02 & .03 \\
\hline 4) Education & & & & -- & .03 & .07 & .07 & .11 & .04 & $-.17 *$ & -.03 & -.10 & -.05 & -.04 & -.05 & -.01 \\
\hline 5) Service Branch & & & & & -- & -.13 & -.06 & $.17 *$ & -.06 & -.11 & .02 & -.06 & -.04 & -.05 & -.01 & .09 \\
\hline 6) Combat Exposure & & & & & & -- & .05 & $.15^{*}$ & -.12 & .07 & .05 & $.49 * *$ & $.14^{*}$ & .13 & $.14 *$ & .09 \\
\hline 7) Deployment Location & & & & & & & -- & $.52 * *$ & $.17 *$ & -.03 & $-.15^{*}$ & .04 & .09 & .06 & .09 & -.01 \\
\hline 8) Number of Deployments & & & & & & & & -- & .13 & -.11 & -.02 & .09 & .01 & -.001 & .02 & .04 \\
\hline 9) Rank & & & & & & & & & -- & $-.15^{*}$ & .06 & $-.23 * *$ & $-.22 * *$ & $-.20 * *$ & $-.21 * *$ & .12 \\
\hline $\begin{array}{l}\text { 10) Not an Honorable } \\
\text { Discharge }\end{array}$ & & & & & & & & & & -- & .12 & $.22 * *$ & $.27 * *$ & $.22 * *$ & $.29 * *$ & $-.17 *$ \\
\hline 11) Using VA Services & & & & & & & & & & & -- & $.18 * *$ & $.25^{* *}$ & $.25^{* *}$ & $.22 * *$ & $-.17 *$ \\
\hline 12) Moral Injury & & & & & & & & & & & & -- & $.50 * *$ & $.46^{* *}$ & $.49 * *$ & $-.26 * *$ \\
\hline 13) Shame and Guilt & & & & & & & & & & & & & -- & $.95 * *$ & $.94 * *$ & $-.67 * *$ \\
\hline 14) Shame Alone & & & & & & & & & & & & & & -- & $.80 * *$ & $-.65 * *$ \\
\hline 15) Guilt Alone & & & & & & & & & & & & & & & -- & $-.62 * *$ \\
\hline 16) Self- Forgiveness & & & & & & & & & & & & & & & & -- \\
\hline$M$ & 1.08 & 2.21 & 4.80 & 3.05 & 6.44 & 1.18 & 1.87 & 2.00 & 1.57 & 1.09 & 1.55 & 39.48 & 21.73 & 10.61 & 11.16 & 25.78 \\
\hline$S D$ & 0.34 & 0.70 & 0.86 & 1.44 & 3.81 & 0.38 & 0.75 & 0.97 & 0.78 & 0.39 & 0.5 & 10.21 & 10.63 & 5.68 & 5.51 & 6.92 \\
\hline
\end{tabular}

${ }^{*} p<.05, * * p<.01$.

$N=198$ 
MORAL INJURY, SHAME, GUILT, AND SELF-FORGIVENESS

Statistical Assumptions. Prior to performing the regression analyses of this study, six statistical assumptions were evaluated. First, independence in observations were determined via the Durbin-Watson statistical test. Results of the Durbin-Watson found all variables produced independent residuals ranging from 1.92 to 2.03 . Secondly, multicollinearity was assessed by analyzing the Variance Inflation Factor (VIF). Coefficient tables for all analyses revealed a VIF between 1.00 and 1.60, which suggests that multicollinearity is minimal to nonexistent among study variables. Collinearity statistical tolerance was reported between .58 and .63 for all study items, which is deemed acceptable tolerance. Additionally, linearity and homoscedasticity were examined by plotting study variables. Predictor variables (MIQ-M, Self-Forgiveness, and Moral Injury x Self-Forgiveness) were inputted in the x-axis and outcome variables (Shame Alone, Guilt Alone, and Shame and Guilt combined) were inputted in the y-axis to investigate associations with outcome variables (See Appendix M). All scatterplots were visually inspected and indicated linear relationships and homoscedasticity within acceptable statistical parameters for the planned analyses.

The fifth statistical assumption examined data normality. To assess normality of each variable in this study, normal probability plots were created, including histograms and Normal PP Plots (See Appendix M). Each study variable displayed normal distribution via visual inspection. Finally, outliers were examined as the last of the six statistical assumptions. To examine outliers within this study a casewise diagnostic was conducted and reviewed to determine if all data points were within three standard deviations of study variables. There were no identified statistical outliers and results reflect findings using the complete data set. Beyond preliminary statistics, a series of three hierarchical multiple regressions were performed to examine how various predictor variables (significant demographic and exposure variables, moral 
MORAL INJURY, SHAME, GUILT, AND SELF-FORGIVENESS

injury, self-forgiveness, and the interaction between moral injury and self-forgiveness) predict each criterion variable (shame alone, guilt alone, and shame and guilt combined).

\section{Primary Analyses}

\section{SSGS Shame Alone.}

Hypothesis 1: It was hypothesized self-forgiveness moderates the relationship between moral injury and shame alone. Hypothesis one was investigated with shame being examined as the criterion variable and variables of interest were entered in a hierarchical process producing 4 models. Model 1, with the statistically significant demographic and exposure variables (gender, age, combat exposure, rank, discharge, and use of VA services) as the predictors, explained $16.8 \%$ of variance (Adjusted $\left.R^{2}=.168\right)$ and was statistically significant $(F(5,192)=8.974, p<$ .001). Model 2, in which moral injury was added, explained significantly more of the variance $\left(R^{2}\right.$ change $=.125,(F(1,191)=34.871, p<.001)$. This model explained $29.1 \%$ of the variance in shame alone (Adjusted $R^{2}=.291$ ), and the significant predictors were gender, use of VA services, and moral injury. 
MORAL INJURY, SHAME, GUILT, AND SELF-FORGIVENESS

Model 2

Moral Injury Predicting Shame Alone and Selected Demographic and Exposure Variables

\begin{tabular}{lcccc}
\hline \multirow{2}{*}{ Predictor } & \multicolumn{4}{c}{ Shame } \\
\cline { 2 - 5 } & $B$ & $S E B$ & $\beta$ & $R^{2}$ \\
\hline Gender & $3.36^{* *}$ & 1.04 & .20 & $.29^{* * *}$ \\
Age Range & 0.19 & 0.54 & .02 & \\
Combat Exposure & -1.00 & 1.04 & -.07 & \\
Rank & -0.75 & 0.48 & -.10 & \\
Discharge & 1.56 & 0.94 & .11 & \\
Using VA Services & $2.03^{* *}$ & 0.71 & .18 & \\
Moral Injury & $0.24^{* * *}$ & 0.04 & .43 & \\
\hline
\end{tabular}

$* p<.05, * * p<.01, * * * p<.001$.

$N=198$

Model 3, in which self-forgiveness was added, explained significantly more of the variance $\left(R^{2}\right.$ change $=.219,(F(1,190)=89.017, p<.001)$. The model explains $51.4 \%$ of the variance in shame alone (Adjusted $R^{2}=.514$ ), and the significant predictors were use of VA services, moral injury, and self-forgiveness. 
MORAL INJURY, SHAME, GUILT, AND SELF-FORGIVENESS

Model 3

Self-Forgiveness Predicting Shame Alone and Selected Demographic and Exposure Variables

\begin{tabular}{lcccc}
\hline \multicolumn{1}{c}{ Predictor } & \multicolumn{5}{c}{ Shame } \\
\cline { 2 - 5 } & & $S E B$ & $\beta$ & $R^{2}$ \\
\hline Gender & 1.33 & 0.89 & .08 & $.51 * * *$ \\
Age Range & 012 & 0.44 & .02 & \\
Combat Exposure & 0.75 & 0.88 & .05 & \\
Rank & -0.52 & 0.40 & -.07 & \\
Discharge & 0.90 & 0.78 & .06 & \\
Using VA Services & $1.29 *$ & 0.59 & .11 & \\
Moral Injury & $0.14 * * *$ & 0.04 & .26 & \\
Self-Forgiveness & $-0.43 * * *$ & 0.05 & -.53 & \\
\hline$* p<.05, * * p<.01, * * * p<$ & .001. & & & \\
$N=198$ & & & &
\end{tabular}

In the final model of the first regression, in which the interaction variable of moral injury and self-forgiveness was added, significantly more of the variance was explained $\left(R^{2}\right.$ change $=.023$, $(F(1,189)=9.618, p<.01)$. The final model explains $53.5 \%$ of the variance in shame alone (Adjusted $R^{2}=.535$ ), and the significant predictors were use of VA services, moral injury, selfforgiveness, and the interaction between moral injury and self-forgiveness. 
MORAL INJURY, SHAME, GUILT, AND SELF-FORGIVENESS

Model 4

Moral Injury Moderated by Self-Forgiveness Predicting Shame Alone and Selected Demographic and Exposure Variables

\begin{tabular}{|c|c|c|c|c|}
\hline \multirow[b]{2}{*}{ Predictor } & \multicolumn{4}{|c|}{ Shame } \\
\hline & $B$ & $S E B$ & $\beta$ & $R^{2}$ \\
\hline & & & & $.54 * *$ \\
\hline Gender & 1.72 & 0.88 & .10 & \\
\hline Age Range & -0.01 & 0.44 & $<.00$ & \\
\hline Combat Exposure & 0.42 & 0.87 & .03 & \\
\hline Rank & -0.51 & 0.39 & -.07 & \\
\hline Discharge & 0.56 & 0.77 & .04 & \\
\hline Using VA Services & $1.43 *$ & 0.58 & .13 & \\
\hline Moral Injury & $0.15 * * *$ & 0.04 & .27 & \\
\hline Self-Forgiveness & $-0.43 * * *$ & 0.05 & -.52 & \\
\hline $\begin{array}{l}\text { Moral Injury x Self- } \\
\text { Forgiveness }\end{array}$ & $-0.01 * *$ & $<0.01$ & -.16 & \\
\hline
\end{tabular}

\section{SSGS Guilt Alone.}

Hypothesis 2: It is hypothesized self-forgiveness moderates the relationship between moral injury and guilt. In the second regression, I examined hypothesis two to consider guilt alone. Guilt was entered as the criterion variable and was also evaluated in four models. Model 1, with the statistically significant demographic and exposure variables (gender, age, combat exposure, rank, discharge, and use of VA services) as the predictors, explained $19.6 \%$ of the variance (Adjusted $\left.R^{2}=.196\right)$ and was significant $(F(5,192)=10.602, p<.001)$. All predictors were significant in this model. Model 2, in which moral injury was added, explained significantly more of the variance $\left(R^{2}\right.$ change $=.134,(F(1,191)=39.378, p<.001)$. The model 


\section{MORAL INJURY, SHAME, GUILT, AND SELF-FORGIVENESS}

explains $32.7 \%$ of the variance in guilt alone (Adjusted $R^{2}=.327$ ), and the significant predictors were gender, discharge, use of VA services, and moral injury.

Model 2

Moral Injury Predicting Guilt Alone and Selected Demographic and Exposure Variables

\begin{tabular}{lcccc}
\hline \multicolumn{1}{c}{ Predictor } & \multicolumn{5}{c}{ Guilt } \\
\cline { 2 - 5 } & $B$ & $S E B$ & $\beta$ & $R^{2}$ \\
\hline Gender & $3.27 * *$ & 0.98 & .20 & $.33^{* * *}$ \\
Age Range & -0.17 & 0.51 & -.02 & \\
Combat Exposure & -0.89 & 0.98 & -.06 & \\
Rank & -0.57 & 0.45 & -.08 & \\
Discharge & $2.48 * *$ & 0.89 & .17 & \\
Using VA Services & $1.71 *$ & 0.67 & .16 & \\
Moral Injury & $0.24 * * *$ & 0.04 & .44 & \\
\hline$* p<.05, * * p<.01, * * * p<$ & .001. & & & \\
$N=198$ & & & & \\
& & &
\end{tabular}

Model 3, in which self-forgiveness was added, explained considerably more of the variance $\left(R^{2}\right.$ change $=.179,(F(1,190)=72.361, p<.001)$. The model explains $51.0 \%$ of the variance in guilt alone (Adjusted $R^{2}=.510$ ), and the significant predictors were discharge, moral injury, and selfforgiveness. 
MORAL INJURY, SHAME, GUILT, AND SELF-FORGIVENESS

Model 3

Self-Forgiveness Predicting Guilt Alone and Selected Demographic and Exposure Variables

\begin{tabular}{lcccc}
\hline \multicolumn{1}{c}{ Predictor } & \multicolumn{5}{c}{ Guilt } & \multicolumn{1}{c}{$R^{2}$} \\
\cline { 2 - 5 } & & $S E B$ & $\beta$ & $.51^{* * *}$ \\
Gender & 1.48 & 0.87 & .09 & \\
Age Range & -0.23 & 0.43 & -.03 & \\
Combat Exposure & 0.65 & 0.86 & .05 & \\
Rank & -0.37 & 0.39 & -.05 & \\
Discharge & $1.89 *$ & 0.76 & .13 & \\
Using VA Services & 1.06 & 0.58 & .10 & \\
Moral Injury & $0.15 * * *$ & 0.03 & .28 & \\
Self-Forgiveness & $-0.38^{* * *}$ & 0.05 & -.48 & \\
\hline$* p<.05, * * p<.01, * * * p<$ & .001. & & & \\
$N=198$ & & &
\end{tabular}

The final model in this regression, in which the interaction variable of moral injury and selfforgiveness was added, explained more of the variance $\left(R^{2}\right.$ change $=.011,(F(1,189)=4.388, p$ $<.05$ ). The final model explains $51.9 \%$ of the variance in guilt alone (Adjusted $R^{2}=.519$ ), and the significant predictors were gender, discharge, use of VA services, moral injury, selfforgiveness, and the interaction between moral injury and self-forgiveness. 
MORAL INJURY, SHAME, GUILT, AND SELF-FORGIVENESS

Model 4

Moral Injury Moderated by Self-Forgiveness Predicting Guilt Alone and Selected Demographic and Exposure Variables

\begin{tabular}{|c|c|c|c|c|}
\hline \multirow[b]{2}{*}{ Predictor } & \multicolumn{4}{|c|}{ Guilt } \\
\hline & $B$ & $S E B$ & $\beta$ & $R^{2}$ \\
\hline & & & & $.52 *$ \\
\hline Gender & $1.75^{*}$ & 0.87 & .11 & \\
\hline Age Range & -0.32 & 0.43 & -.04 & \\
\hline Combat Exposure & 0.42 & 0.85 & .03 & \\
\hline Rank & -0.36 & 0.38 & -.05 & \\
\hline Discharge & $1.67 *$ & 0.76 & .12 & \\
\hline Using VA Services & $1.16^{*}$ & 0.57 & .11 & \\
\hline Moral Injury & $0.16 * * *$ & 0.03 & -.29 & \\
\hline Self-Forgiveness & $-0.38 * * *$ & 0.04 & -.47 & \\
\hline $\begin{array}{l}\text { Moral Injury x Self- } \\
\text { Forgiveness }\end{array}$ & $-0.01 *$ & $<0.01$ & -.11 & \\
\hline
\end{tabular}

\section{SSGS Shame and Guilt Combined.}

Hypothesis 3: It is hypothesized that moral injury is positively correlated with feelings of shame and guilt. Shame and guilt combined were entered as the criterion variable to be analyzed using a 4 -part model in the final regression of this study. In Model 1, I entered the statistically significant demographic and exposure variables (gender, age, combat exposure, rank, type of military discharge, and use of VA mental health services) as the first set of predictor variables, which explained $20.0 \%$ of variance (Adjusted $\left.R^{2}=.200\right)$ and was significant $(F(5,192)=$ $10.842, p<.001)$. Model 2, in which moral injury was added, explained significantly more of the variance $\left(R^{2}\right.$ change $=.149,(F(1,191)=45.264, p<.001)$. The model explains $34.7 \%$ of the 


\section{MORAL INJURY, SHAME, GUILT, AND SELF-FORGIVENESS}

variance in combined shame and guilt (Adjusted $R^{2}=.347$ ), and the significant demographic predictors were gender, discharge, use of VA services, and moral injury.

Model 2

Moral Injury Predicting Shame and Guilt and Selected Demographic and Exposure Variables

\begin{tabular}{lcccc}
\hline \multicolumn{1}{c}{ Predictor } & \multicolumn{4}{c}{ Shame and Guilt } \\
\cline { 2 - 5 } & $B$ & $S E B$ & $\beta$ & $R^{2}$ \\
\hline Gender & $6.65^{* * *}$ & 1.87 & .21 & $.35^{* * *}$ \\
Age Range & 0.04 & 0.96 & $<.01$ & \\
Combat Exposure & -2.03 & 1.87 & -.07 & \\
Rank & -1.27 & 0.86 & -.09 & \\
Discharge & $4.00^{*}$ & 1.68 & .15 & \\
Using VA Services & $3.63 * *$ & 1.27 & .17 & \\
Moral Injury & $0.49 * * *$ & 0.07 & .47 & \\
\hline$* p<.05, * * p<.01, * * * p<$ & .001. & & \\
$N=198$ & & &
\end{tabular}

In the third model of this regression, in which self-forgiveness was added, significantly more of the variance was explained $\left(R^{2}\right.$ change $=.220,(F(1,190)=102.078, p<.001)$. The model explains $57.3 \%$ of the variance in shame and guilt (Adjusted $R^{2}=.573$ ), and the significant predictors were type of military discharge, use of VA mental health services, moral injury and self-forgiveness. 
MORAL INJURY, SHAME, GUILT, AND SELF-FORGIVENESS

Model 3

Self-Forgiveness Predicting Shame and Guilt and Selected Demographic and Exposure Variables

\begin{tabular}{lllcl}
\hline \multirow{2}{*}{ Predictor } & \multicolumn{5}{c}{ Shame and Guilt } \\
\cline { 2 - 5 } & $B$ & $S E B$ & $\beta$ & $R^{2}$ \\
\hline Gender & 2.82 & 1.56 & .09 & $.57 * * *$ \\
Age Range & -0.09 & 0.78 & -.01 & \\
Combat Exposure & 1.25 & 1.54 & .05 & \\
Rank & -0.85 & 0.70 & -.06 & \\
Discharge & $2.75 *$ & 1.37 & .10 & \\
Using VA Services & $2.23 *$ & 1.04 & .11 & \\
Moral Injury & $0.31 * * *$ & 0.06 & .29 & \\
Self-Forgiveness & $-0.81 * * *$ & 0.08 & -.53 & \\
\hline$* p<.05, * * p<.01, * * * p<$ & .001. & & & \\
$N=198$ & & &
\end{tabular}

Hypothesis 4: It is hypothesized that self-forgiveness moderates the relationship between moral injury and feelings of shame and guilt. In the final model of this regression, in which the interaction between moral injury and self-forgiveness was added, considerably more of the variance was explained $\left(R^{2}\right.$ change $=.017,(F(1,189)=8.348, p<.01)$. The final model explains $58.9 \%$ of the variance in shame and guilt (Adjusted $R^{2}=.589$ ), and the significant predictors were gender, use of VA services, moral injury, self-forgiveness, and the interaction between moral injury and self-forgiveness. 
MORAL INJURY, SHAME, GUILT, AND SELF-FORGIVENESS

Model 4

Moral Injury Moderated by Self-Forgiveness Predicting Shame and Guilt and Selected Demographic and Exposure Variables

\begin{tabular}{|c|c|c|c|c|}
\hline \multirow[b]{2}{*}{ Predictor } & \multicolumn{4}{|c|}{ Shame and Guilt } \\
\hline & $B$ & $S E B$ & $\beta$ & $R^{2}$ \\
\hline & & & & $.59 * *$ \\
\hline Gender & $3.48^{*}$ & 1.55 & .11 & \\
\hline Age Range & -0.32 & 0.77 & -.02 & \\
\hline Combat Exposure & 0.70 & 1.53 & .03 & \\
\hline Rank & -0.83 & 0.68 & -.06 & \\
\hline Discharge & 2.20 & 1.35 & .08 & \\
\hline Using VA Services & $2.47 *$ & 1.02 & .12 & \\
\hline Moral Injury & $0.32 * * *$ & 0.06 & .30 & \\
\hline Self-Forgiveness & $-0.80 * * *$ & 0.08 & -.52 & \\
\hline $\begin{array}{l}\text { Moral Injury x Self- } \\
\text { forgiveness }\end{array}$ & $-0.02 * *$ & 0.01 & -.14 & \\
\hline
\end{tabular}

In the Discussion chapter I will expand on the results of this study. In the final chapter, I have identified implications for clinical practice, limitations of this study, and have outlined future directions for moral injury research. 
MORAL INJURY, SHAME, GUILT, AND SELF-FORGIVENESS

\section{Chapter IV: Discussion}

\section{General Discussion}

Recent conflicts in Iraq and Afghanistan present unique opportunities for servicemen and women to be exposed to potentially morally injurious experiences, which have been shown to contribute to adverse mental health consequences (Bryan et al., 2014; Drescher et al., 2011; Jinkerson, 2016; Litz et al., 2009; Maguen et al., 2010; Maguen et al., 2011; Maguen \& Litz, 2012; Schumacher, 2017). Moreover, moral injury research has demonstrated exposure to potentially morally injurious experiences may result in Veterans sustaining psychological injuries that impact their moral foundations and inhibit the ability to make meaning of their traumas after returning from deployments (Currier et al., 2015; Drescher et al., 2011; Litz et al., 2009). Reconciling the experiences service members may have witnessed, learned about, or participated in while deployed, with their preexisting moral values and beliefs, may be difficult and can leave Veterans with high levels of shame and guilt (Schumacher, 2017).

High levels of shame and guilt have been correlated with higher rates of suicidal ideations and suicide attempts among military Veterans (Bryan et al., 2015; Bryan et al., 2014; Bryan et al., 2013). Furthermore, estimated Veteran suicide rates are approximately 22 per day (Kemp \& Bossarte, 2012) and account for $18 \%$ of all adult suicides in the United States, even though Veterans only account for $8 \%$ of the American population (Center for Deployment Psychology, n.d.). Intense feelings of shame and guilt are also correlated with greater mental health issues (e.g., depression and anxiety) (Drescher et al., 2011; Litz et al., 2009; Shay, 2012; Wisco et al., 2017). Given the results of this study, exposure to potentially morally injurious experiences is associated with higher levels of shame and guilt, which can have significant 
MORAL INJURY, SHAME, GUILT, AND SELF-FORGIVENESS

mental health consequences for those who serve our nation, and without appropriate treatment, it may cost them their lives.

Recent literature on Veterans returning home from the conflicts in Iraq and Afghanistan has only begun to focus more attention on the moral weight of war and self-forgiveness in the light of the inability to reconcile conflicting emotions and thoughts in order to make meaning of combat experience and behavior. For instance, Litz et al. (2009) presented a conceptual model of moral injury and presented a modified cognitive behavioral therapy for treating those who endorsed potentially morally injurious experiences and adverse health consequences. While selfforgiveness research with war Veterans is not a new concept, with studies such as Witvliet et al. (2004) finding a lack self-forgiveness was significantly linked to PTSD symptom severity for Veterans of the Vietnam War, more research on moral injury and self-forgiveness was needed to investigate Veterans' experiences and feelings of shame and guilt. Given the current empirical literature differentiating PTSD from moral injury (e.g., Currier et al., 2015; Drescher et al., 2011; Gray et al., 2012; Jinkerson, 2016; Litz et al., 2009), the primary objective of the present study was to assess the relationship between moral injury and feelings of shame and guilt, and to examine further the unique role of self-forgiveness on moderating the identified relationship for Veterans who served in Iraq and Afghanistan.

\section{Preliminary Analyses}

A preliminary analysis revealed several statistically significant bivariate correlations among the study variables. As expected, significant positive correlations were discovered between self-reported potentially morally injurious experiences and the endorsement of shame alone, guilt alone, and shame and guilt combined. Self-forgiveness and moral injury were also positively correlated. Furthermore, while rank was negatively correlated with moral injury, the 
MORAL INJURY, SHAME, GUILT, AND SELF-FORGIVENESS

use of VA mental health services was positively correlated with moral injury, which is consistent with other research on Veterans and trauma and the development of mental health problems, as higher rank and mental health treatment utilization have been identified as protective factors (e.g., Seal, Metzler, Gima, Bertenthal, Maguen, \& Marmar, 2009). The negative correlations between rank and moral injury and feelings of shame and guilt in this study highlight issues among junior enlisted (E-1 to E4) and lower-ranking Veterans, as they are less likely to have received mental health treatment for mental health conditions and substance abuse while in the military (Ames \& Cunradi, 2004). Ames and Cunradi (2004) identified excessive drinking behaviors of lower enlisted military personnel as a means for coping with military life, which includes dealing with feelings of shame and guilt related to traumas they experienced. To put these results in context, the average age range of junior enlisted personnel is 18 to 22 , but researchers suggest full brain development does not occur until the mid-20s (Pujol, Vendrell, Junque, Marti-Vilata, \& Capdevila, 1993). Additionally, significant levels of stigma are associated with mental health treatment while in the military (Gibbs, Olmsted, Brown, \& Clinton-Sherrod, 2011). In the context of the wars in Iraq and Afghanistan, many lower ranking enlisted Veterans were exposed repeatedly to combat traumas, were not developmentally prepared to synthesize those experiences, and were trained in a culture in which substance use and masculinity were viewed as acceptable as opposed to seeking help. Thus, the positive correlation between VA mental health services use and the endorsement of intense feelings of shame and guilt come as no surprise. Many Veterans who have sustained significant moral injuries may retain the notion that seeking help is a sign of weakness which inhibits their ability to receive the services they need to deal with shame and guilt. 
MORAL INJURY, SHAME, GUILT, AND SELF-FORGIVENESS

Of note, combat experiences have been positively linked to moral injury development in previous studies (e.g., Currier et al., 2015) and were also statistically significant in this study. Considering Litz et al.'s (2009) conceptual model that moral injury results in feelings of shame and guilt from exposure to aversive experiences, varying degrees of combat exposure provide ample opportunities for moral injuries to occur. Nevertheless, in the regression models of this study, all models that examined combat exposure and feelings of shame alone, guilt alone, and shame and guilt combined, while factoring other study variables, found no significant correlations with combat exposure. As such, the positive correlation between combat exposure and moral injury via bivariate correlation is consistent with being an identified risk factor outlined by Litz et al. (2009), but gender, type of discharge, and engagement in mental health treatment appear to be more consistent predictors when accounting for Veterans holistically. However, the identified positive association between combat exposure and VA mental health treatment utilization is consistent with previous research that linked combat exposure with more severe mental health issues (Frankfurt \& Frazier, 2016; Fontana \& Rosenheck, 2004; Killgore et al., 2008) and low treatment utilization (DeViva, 2014).

Preliminary analyses also found that the type of military discharge was positively associated with moral injury. Of note, the Veteran Health Administration is now allocating more mental health resources for Veterans who may have received bad conduct or dishonorable discharges on a case-by-case basis (Geppert, 2017). The present study results identify a need to examine the type of discharge among Veterans who endorse moral injury due to limited resources they have been able to access historically. Some research has been conducted among Veterans who have received discharges from the military that were other-than-honorable. Specifically, Brooks-Holliday and Pedersen (2017) found that Veterans who received discharges 
MORAL INJURY, SHAME, GUILT, AND SELF-FORGIVENESS

other-than-honorable were at greater risk for mental health issues (e.g., PTSD symptoms, generalized anxiety, and depression) and substance misuse (e.g., cannabis and alcohol). Another study by Brignone, Fargo, Blais, Carter, Samore, and Gundlapalli (2017) found discharges otherthan-honorable strongly predicted VHA-diagnosed mental illness, substance abuse, and suicidality, especially among those with disqualifying or misconduct discharges (e.g., personality disorders, substance abuse, and suicidal ideations or behaviors). Further research may contribute to a greater understanding of these Veterans' needs and increased mental health access for a subset of the population not currently being served but at a similar elevated risk to their Veteran peers currently receiving services.

In the context of moral injury, based on Shay's (2003) conceptual understanding of betrayal, many of those who served in recent conflicts that have been discharged for substance abuse related to coping with military traumas may have developed resentment and a sense of betrayal by their government. Their engagement with VHA mental health resources may be limited due to restricted access and a developed distrust with the government health system. As a result, these Veterans' traumas may remain unprocessed, and increased symptoms of shame and guilt can manifest over time. Engaging these Veterans in mental health treatment is the first step to address moral injury among this subset of the Veteran population.

Another subset of the Veteran population that requires research attention is related to gender. In 2010, The Don't Ask, Don't Tell Repeal Act of 2010 was passed into policy, thus allowing those of varying gender identities to serve openly in the United States military (H.R. 2965, S.4023). However, gender is a complex construct and even more difficult when considering military service. In March 2019, David L. Norquist (United Stated Deputy Secretary of Defense) reinstated restrictions for transgender personnel to serve in the United States military 
MORAL INJURY, SHAME, GUILT, AND SELF-FORGIVENESS

via the Directive-type memorandum-19-004. By the end of March 2019, H.Res.124-116 ${ }^{\text {th }}$

Congress passed legislation opposing President Trump's ban on transgender members serving in the American Armed Forces. Regardless of legality, according to the 2015 U.S. Transgender Survey, USTS respondents served in the military at nearly two times the rate of the U.S. population (U.S. Transgender Survey, 2015). Within the gender subset (other than heterosexual males) of the Veteran population are also women Veterans. Women constitute a growing presence in the U.S. Armed Forces with growth from 42,000 in 1973 to 167,000 in 2010 (Patten \& Parker, 2011). Furthermore, the women Veteran population is projected to comprise 16.3 percent of the entire Veteran population by 2043 (Department of Veteran Affairs, 2017).

Research on moral injury related to gender is particularly relevant when considering the results of this study. Gender was statistically significant in both bivariate correlations and primary analyses with study outcome variables. As combat roles continue to expand and become all inclusive, the likelihood of exposures to potentially morally injurious experiences will continue to increase. Previous research has indicated that women are more likely to screen positive for depression and military sexual trauma than their male peers (Haskell et al., 2010). Similarly, Beckman, Shepherd, Simpson, and Lhavot (2019) found that transgender Veterans were also significantly at risk for Military Sexual Assault (MSA) and, for those who endorsed MSA, they reported greater PTSD and depression symptom severity. According to Olff (2017), women have an increased lifetime PTSD prevalence rate than men that is attributed to greater exposure to high-impact traumas (e.g., sexual traumas) even though men may have more accumulative traumatic events. In the context of moral injury, this gender subset (other than heterosexual males) of the Veteran population are at increased risk for moral injury development. This subset of the Veteran population who have potentially experienced military sexual trauma 
MORAL INJURY, SHAME, GUILT, AND SELF-FORGIVENESS

have experienced betrayal by those with whom they have trusted to ensure the very preservation of their own lives. These individuals may have had to continue to operate in combat situations with their perpetrators long after the assault to ensure they survived their deployments. Males also experience military sexual trauma, but this subset of the population are at increased risk. All military members who experience sexual trauma may struggle with moral injuries in combination with combat experiences. In the context of this study, only 13 of the 198 individuals responding identified as non-male, so inferences from these data must be cautious, and more study will be needed to identify and clarify how sex and gender interact with the variables pertaining to moral injury and self-forgiveness.

\section{Primary Analyses}

The present study included three separate regressions for the primary analyses and discovered more correlations between study variables. In the first regression, after entering demographic and exposure variables to account for their explained variance, the relationship between moral injury and feelings of shame was statistically significant, as was the negative correlation between shame and self-forgiveness.

To examine the moderating effects of self-forgiveness, a third predictor variable was generated from the interaction between moral injury and self-forgiveness, and the data supported the hypothesis that the interaction term moderated the relationship between moral injury and feelings of shame. Likewise, in the second regression, hypothesis two postulated the relationship between moral injury and feelings of guilt would be moderated by self-forgiveness. Hypothesis two was also supported when examining guilt alone. The third hypothesis examined the correlation between moral injury and the combined score of shame and guilt. Specifically, moral injury was hypothesized to be positively correlated with self-reports of feelings of shame and 
MORAL INJURY, SHAME, GUILT, AND SELF-FORGIVENESS

guilt among Veterans who deployed in or around Iraq and Afghanistan, and self-forgiveness would be negatively correlated with those feelings of shame and guilt. When accounting for selected demographic and exposure variables, hypothesis three was supported by the data.

The third regression of the series was used to examine hypothesis four, which stated that self-forgiveness would moderate the relationship between moral injury and feelings of shame and guilt combined.

\section{Self-Forgiveness}

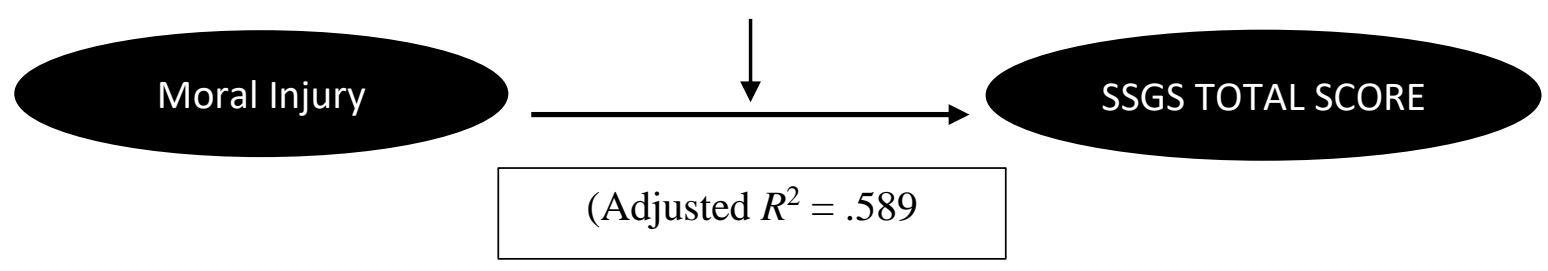

Figure 4

The final regression model demonstrated in figure 4 above illustrates the highest level of explained variance (59\%) in the present study. Again, the data supported the moderating effects of self-forgiveness on the hypothesized relationship, identified by Schumacher (2017), between moral injury and feelings of shame and guilt.

The series of regression models investigated in this study highlight the role of selfforgiveness in moderating the relationship between self-reported exposure to potentially morally injurious experiences and feelings of shame and guilt. Consistent with Currier et al.'s (2015) findings that forgiveness could aid in integrating military experiences by alleviating guilt and/or shame, the present results illustrate self-forgiveness does have a statistically significant negative relationship with reported shame and guilt levels among Gulf Era II Veterans. Veterans deployed to Iraq and Afghanistan were often presented with ambiguous civilian threats and found 
MORAL INJURY, SHAME, GUILT, AND SELF-FORGIVENESS

themselves in countless situations that challenged their moral values and beliefs. After experiencing, witnessing, or learning about traumas that go against one's moral foundation, many Veterans struggle with intense shame and guilt, which can leave Veterans feeling isolated and fixed in a state of cognitive dissonance. The deleterious effects of not resolving the war traumas experienced by Veterans with what those Veterans have done and what it means to be them moving forward as civilians can result in issues with aggression and self-condemnation (Litz et al., 2009). For these Veterans, moral injury is a matter of life or death. While substance use is likely to be an employed coping mechanism for these Veterans (Wisco et al., 2014), comfortability with weapons and high rates of depression can result in taking one's life. The present study underlines the need for Veterans to reconcile the differences between their moral values and beliefs held before their service with the behaviors required of them during war and the beliefs that result once they return home (e.g., "I am a bad person").

\section{Clinical Implications}

Osran, Smee, Sreenivasan, and Weinberger (2010) wrote about Veterans returning from war and dealing with the transition back to civilian life as "operating outside the wire." These authors clarified that being outside the wire implied service members would leave the safety of their military bases to enter direct combat zones and execute front-line missions. For many Veterans, the psychological undertaking of transitioning to civilian life and processing their military experiences can produce a similar sentiment. Without their trusted military peers as a psychological safety net, many Veterans may again feel as though they have left the "wire;" however, this time, they will leave it alone. Afghanistan and Iraq Veterans have come home to a harsh reality that war never ends as evidenced by astronomical substance abuse rates (Ames \& Cunradi, 2004; McCauley et al. 2012; Seal et al., 2010) and devastating suicide rates among their 
MORAL INJURY, SHAME, GUILT, AND SELF-FORGIVENESS

Veteran peers (Kemp \& Bossarte, 2012). Compounding these transitions are the unique experiences Iraq and Afghanistan Veterans have had that may have resulted in moral injuries.

Given the present results, self-forgiveness appears to be a principle factor that may aid in treating traumatized vets, which is consistent with Litz et al.'s (2009) conceptual model. Various treatment modalities have been developed to treat combat trauma and military experiences such as Impact of Killing in War (IOK) (Maguen \& Burkman, 2014), which has demonstrated reductions in psychiatric symptoms, anxiety, and depression among combat exposed participants (Burkman et al., 2013). IOK approaches killing in war through a cognitive-behavioral lens and implements elements of self-forgiveness and forgiveness of others. However, killing in war does not directly and unavoidably equate to moral injury development, and a plethora of situations can intervene (e.g., excessive violence) beyond killing that can result in moral injuries.

Another treatment modality for moral injury is a treatment called Adaptive Disclosure. Adaptive Disclosure is a brief experiential exposure-based protocol that focuses on imaginal exposures and strategies targeting PTSD, loss/trauma grief, and moral injury (Litz, Lebowitz, Gray \& Nash, 2015). Adaptive Disclosure is shorter than other trauma-focused treatments, consisting of six to eight sessions (Gray et al., 2012; Litz et al., 2015). However, Adaptive Disclosure remains in its infancy, and randomized controlled trials are still be conducted.

Clinically, assessing Veterans' cognitive perceptions related to their experiences is a fundamental initial step. By assessing these cognitions, clinicians can begin to establish a Veteran's attribution of responsibility towards themselves and others. In the initial step, clinicians may assist Veterans with clarification about what happened and discover a possible sense of betrayal (e.g., betrayal with one's self, betrayal by peers, or betrayal by those in a higher ranking/trusted position). By elucidating betrayal and degrees of responsibility, the clinician and 
MORAL INJURY, SHAME, GUILT, AND SELF-FORGIVENESS

Veteran can begin to examine held feelings of shame and/or guilt. Techniques that may be useful with Veterans are cognitive restructuring, validation, and reflective listening. Self-forgiveness can be incorporated through the identification of the situational context (as many Veterans oversimplify their experiences) in contrast with their other life experiences. While two moral injury treatment modalities are identified in this dissertation, moral injury treatment remains a needed area of continued development. Veterans with military-related moral injury have endured great sacrifice and require targeted and evidence-based psychological interventions.

\section{Strengths of the Study}

The present study produced statistically significant results in which various strengths can be identified. First, the design and aim of this study sought to replicate and extend the works of Currier et al. (2014), Litz et al. (2009), and Schumacher (2017) to examine moral injury and adverse mental health issues. Through correlational analyses, the present study identified relationships between moral injury and feelings of shame and guilt among military Veterans. Additionally, this study identified self-forgiveness as a moderator of the relationship between moral injury and feelings of shame and guilt.

Secondly, the use of convenience sampling via social media produced a large sample $(n=$ 198) of Iraq and Afghanistan Veterans who reported combat exposure and exposure to morally injurious experiences, which is comparative to Currier and Colleagues (2014), who collected a smaller sample $(n=131)$.

Third, study results identified demographic variables of interest for future study. As this study identified gender, VA mental health use, and type of discharge as variables correlated with the outcome variables, additional gaps in the literature can now be examined. 
MORAL INJURY, SHAME, GUILT, AND SELF-FORGIVENESS

Fourth, the strength of this study in relation to feelings of shame and guilt is the measurement of those feelings at the state level. As state feelings do fluctuate, this study provides empirical evidence to suggest clinical assessment and psychotherapeutic intervention employing self-forgiveness may inversely relate to the established relationship between moral injury and feelings of shame and guilt via moderation.

\section{Limitations and Future Directions}

As in most social science research, there are limitations to this study that constrain the preliminary and primary findings and subsequent conclusions. Considering the design of this study, due to the cross-sectional nature, I was only able to identify correlational relationships between study variables at one point in time and, thus, my ability to draw causal inferences between the relationship of moral injury and feelings of shame and guilt is limited. As the data in this study was collected via self-report measures, various issues related to readability and understanding of survey items can limit the validity of the results because it was not possible to control how survey items were interpreted by the participants. Due to the online nature of this methodology, I cannot verify if individuals met the eligibility requirements of the survey beyond the survey screening items (i.e., U.S. military Veteran and deployed to Iraq or Afghanistan after 2001). This study is also limited due to the range of years separated from military service as some service members may have a recency effect from their separation from the military and combat experiences. However, other Veterans in this study may have been out of the service for many years due to the long-standing nature of the conflicts in Iraq and Afghanistan. As such, those who discharged years ago may have developed adaptive strategies to accommodate their military experiences and traumas, whereas those who recently discharged may not. Future 
MORAL INJURY, SHAME, GUILT, AND SELF-FORGIVENESS

studies may account for the amount of time since discharge by separating Veteran responses of those who recently discharged from those who have been out for a longer period.

Another possible limitation, though unassessed, could be comorbid mental health conditions that these Veterans experience before, during, and after their military service, which may better account for their endorsed symptoms of shame and guilt. Future studies should explore moral injury development among military service members by employing a variety of longitudinal designs to track service members such as recording pre-enlistment or predeployment shame, guilt, moral injury, and self-forgiveness levels for comparison to postdeployment or discharge levels. Longitudinal designs would provide researchers with more information related to the etiology and prognosis of moral injury and, in turn, aid in better understanding civilian reintegration for those who have been exposed to potentially morally injurious experiences during their military service.

While this study does represent limited diversity (e.g., ethnic backgrounds, number of deployments, service branch, education level, etc.), due to the study being conducted via social media, Veterans who may be of the lowest socioeconomic status may have not had the ability to participate in this study due to limited or no access to social media. More so, those Veterans could represent a subset of the Veteran population with the greatest level of psychological distress and the lowest level of available resources. Future studies may seek to collaborate with programs designed to connect with these specific Veterans (e.g., VA Homeless Veteran Program) to attempt to investigate their needs and assess those Veterans' levels of shame, guilt, moral injury, and self-forgiveness in comparison to their non-homeless Veteran peers.

Although a large sample was collected $(n=198)$, this study is limited in terms of its generalizability due to the use of convenience sampling. Furthermore, more sophisticated 
MORAL INJURY, SHAME, GUILT, AND SELF-FORGIVENESS

methodological studies such as those employing path analysis or structural equation modeling will be needed to establish directionality between this study's variables of interest. The instruments used in the study present an additional limitation.

There is a significant complication within current moral injury research and measurement, as identified by Malott (2013), which identifies the difficulty in differentiating between moral injury as a construct and moral injury as a measurement. Currently, only two moral injury measurement tools have been developed and extensively utilized, the Moral Injury Event Scale (MIES) and the Moral Injury Questionnaire - Military Version (MIQ-M), both of which assess the exposure of an individual to potentially morally injurious situations; however, simply being exposed to potentially morally injurious experiences does not equate to the development of moral injury or predict the significance of the associated symptom severity. Future research on the measurement of moral injury could contribute to the etiological basis of moral injury and possibly clarify the prognosis of moral injury beyond the assessment of varying levels of exposure. New measures are being developed, such as the Moral Injury Symptom Scale (MISS-M) (Koenig et al., 2018) but need additional validation studies. While Litz et al. (2009) described moral injury as a dimensional problem, Jinkerson (2016) stated that there had been adequate research conducted to suggest moral injury is a syndrome. However, provided the inability of moral injury researchers to differentiate between exposure and development, until new psychometrics for assessing moral injury are developed and validated beyond the measurement of exposure to moral injuries literature will remain stagnant.

Another measurement consideration for the present study is the use of the State Shame and Guilt Scale (SSGS) to measure maladaptive feelings of shame, guilt, and shame/guilt combined. The SSGS was selected for this study because it has been used in previous moral 
MORAL INJURY, SHAME, GUILT, AND SELF-FORGIVENESS

injury research (e.g., Schumacher, 2017) examining Veterans of Iraq and Afghanistan. As this study was designed to replicate and extend the work of Schumacher (2017), by examining the model presented by Litz et al. (2009) that postulated internal conflicts are, in fact, the foremost factors contributing to moral injury development, this study used the SSGS to measure shame and guilt as outcome variables, instead of mediators. While this study does yield statistically significant results, the results should be interpreted with caution due to the difficulty of differentiating the emotions of shame and guilt at the state level and limited questions asked related to shame and guilt (5 items per scale). Future research could expand moral injury literature related to internal conflicts, resulting in shame and guilt, through the examination of both variables using proneness measures (e.g., TOSCA-3), which examine emotions of shame and guilt through cross-situational dispositions to account for feeling proneness at a trait level.

This study examined shame and guilt at the state level to investigate the ways Veterans felt in relation to their military experiences as state feelings change over time with a person's environment and circumstances such as those that result from experiencing potentially morally injurious situations. However, moral injury could have a deep impact on one's values and beliefs that could become global to a person's sense of self and alter his/her core beliefs and values. Future studies could use trait level shame and guilt to investigate the long-term, stable, and inherent changes that could result from sustained moral injuries. Future research on trait level shame and guilt and the effects of moral injury would likely benefit from longitudinal studies to document changes over time (e.g., prior to military service, during service, after discharge, and 5-years post-discharge).

Future studies could also use other existing measures for assessing individual emotions such as the Trauma-Related Guilt Inventory (TRGI) by Kubany (1997), which is an inventory for 
MORAL INJURY, SHAME, GUILT, AND SELF-FORGIVENESS

assessing cognitive and emotional aspects of guilt, or the Internalized Shame Scale (SSI) by Cook (1994/2001) which was designed to measure trait shame in adolescents and adults.

Similar to other measures used in this study, the use of the Heartland Forgiveness Scale's (HFS) self-forgiveness subscale was selected for its strong psychometric properties (Thompson et al., 2005), and use among Veterans with combat trauma (e.g., Bryan, Theriault, \& Bryan, 2015; Karairmak \& Guloglu, 2014; Schuettler \& Boals, 2011). However, the HFS selfforgiveness subscale is a brief measure of self-forgiveness and longer measures may provide additional information such as the 21-item state forgiveness scale (The State Self-Forgiveness Scale) by Wohl, DeShea, and Wahkinney (2008). Furthermore, the use of the HFS selfforgiveness subscale alone limits the ability of this study to examine the forgiveness of others and situations. While the purpose of this study was only to examine self-forgiveness, future studies may include the other subscales of the HFS to evaluate the contributions forgiveness of others or situations can have on self-reported shame and guilt.

\section{Summary}

While replicating and expanding on the works of Currier et al. (2015), Litz et al. (2009) and Schumacher (2017), the results of this study provide continuing evidence of the associations between moral injury and feelings of shame and guilt and provides support that self-forgiveness moderates the strength of the identified relationship. Though several limitations have been identified with this study, this study produced sound statistical evidence via self-report from Iraq and Afghanistan Veterans, more than three-fourths of which reported direct combat exposure and exposure to potentially morally injurious experiences. All hypotheses in this study were supported by the data. 
MORAL INJURY, SHAME, GUILT, AND SELF-FORGIVENESS

From a clinical standpoint, this study illuminates the need for incorporating selfforgiveness in trauma work with those who have deployed to Iraq and/or Afghanistan, as the results of this study demonstrated negative correlations between self-forgiveness and the study's outcome variables. Few treatment protocols have been developed to address moral injuries but have included some elements of self-forgiveness (i.e., Adaptive Disclosure). While Adaptive disclosure's initial clinical trial proved effective (Gray et al., 2012), more research is needed to understand how moral injury impacts or is impacted by feelings of shame and guilt. The results of this study suggest great incorporation of self-forgiveness may have a desired clinical effect. Additional research will also be needed to aid in incorporating self-forgiveness in trauma treatment protocols to establish maximum benefit for those receiving treatment for moral injury. Finally, like other studies, Veterans in this study endorsed low rates of VA treatment engagement, which may contribute to Veterans not receiving the care they need. This data also identifies the need to find better means for engaging Iraq and Afghanistan Veterans in mental health treatment, especially when considering genders other than male and types of discharges, particularly for those who report significant levels of shame and guilt.

Moral injury does correlate with high levels of shame and guilt, and those high levels have been associated with more significant mental health issues and attempted and completed suicides. Veterans who have fought in Iraq and Afghanistan have returned home with significant PTSD and substance abuse rates. As moral injury has conceptually and empirically been identified as having a unique etiology from PTSD, though they can co-occur, it may account for American mental health providers' inability to treat some Veterans with such traumas effectively. For these Veterans who struggle with moral injury, they have witnessed, learned about, or participated in acts that have changed the essence of who they are as a person. As moral 
MORAL INJURY, SHAME, GUILT, AND SELF-FORGIVENESS

injury is a reflective process of reviewing their actions in relation to their moral beliefs, many Veterans find themselves alone. Through isolation, avoidance, and self-condemnation these Veterans only confirm maladaptive beliefs about themselves that contribute to a cycle of unmitigated shame and guilt.

\section{Conclusion}

In 1999, Senator and combat Veteran John McCain addressed the American Red Cross. He reportedly spoke to those present about Veterans and war and stated the following: Few veterans cherish a romantic remembrance of war. War is awful. When nations seek to settle their differences by force of arms, a million tragedies ensue. Nothing, not the valor with which it is fought nor the nobility of the cause it serves, can glorify war. War is wretched beyond description, and only a fool or a fraud could sentimentalize its cruel reality. (Benac, 2018, para. 6).

In preparing this dissertation, both as a beginning researcher, and a combat Veteran, I could not help but reflect on the power of these words and appreciate their moral weight. Like the words of John McCain, I have learned that the romanticized idea of war is a fictional construct utilized by American cinema to allure viewers and captivate audiences. In reality, War comes at a devastating and astronomical cost, and as seen in this study, the cost of these recent conflicts has not ended when our Veterans return home. The continuous impact of combat-based trauma is

evidenced by the staggering number of Veterans lost yearly to completed suicides and substance overdoses, not to mention prevalent issues with unemployment, homelessness, failed marriages, and other mental health issues.

In 1973, the United States adopted the all-volunteer force as means for employing a costeffective and professional military force (Rostker, 2006). However, as Dr. Eric Hodges presented 
MORAL INJURY, SHAME, GUILT, AND SELF-FORGIVENESS

in his 2013 TedX talk, since the all-volunteer force was enacted, fewer and fewer prior service members are serving in the legislative branch, and more quickly is the United States to engage in armed conflict (Hodges, 2013). As a result, according to McCarthy (2018), less than $1 \%$ of the U.S. population has fought in these 20 -year campaigns. We, as a society, have asked our youth to join the military and to repeatedly deploy to combat zones on our behalf. There, many will die, others will be injured, and many more will return home and appear unscathed. These invisible wounds are profound and erode the very essence of one's self, their sense of morality, and their views of the goodness of others and the world around them. The dedication of this dissertation speaks to all these issues as it is representative of those lost in combat and those who lost the battle here at home. It was these personal losses that provided me clarity on the notion that war never ends, and it never leaves you. In studying the impact of self-forgiveness on moral injury and the accompanying feelings of shame and guilt, I aspired to provide some hope that there might be a path towards acceptance and a way back to wholeness for our wounded warriors. I believe that families, health care providers, and communities can aid in fostering self-forgiveness through reflective listening and emotional support for those who carry the burdens of shame and guilt related to their moral injuries as a result of their sacrifices for our freedoms. As Alexander Pope reminded us in his Essay on Criticism (1711), “To err is human, to forgive divine." Perhaps self-forgiveness is a spark of that divinity that dwells in us all. 
MORAL INJURY, SHAME, GUILT, AND SELF-FORGIVENESS

\section{REFERENCES}

American Psychiatric Association. (2013). Diagnostic and statistical manual of mental disorders ( $5^{\text {th }}$ ed.). Washington, DC: Author.

Alpert, J., \& Kent, E.G. (2011). Wartorn 1861 - 2010 [Motion Picture]. New York: HBO Documentary Film, 2011.

Armstrong, A., Hawley, C., Darter, B., Sima, A., Dinardo, J., \& Inge, K. (2018). Operation enduring freedom and operation Iraqi freedom Veterans with amputation: An exploration of resilience, employment and individual characteristics. Journal of Vocational Rehabilitation, 48(2), 167-175. doi:10.3233/JVR-180923

Cohen, J. (1992). A power primer. Psychological Bulletin, 112(1), 155-9.

Bandura, A. (1999). Moral disengagement in the perpetration of inhumanities. Personality and Social Psychology Review, 3(3), 193-209. doi:10.1207/s15327957pspr0303_3

Baskin, T., \& Enright, R. (2004). Intervention studies on forgiveness: A meta-Analysis. Journal of Counseling and Development, 82(1), 79-90.

Beckham, J., Feldman, M., \& Kirby, A. (1998). Atrocities exposure in Vietnam combat Veterans with chronic posttraumatic stress disorder: Relationship to combat exposure, symptom severity, guilt, and interpersonal violence. Journal of Traumatic Stress, 11(4), 777-785. doi:10.1023/A:1024453618638

Beckman, K., Shipherd, J., Simpson, T., \& Lehavot, K. (2018). Military sexual assault in transgender Veterans: Results from a nationwide survey. Journal of Traumatic Stress, 31(2), 181-190. https://doi.org/10.1002/jts.22280 
MORAL INJURY, SHAME, GUILT, AND SELF-FORGIVENESS

Benac, N. (2018, August 25). War hero and presidential candidate John McCain has died. The Columbian. Retrieved from https://www.columbian.com/news/2018/aug/25/war-heroand-presidential-candidate-john-mccain-has-died/

Bonner, J. M., Greenbaum, R. L., \& Quade, M. J. (2017). Employee unethical behavior to shame as an indicator of self-image threat and exemplification as a form of self-image protection: The exacerbating role of supervisor bottom-line mentality. Journal of Applied Psychology, 102(8), 1203-1221.

http://dx.doi.org.www.libproxy.wvu.edu/10.1037/ap10000222

Braitman, A. L., Battles, A. R., Kelley, M. L., Hamrick, H. C., Cramer, R. J., Ehlke, S., \& Bravo, A. J. (2018). Psychometric properties of a Modified Moral Injury Questionnaire in a military population. Traumatology, 24(4), 301-312. https://doi-

org.www.libproxy.wvu.edu/10.1037/trm0000158

Brignone, E., Fargo, J., Blais, R., Carter, M., Samore, M., \& Gundlapalli, A. (2017). Non-routine discharge from military service: Mental illness, substance use disorders, and suicidality. American Journal of Preventive Medicine, 52(5), 557-565.

doi:10.1016/j.amepre.2016.11.015

Brooks-Holliday, S., \& Pedersen, E. R. (2017). The association between discharge status, mental health, and substance misuse among young adult Veterans. Psychiatry Research, 256, 428-434. doi:10.1016/j.psychres.2017.07.011

Browne, K., Trim, R., Myers, U., \& Norman, S. (2015). Trauma-related guilt: Conceptual development and relationship with posttraumatic stress and depressive symptoms. Journal of Traumatic Stress, 28(2), 134-41. doi:10.1002/jts.21999 
MORAL INJURY, SHAME, GUILT, AND SELF-FORGIVENESS

Bryan, A., Bryan, C., Sannerud, B., Morrow, C., \& Etienne, N. (2014). Moral injury, suicidal ideation, and suicide attempts in a military sample. Traumatology, 20(3), 154-160. doi:10.1037/h0099852

Bryan, C.J., Ray-Sannerud, B., Morrow, C.E., \& Etienne, N. (2013). Guilt is more strongly associated with suicidal ideations among military personnel with direct combat exposure. Journal of Affective Disorders, 148, 37-41. doi: 10.1016/j.jad.2012.11.044

Bryan, A. O., Theriault, J. L., \& Bryan, C. J. (2015). Self-forgiveness, posttraumatic stress, and suicide attempts among military personnel and Veterans. Traumatology, 21(1), 40-46. http://dx.doi.org/10.1037/trm0000017

Calhoun, P., Elter, J., Jones, E., Kudler, H., \& Straits-Troster, K. (2008). Hazardous alcohol use and receipt of risk-reduction counseling among U.S. Veterans of the wars in iraq and Afghanistan. The Journal of Clinical Psychiatry, 69(11), 1686-1693. doi:10.4088/JCP.v69n1103

Clifton, E., Feeny, N., \& Zoellner, L. (2017). Anger and guilt in treatment for chronic posttraumatic stress disorder. Journal of Behavior Therapy and Experimental Psychiatry, 54, 9-16. doi:10.1016/j.jbtep.2016.05.003

Conway, A.H. (2013). Signs and symptoms of moral injury in female Vietnam Veterans: A qualitative examination of the NVVRS (Doctoral dissertation). Pepperdine University: Malibu, California.

Cook, D. R. (1987). Measuring shame: The internalized shame scale. Alcoholism Treatment Quarterly, 4, 197-215.

Currier, J., Jones, H., Sheu, S., \& Holland, J. (2014). Involvement in abusive violence among Vietnam Veterans: Direct and indirect associations with substance use problems and 
MORAL INJURY, SHAME, GUILT, AND SELF-FORGIVENESS

suicidality. Psychological Trauma: Theory, Research, Practice, and Policy, 6(1), 73-82. doi:10.1037/a0032973

Currier, J., Holland, J., Drescher, K., \& Foy, D. (2015). Initial psychometric evaluation of the moral injury questionnaire-Military version. Clinical Psychology \& Psychotherapy, 22(1), 54-63. doi:10.1002/cpp.1866

Currier, J., Holland, J., \& Malott, J. (2014). Moral injury, meaning making, and mental health in returning Veterans: Moral injury and meaning. Journal of Clinical Psychology, 71(3), 229-240. doi:10.1002/jclp.22134

Currier, J., McCormick, W., \& Drescher, K. (2015). How do morally injurious events occur? A qualitative analysis of perspectives of Veterans with PTSD. Traumatology, 21(2), 106116. doi:10.1037/trm0000027

Dearing, R. L., \& Tangney, J. P. (Eds.). (2011). Shame in the therapy hour. Washington, DC, US: American Psychological Association. http://dx.doi.org/10.1037/12326-000

Department of Veterans Affairs. (2015). Epidemiology Program, Post Deployment Health Group, Office of Public Health, Veterans Health Administration. Analysis of VA Health Care Utilization among Operation Enduring Freedom, Operation Iraqi Freedom, and Operation New Dawn Veterans, from 1st Qtr FY 2002 through $2^{\text {nd }}$ Qtr FY 2015.Washington, DC: Retrieved from http://www.publichealth.va.gov/docs/epidemiology/ healthcare-utilization-report-fy2015qtr2.pdf; accessed September 1, 2018.

Department of Veteran Affairs. (2017). Women Veterans Report. Washington, D.C. : National center for Veterans Analysis and Statistics. 
MORAL INJURY, SHAME, GUILT, AND SELF-FORGIVENESS

DeViva, J. C. (2014). Treatment utilization among OEF/OIF veterans referred for psychotherapy for PTSD. Psychological Services, 11(2), 179-184. https://doi.org/10.1037/a0035077

Drescher, K., Foy, D., Kelly, C., Leshner, A., Schutz, K., \& Litz, B. (2011). An exploration of the viability and usefulness of the construct of moral injury in war Veterans.

Traumatology, 17(1), 8-13. doi.org.www.libproxy.wvu.edu/10.1177/1534765610395615

Enright, R. (2001). Forgiveness is a choice: A step-by-step process for resolving anger and restoring hope (1st ed. ed., APA life tools). Washington, DC: American Psychological Association.

Enright, R. D., \& the Human Development Study Group (1996). Counseling within the forgiveness triad: On forgiving, receiving forgiveness, and self-forgiveness. Counseling and Values, 40(2), 107-126.

Faul, F., Erdfelder, E., Buchner, A., \& Lang, A.G. (2009). Statistical power analyses using G*Power 3.1: Tests for correlation and regression analyses. Behavior Research Methods, 41, 1149-1160. doi: 10.3758/BRM.41.4.1149.

Farnsworth, J., Drescher, K., Nieuwsma, J., Walser, R., \& Currier, J. (2014). The role of moral emotions in military trauma: Implications for the study and treatment of moral injury. Review of General Psychology, 18(4), 249-262. doi:10.1037/gpr0000018

Fehr, R., Gelfand, M., \& Nag, M. (2010). The road to forgiveness: A meta-analytic synthesis of its situational and dispositional correlates. Psychological Bulletin, 136(5), 894-894.

Fenichel, O. (1945). The psychoanalytic theory of neurosis. New York: W.W. Norton.

Festinger, L. (1962). A theory of cognitive dissonance (Mass communication series (voice of America), 2). Stanford, California: Stanford University Press. 
MORAL INJURY, SHAME, GUILT, AND SELF-FORGIVENESS

Fontana, A., \& Rosenheck, R. (1999). A model of war zone stressors and posttraumatic stress disorder. Journal of Traumatic Stress, 12(1), 111-126. doi:10.1023/A:1024750417154

Fontana, A., \& Rosenheck, R. (2004). Trauma change in strength of religious faith, and mental health service use among Veterans treated for PTSD. The Journal of Nervous and Mental Disease, 192(9), 579-84.

Frankfurt, S. \& Frazier, P. (2016). A review of research on moral injury in combat Veterans. Military Psychology, 5, 1-10. doi: 10.1037/mil0000132

Frazier, P., Tix, A., \& Barron, K. (2004). Testing moderator and mediator effects in counseling psychology research. Journal of Counseling Psychology, 51(1), 115-134. doi: 10.1037/0022-0167.51.1.115.

Gassin, E., Enright, R., \& Knutson, J. (2005). Bringing peace to the central city: Forgiveness education in Milwaukee. Theory into Practice, 44(4), 319-328.

Gradus, J. L. (2007). Epidemiology of PTSD. Retrieved from http://www.ptsd.va.gov/professional/pages/epidemiological-facts-ptsd.asp

Gawande, A. (2004). Casualties of war--military care for the wounded from Iraq and Afghanistan. The New England Journal of Medicine, 351(24), 2471-5.

Gino, F., Ayal, S., \& Ariely, D. (2013). Self-serving altruism? The lure of unethical actions that benefit others. Journal of Economic Behavior \& Organization, 93, 285-285. doi: 10.1016/j.jebo.2013.04.005.

Gray, M., Schorr, Y., Nash, W., Lebowitz, L., Amidon, A., Lansing, A., . . Litz, B. (2012). Adaptive disclosure: An open trial of a novel exposure-based intervention for service members with combat-related psychological stress injuries. Behavior Therapy, 43(2), 407-415. doi:10.1016/j.beth.2011.09.001 
MORAL INJURY, SHAME, GUILT, AND SELF-FORGIVENESS

Grossman, D. (2009). On killing: The psychological cost of learning to kill in war and society. New York: Bay Back.

Haskell, S. G., Gordon, K. S., Mattocks, K., Duggal, M., Erdos, J., Justice, A., \& Brandt, C. A. (2010). Gender differences in rates of depression, PTSD, pain, obesity, and military sexual trauma among Connecticut War Veterans of Iraq and Afghanistan. Journal of Women's Health, 19(2), 267-271. https://doi.org/10.1089/jwh.2008.1262

Hautzinter, S., Howell, A., Scandlyn, J., Wool, Z., \& Zogas, A. (2015). Costs of War: US Veterans \& Military Families. Watson Institute International \& Public Affairs, Brown University. Retrieved from http://watson.brown.edu/ costsofwar/costs/human/Veterans

Held, P., Owens, G., \& Anderson, S. (2015). The interrelationships among trauma-related guilt and shame, disengagement coping, and PTSD in a sample of treatment-seeking substance users. Traumatology, 21(4), 285-292. doi:10.1037/trm0000050

Hendin, H., \& Haas, A.P. (1991). Suicide and guilt as manifestations of PTSD in Vietnam combat Veterans. American Journal of Psychiatry, 148, 586-591. doi: 10.1176/ajp.148.5.586

Heppner, P., Wampold, B., Owen, J., \& Wang, K.T. (2016). Research design in counseling. (4 $^{\text {th }}$ Ed.). Boston, MA: Cengage Learning.

Higgins, E. T. (1987). Self-discrepancy: A theory relating self and affect. Psychology Review, Vol 94(3), 319-340.

Hodges, E. (2020, April). The moral injury of war. TEDxVirginiaTech. Blacksburg.

Hoge, C. (2010). Once a warrior, always a warrior. New York, NY: Guilford Pres. Connecticut: Lyons Press. 
MORAL INJURY, SHAME, GUILT, AND SELF-FORGIVENESS

Hoge, C., Castro, C., Messer, S., McGurk, D., Cotting, D., \& Koffman, R. (2004). Combat duty in Iraq and Afghanistan, mental health problems, and barriers to care. The New England Journal of Medicine, 351(1), 13-22. doi: 10.1056/NEJMoa040603

Hu, L., \& Bentler, P. M. (1999). Cutoff criteria for fit indexes in covariance structure analysis: Conventional criteria versus new alternatives. Structural Equation Modeling, 6(1), 1-55.

International Business Machines Corp. (2013). IBM SPSS statistics for windows, version 22.0. Retrieved from http://www.ibm.com/analytics/us/en/technology/spss/.

Jinkerson, J. (2016). Defining and assessing moral injury: A syndrome perspective. Traumatology, 22(2), 122-130. doi:10.1037/trm0000069

Karaırmak, Ö, \& Güloğlu, B. (2014). Forgiveness and ptsd among Veterans: The mediating role of anger and negative affect. Psychiatry Research, 219(3), 536-542. doi:10.1016/j.psychres.2014.05.024

Kashdan, T., Julian, T., Merritt, K., \& Uswatte, G. (2006). Social anxiety and posttraumatic stress in combat Veterans: Relations to well-being and character strengths. Behaviour Research and Therapy, 44(4), 561-583. doi:10.1016/j.brat.2005.03.010

Keltner, D., \& Harker, L. (1998). The forms and functions of the nonverbal signal of shame. In P. Gilbert \& B. Andrews (Eds.), Series in affective science. Shame: Interpersonal behavior, psychopathology, and culture (pp. 78-98). New York, NY, US: Oxford University Press.

Kemp, J., \& Bossarte, R. (2012). Suicide data report, 2012. Department of Veteran Affairs Mental Health Services Suicide Prevention Program. Retrieved from https://www.ncbi.nlm.nih.gov/pmc/articles/PMC3496454/ 
MORAL INJURY, SHAME, GUILT, AND SELF-FORGIVENESS

Kim, S., Thibodeau, R., \& Jorgensen, R. (2011). Shame, guilt, and depressive symptoms: A meta-Analytic review. Psychological Bulletin, 137(1), 68-68. http://dx.doi.org/10.1037/a0021466

Kohlberg, L. (1969). Stage and sequence: The cognitive development approach to socialization. In D. A. Goslin (Ed.). Handbook of socialization theory (pp. 347-480). Chicago, IL, Rand McNally.

Kubany, E., Abueg, F., Kilauano, W., Manke, F., \& Kaplan, A. (1997). Development and validation of the sources of trauma-related guilt survey—war-zone version. Journal of Traumatic Stress, 10(2), 235-258. doi:10.1002/jts.2490100206

Kubany, E. S., Haynes, S. N., Abueg, F. R., Manke, F. P., Brennan, J. M., \& Stahura, C. (1996). Development and validation of the Trauma-Related Guilt Inventory (TRGI). Psychological Assessment, 8(4), 428-444. http://dx.doi.org.www.libproxy.wvu.edu/10.1037/1040-3590.8.4.428

Kubany, E.S., Gino, A., Denny, N.R., \& Torigoe, R.Y. (1994). Relationship of cynical hostility and PTSD among Vietnam Veterans. Journal of Traumatic Stress, 7(1), 21-31. https://doi.org/10.1002/jts.2490070104

Lapierre, C., Schwegler, A., \& Labauve, B. (2007). Posttraumatic stress and depression symptoms in soldiers returning from combat operations in Iraq and Afghanistan. Journal of Traumatic Stress, 20(6), 933-43.

Leith, K., \& Baumeister, R. (1998). Empathy, shame, guilt, and narratives of interpersonal conflicts: Guilt-Prone people are better at perspective taking. Journal of Personality, 66(1), 1-37. doi:10.1111/1467-6494.00001

Lewis, H.B. (1971). Shame and guilt in neurosis. New York: International University Press. 
MORAL INJURY, SHAME, GUILT, AND SELF-FORGIVENESS

Lindell, M. K., \& Whitney, D. J. (2001). Accounting for common method variance in crosssectional research designs. Journal of Applied Psychology, 86(1), 114-121. http://dx.doi.org/10.1037/0021-9010.86.1.114

Litz, B. (2007). Research on the impact of military trauma: Current status and future directions. Military Psychology, 19(3), 217-238.

Litz, B. T., Lebowitz, L., Gray, M. J., \& Nash, W. P. (2016). Adaptive disclosure: A new treatment for military trauma, loss, and moral injury. The Guilford Press.

Litz, B., Stein, N., Delaney, E., Lebowitz, L., Nash, W., Silva, C., \& Maguen, S. (2009). Moral injury and moral repair in war Veterans: A preliminary model and intervention strategy. Clinical Psychology Review, 29(8), 695-706. doi:10.1016/j.cpr.2009.07.003

MacCallum, R. C., Browne, M. W., \& Sugawara, H. M. (1996). Power analysis and determination of sample size for covariance structure modeling. Psychological Methods, $1,130-149$.

Maguen, S., \& Litz, B. (2012). Moral injury in Veterans of war. PTSD Research Quarterly, 23, $1-6$.

Maguen, S., Lucenko, B., Reger, M., Gahm, G., Litz, B., Seal, K., . . Marmar, C. (2010). The impact of reported direct and indirect killing on mental health symptoms in iraq war Veterans. Journal of Traumatic Stress, 23(1), 86-90. doi:10.1002/jts.20434

Maguen, S., Luxton, D., Skopp, N., Gahm, G., Reger, M., Metzler, T., \& Marmar, C. (2011). Killing in combat, mental health symptoms, and suicidal ideation in iraq war Veterans. Journal of Anxiety Disorders, 25(4), 563-567. doi:10.1016/j.janxdis.2011.01.003 
MORAL INJURY, SHAME, GUILT, AND SELF-FORGIVENESS

Maguen, S., Metzler, T., Litz, B., Seal, K., Knight, S., \& Marmar, C. (2009). The impact of killing in war on mental health symptoms and related functioning. Journal of Traumatic Stress, 22(5), 435-43. doi:10.1002/jts.20451

Maguen, S., Vogt, D.S., King, L.A., King, D.W., Litz, B.T., \& Knight, S.J. (2010). The impact of killing on mental health symptoms in gulf war Veterans. Psychological Trauma: Theory, Research, Practice, and Policy, 3(1), 21-26.doi:10.1037/a0019897

Mauger, P.A., Perry, J.E., Freeman, T., Grove, D.C., McBride, A.G., \& McKinney, K.E. (1992). The measurement of forgiveness: Preliminary research. Journal of Psychology and Christianity, 11, 170-180.

McCarthy, N. (2018, March 20). 2.77 Million Service Members Have Served On 5.4 Million Deployments Since 9/11 [Infographic]. Retrieved April 23, 2020, from https://www.forbes.com/sites/niallmccarthy/2018/03/20/2-77-million-service-membershave-served-on-5-4-million-deployments-since-911-infographic/\#2d6e351150db

McCauley, J., Killeen, T., Gros, D., Brady, K., \& Back, S. (2012). Posttraumatic stress disorder and co-Occurring substance use disorders: Advances in assessment and treatment. Clinical Psychology: Science and Practice, 19(3), 283-304. doi:10.1111/cpsp.12006

Marschall, D., Sanftner, J., \& Tangney, J.P. (1994). The State Shame and Guilt Scale. Fairfax, VA: George Mason University [includes full scale].

Nash, W., Marino, C., Mills, M., Au, T., Goldsmith, A., \& Litz, B. (2013). Psychometric evaluation of the moral injury events scale. Military Medicine, 178(6), 646-52. doi:10.7205/MILMED-D-13-00017 
MORAL INJURY, SHAME, GUILT, AND SELF-FORGIVENESS

Nazarov, A., Walaszczyk, V., Frewen, P., Oremus, C., Lanius, R., \& McKinnon, M. (2016). Moral reasoning in women with posttraumatic stress disorder related to childhood abuse. European Journal of Psychotraumatology, 7(1). doi:10.3402/ejpt.v7.31028

Olff, M. (2017). Sex and gender differences in post-traumatic stress disorder: An update. European Journal of Psychotraumatology, 8. doi:10.1080/20008198.2017.1351204

Osran, H., Smee, D., Sreenivasan, S., \& Weinberger, L. (2010). Living outside the wire: Toward a transpersonal resilience approach for oif/oef veterans transitioning to civilian life. Journal of Transpersonal Psychology, 42(2), 209-235.

Pope, Alexander (1711). Butt, John (ed.) (1963). The Poems of Alexander Pope (a one-volume edition of the Twickenham text ed.). Yale University Press. ISBN 0300003404. OCLC 855720858.

Possemato, K., Wade, M., Andersen, J., \& Ouimette, P. (2010). The impact of PTSD, depression, and substance use disorders on disease burden and health care utilization among OEF/OIF Veterans. Psychological Trauma: Theory, Research, Practice, and Policy, 2(3), 218-223. doi:10.1037/a0019236

Pujol, J., Vendrell, P., Junqué, C., Martí-Vilalta, J.L. and Capdevila, A. (1993), When does human brain development end? Evidence of corpus callosum growth up to adulthood. Ann Neurol., 34: 71-75. doi:10.1002/ana.410340113

Random.org. (2019). Retrieved from https://www.random.org/

Robinaugh, D., \& McNally, R. (2010). Autobiographical memory for shame or guilt provoking events: Association with psychological symptoms. Behaviour Research and Therapy, 48(7), 646-652. doi:10.1016/j.brat.2010.03.017 
MORAL INJURY, SHAME, GUILT, AND SELF-FORGIVENESS

Robins, R.W., Noftle, E.E., \& Tracy, J.L. (2007). Assessing self-conscious emotions: A review of self-report and nonverbal measures. In Tracy, J.L., Robins, R.W., \& Tangney, J.P. (Eds.), The self-conscious emotions: Theory and research. Retrieved from https://pdfs.semanticscholar.org/4717/d972ffa13d6b75e580f04dcdb9075a05c8a3.pdf

Rodriguez, L. M., Young, C. M., Neighbors, C., Tou, R., \& Lu, Q. (2016). Cultural differences and shame in an expressive writing alcohol intervention. Journal of Ethnicity in Substance Abuse, 15(3), 252-267. http://dx.doi.org.www.libproxy.wvu.edu/10.1080/15332640.2015.1024812

Rostker, \& D., B. (2006, August 28). The Evolution of the All-Volunteer Force. Retrieved April 23, 2020, from https://www.rand.org/pubs/research_briefs/RB9195.html

Rubin, D., Dennis, M., \& Beckham, J. (2011). Autobiographical memory for stressful events: The role of autobiographical memory in posttraumatic stress disorder. Consciousness and Cognition, 20(3), 840-56. doi: 10.1016/j.concog.2011.03.015

Sayer, N., Carlson, K., \& Frazier, P. (2014). Reintegration challenges in u.s. service members and Veterans following combat deployment. Social Issues and Policy Review, 8(1), 3373. doi:10.1111/sipr.12001

Schuettler, D., \& Boals, A. (2011). The path to posttraumatic growth versus posttraumatic stress disorder: Contributions of event centrality and coping. Journal of Loss and Trauma, 16(2), 180-194. doi:10.1080/15325024.2010.519273

Schumacher, W. M. (2017). Moral injury and suicidal ideation after military service: Medicating and moderating factors (Doctoral dissertation). University of Oregon: Eugene, Oregon. 
MORAL INJURY, SHAME, GUILT, AND SELF-FORGIVENESS

Seal, K., Maguen, S., Cohen, B., Gima, K., Metzler, T., Ren, L., . . Marmar, C. (2010). VA mental health services utilization in iraq and afghanistan Veterans in the first year of receiving new mental health diagnoses. Journal of Traumatic Stress, 23(1), 5-16. doi:10.1002/jts.20493

Seal K, Metzler T, Gima K, Bertenthal D, Maguen S, Marmar C. Trends and risk factors for mental health diagnoses among Iraq and Afghanistan Veterans using Department of Veterans Affairs health care, 2002-2008. American Journal of Public Health. 2009;99 (9):1651-1658.

Shay, J. (1994). Achilles in Vietnam: Combat trauma and the undoing of character. New York, NY: Scribner.

Shay, J. (2003). Odysseus in America: Combat trauma and the trials of homecoming. New York, NY: Scribner.

Shay, J. (2012). Moral injury. Intertexts, 16(1), 57-66.

Shay, J. (2014). Moral injury. Psychoanalytic Psychology, 31(2), 182-191. doi:10.1037/a0036090

Snider, J.J. (2015). Moral injury: repair through self-forgiveness (Doctoral dissertation). George Fox University: Newberg, Oregon.

Stein, N., Mills, M., Arditte, K., Mendoza, C., Borah, A., Resick, P., . . Wright, E. (2012). A scheme for categorizing traumatic military events. Behavior Modification, 36(6), 787807. doi:10.1177/0145445512446945

Tangney, J. P. (1996). Conceptual and methodological issues in the assessment of shame and guilt. Behavior Research and Therapy, 34, 741-754. 
MORAL INJURY, SHAME, GUILT, AND SELF-FORGIVENESS

Tangney, J.P., Boone, A.L., \& Dearing, R. (1999). Forgiving the self: Conceptual issues and empirical findings. In Worthington, E.L. (Eds.), Handbook of forgiveness. Retrieved from

https://s3.amazonaws.com/academia.edu.documents/43246699/Handbook_of_Forgivenes s.pdf?AWSAccessKeyId=AKIAIWOWYYGZ2Y53UL3A\&Expires=1536965738\&Signa ture=w\%2FgGDxppjV6\%2BQkEQHiuunf9PgoY\%3D\&response-contentdisposition=inline\%3B\%20filename\%3DHandbook_of_Forgiveness.pdf\#page $=168$

Tangney, J. P., \& Dearing, R. L. (2002). Our "Intrapersonal" Relationship: The Self in Shame and Guilt. In Shame and Guilt (pp. 52-77). New York: The Guilford Press.

Tangney, J., Stuewig, J., \& Mashek, D. (2007). Moral emotions and moral behavior. Annual Review of Psychology, 58, 345-72. https://doi.org/10.1146/annurev.psych.56.091103.070145

Tangney, J., Fletcher, C., \& Gramzow, R. (1992). Shamed into anger? The relation of shame and guilt to anger and self-reported aggression. Journal of Personality and Social Psychology, 62, 669-675.

Thompson, L. Y., \& Synder, C. R. (2003). Measuring forgiveness. In S. J. Lopez \& C. R. Snyder (Eds.), Positive psychological assessment: A handbook of models and measures (pp. 301312). Washington, DC, US: American Psychological Association. http://dx.doi.org.www.libproxy.wvu.edu/10.1037/10612-019

Thompson, L. Y., Snyder, C. R., Hoffman, L., Michael, S. T., Rasmussen, H. N., Billings, L. S., . . Roberts, D. J. (2005). Dispositional Forgiveness of Self, Others, and Situations. Journal of Personality, 73(2), 313-359.

http://dx.doi.org.www.libproxy.wvu.edu/10.1111/j.1467-6494.2005.00311.x 
MORAL INJURY, SHAME, GUILT, AND SELF-FORGIVENESS

Tilghman-Osborne, C., Cole, D., Felton, J., \& Ciesla, J. (2008). Relation of guilt, shame, behavioral and characterological self-Blame to depressive symptoms in adolescents over time. Journal of Social and Clinical Psychology, 27(8), 809-842.

U.S. Census Bureau. (2017). American facts for features: CB17-FF.22. Retrieved from https://www.census.gov/newsroom/facts-for-features/2017/Veterans-day.html

U.S. Department of Defense. (2011). The challenge and the promise: Strengthening the force, preventing suicide, and saving lives. Final Report of the Department of Defense Task Force on the Prevention of Suicide by Members of the Armed Forces. Retrieved from http://www.health.mil/dhb/downloads/Suicide\%20Prevention\%20Task\%20Force\%20fina 1\%20report\%208-23-10.pdf.

U.S. Department of Veteran Affairs, National Center for PTSD. (2015). PTSD. Retrieved from https://www.ptsd.va.gov/public/PTSD-overview/basics/how-common-is-ptsd.asp

U.S. Department of Veteran Affairs, Office of Public Health. (2014). Analysis of VA health care utilization among operation enduring freedom (OEF), operation Iraqi freedom (OIF), and operation new dawn (OND) Veterans. Retrieved from https://www.publichealth.va.gov/docs/epidemiology/healthcare-utilization-report-fy2013qtr4.pdf

U.S. Transgender Survey. (2015, 01 01). U.S. Transgender Survey. Retrieved from U.S. Transgender Survey: https://www.transequality.org/sites/default/files/docs/usts/USTSVeteransDayReport.pdf

Vargas, A.F., Hanson, T., Kraus, D., Foy, D., \& Drescher, K. (2013). Moral injury themes in combat Veterans' narrative responses from the national Vietnam veterans' readjustment study. Traumatology, 19(3), 243-250. doi:10.1177/1534765613476099 
MORAL INJURY, SHAME, GUILT, AND SELF-FORGIVENESS

Vermetten, E., \& Jetly, R. (2018). A Critical Outlook on combat-related PTSD: Review and case reports of guilt and shame as drivers for moral injury, Military Behavioral Health, 6:2, 156-164, doi: 10.1080/21635781.2018.1459973

Wohl, M. J. A., DeShea, L., \& Wahkinney, R. L. (2008). Looking within: Measuring state selfforgiveness and its relationship to psychological well-being. Canadian Journal of Behavioural Science / Revue canadienne des sciences du comportement, 40(1), 1-10. https://doi-org.www.libproxy.wvu.edu/10.1037/0008-400x.40.1.1.1

Whealin, J., Stotzer, R., Pietrzak, R., Vogt, D., Shore, J., Morland, L., \& Southwick, S. (2014). Deployment-related sequelae and treatment utilization in rural and urban war Veterans in Hawaii. Psychological Services, 11(1), 114-123. doi:10.1037/a0032782

Wilson, J. P. (2005). The posttraumatic self: Restoring meaning and wholeness to personality. New York: Brunner-Routledge.

Wilson, J., Droždek, B., \& Turkovic, S. (2006). Posttraumatic shame and guilt. Trauma, Violence, \& Abuse, 7(2), 122-141. doi: 10.1177/1524838005285914

Witvliet, C., Phipps, K., Feldman, M., \& Beckham, J. (2004). Posttraumatic mental and physical health correlates of forgiveness and religious coping in military Veterans. Journal of Traumatic Stress, 17(3), 269-273. doi:10.1023/B:JOTS.0000029270.47848.e5

Wisco, B., Marx, B., May, C., Martini, B., Krystal, J., Southwick, S., \& Pietrzak, R. (2017). Moral injury in U.S. combat Veterans: Results from the national health and resilience in Veterans study: W. Depression and Anxiety, 34(4), 340-347. doi:10.1002/da.22614

Woodyatt, L., \& Wenzel, M. (2013). Self-forgiveness and restoration of an offender following an interpersonal transgression. Journal of Social and Clinical Psychology, 32(2), 225-259. doi:10.1521/jscp.2013.32.2.225 


\section{MORAL INJURY, SHAME, GUILT, AND SELF-FORGIVENESS}

Worthington, E. L., Jr. (2006). Forgiveness and reconciliation: Theory and application. New York, NY, US: Routledge/Taylor \& Francis Group.

Worthington, E., \& Langberg, D. (2012). Religious considerations and self-Forgiveness in treating complex trauma and moral injury in present and former soldiers. Journal of Psychology and Theology, 40(4), 274-288. doi: 10.1177/009164711204000403

Yao, S., Chen, J., Yu, X., \& Sang, J. (2017). Mediator roles of interpersonal forgiveness and selfForgiveness between self-Esteem and subjective well-Being. Current Psychology: $A$ Journal for Diverse Perspectives on Diverse Psychological Issues, 36(3), 585-592. doi:10.1007/s12144-016-9447-X 


\author{
APPENDICES \\ Appendix A: Informed Consent

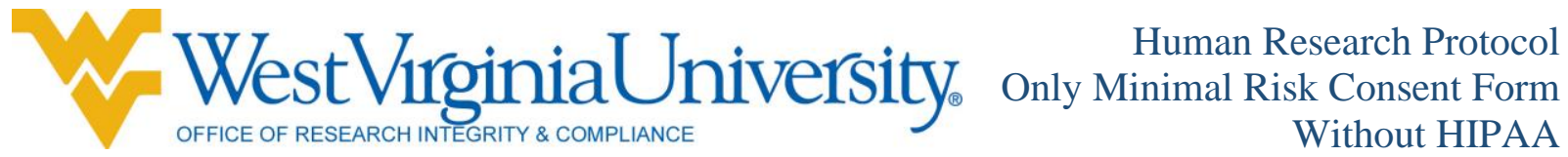 \\ Only Minimal Risk \\ Consent Information Form (without HIPAA) \\ Timothy Swiger \\ Department of Counseling, Rehabilitation Counseling, and Counseling \\ Click here to enter text. \\ Moral Injury, Shame, Guilt, and Forgiveness \\ Jeffrey Daniels Ph.D.
}

Principal Investigator

Department

Psychology

Protocol Number

Study Title

Co-Investigator(s)

\title{
Contact Persons
}

In the event you experience any side effects or injury related to this research, you should contact Dr. Jeffrey Daniels at (304) 293-2235. If you have any questions, concerns, or complaints about this research, you can contact Dr. Jeffrey Daniels (304) 293-2235 or Timothy Swiger at tswiger2@mix.wvu.edu.

For information regarding your rights as a research subject, to discuss problems, concerns, or suggestions related to the research, to obtain information or offer input about the research, contact the Office of Research Integrity and Compliance at (304) 293-7073.

In addition, if you would like to discuss problems, concerns, have suggestions related to research, or would like to offer input about the research, contact the Office of Research Integrity and Compliance at 304-293-7073.

\section{Introduction}

You have been asked to participate in this research study, which has been explained to you through the survey description provided via Facebook sharable post. This study is being conducted by Timothy Swiger, M.S. and supervised by Jeffrey Daniels, Ph. D., in the Department of Counseling, Rehabilitation Counseling, and Counseling Psychology at West Virginia University.

\section{Purpose(s) of the Study}

The purpose of this study is to investigate combat experiences of Veterans who served in and around Iraq and Afghanistan. Specifically, this study will examine experiences that have conflicted with the Veteran's values and beliefs. Additionally, the study will investigate how forgiveness could affect the relationship between those experiences and negative emotions. Finally, this study will expand the literature further by breaching a gap between theory and assessment through providing an assessment measure with a theoretical model of addressing moral injury and negative emotion development.

\section{Description of Procedures}

This study involves answering a demographic questionnaire about yourself, and then answering a longer survey. It will take approximately 5-10 minutes for you to complete. You will be asked to fill out a questionnaire regarding your combat experiences and reflect on your feelings about those experiences. 


\section{Discomforts}

There are minimal foreseeable or expected risks from participating in this study, as Veterans will be asked to think about their military experiences which may result in mild psychological distress. As such, all participants will be provided with a discontinuation option and with a debriefing form (Appendix C) which will include a background to the study, contact information of the researcher, and provide mental health resources should Veterans need them.

\section{Financial Considerations}

There are no special fees for participating in this study.

\section{Confidentiality}

Any information about you that is obtained as a result of your participation in this research will be kept as confidential as legally possible. Your research records and test results, just like hospital records, may be subpoenaed by court order or may be inspected by the study sponsor or federal regulatory authorities (including the FDA if applicable) without your additional consent.

In addition, there are certain instances where the researcher is legally required to give information to the appropriate authorities. These would include mandatory reporting of infectious diseases, mandatory reporting of information about behavior that is imminently dangerous to your child or to others, such as suicide, child abuse, etc.

In any publications that result from this research, neither your name nor any information from which you might be identified will be published without your consent.

\section{Voluntary Participation}

Participation in this study is voluntary and participants may discontinue at any time. You are free to withdraw your consent to participate in this study at any time by simply closing the window.

Refusal to participate or withdrawal will result in no penalty to you.

I willingly agree to be in the study.

$\circ$ Yes $\circ$ No 
MORAL INJURY, SHAME, GUILT, AND SELF-FORGIVENESS

\section{Appendix B: Participant Invitation Request}

Recruiting Participants through Clinical/Counseling Training Directors

Dear Veteran,

My name is Timothy Swiger. I received my masters in Rehabilitation Counseling at West Virginia University and am now earning my Ph.D. in Counseling Psychology at West Virginia University. Currently, I am conducting my dissertation (under the supervision of Jeff Daniels, Ph. D.) in partial fulfillment of my doctoral degree. I am conducting a study examining Veteran war experiences and how Veterans feel about those experiences upon returning home. I invite you to participate in this voluntary study.

The survey itself takes approximately 5-10 minutes. This project has been approved by the Institutional Review Board for the protection of Human Subjects at West Virginia University. A complete informed consent is available on the first page of the survey.

Thank you for your time and willingness to participate in this study.

Insert: Survey Link 


\section{Appendix C: Research Study Summary}

Purpose of the Study: This study investigated the relationship between combat experiences and emotions related to those experiences among combat Veterans of Iraq and Afghanistan campaigns. Research on combat experiences is limited in examining the moral weight of choices made in combat that can result in negative mental health outcomes. Furthermore, less is known about the factors that contributed to healing Veterans who experience such moral dilemmas. This study is meant to assist mental health providers in understanding the moral and ethical challenges of war that result in negative mental health outcomes and aid in identifying protective factors. The result of this study will assist in future treatment interventions for combat-exposed Veterans.

In order to maintain the quality of this study, please do not disclose research procedures to anyone who might participate in this study in the future as this could bias the results.

Contact Information: If you have any questions or concerns regarding your participation in this study or would like to receive a copy of the summary of the findings of this study when it is completed, please feel free to contact me at tswiger2@mix.wvu.edu.

Thank you for your time and participation in this study. Your responses to the survey questions are greatly valued and will optimistically assist in the treatment of combat Veterans in the future.

Mental Health Resources: Veterans who experience combat can experience distress when remembering their military service. As such, Veterans can benefit from discussing their feelings related to their military service. The following resources are provided for you if you are feeling any distress at the completion of this survey or would like to discuss general feelings related to your military service. If you think you might benefit from discussing those feelings please contact one of the following resources:

1. Veterans Crisis Line (VA-Affiliated)

2. Military OneSource

3. Military Helpline

4. Veterans Affairs Mental Health Help
$1-800-273-8255$

$1-866-342-9647$

1-888-457-4838

http://mentalhealth.va.gov/gethelp.asp 


\section{Appendix D: Demographic Information Questionnaire}

1. What is your age?

2. What is your sex?
- Female
- Transgender (Female $\square$ Male)
- Male
- Gender fluid/gender non-conforming
- Transgender (Male $\square$ Female)
- Other

3. Which of the following describes your ethnicity?

- Native American or Alaska Native

- European-American (Caucasian)

- Asian

- Bi-Racial/Mixed Ethnicity

- African-American (Black)

- Other

- Latino/a

4. What is your highest education level?

- High School Diploma or Equivalent (GED)

- Some College

- 2-Year College Degree or Technical Trade School Graduate

- 4-Year College Degree

- Some Graduate School

- Graduate or Professional Degree

5. Type of military discharge?

- Honorable

- General Discharge Under Honorable

- Bad Conduct Conditions

- Other than Honorable (OTH)

- Dishonorable

- Entry-Level Separation

- Currently Serving

6. What branch of service did you serve under?

- U.S. Army (Active)

- U.S. Army Reserves

- U.S. Coast Guard Reserve

- U.S. Army National Guard

- U.S. Marine Corps (Active)

- U.S. Air Force (Active)

- U.S. Marine Corps Reserve

- U.S. Air Force Reserve

- U.S. Navy (Active)

- U.S. Air National Guard

- U.S. Navy Reserve

- U.S. Coast Guard

- Other

7. What was your rank upon discharge?
- E-1 to E-4
- E-5 to E-7
- E-8 to E-9
- O-1 to O-4
- $\mathrm{O}-5$ to O-7

- O-8 to O-10/General of the Army

- W-1 to W-2

- W-3 to W-4

- W-5 
8. How many deployments have you completed in support of operations in and around Iraq and/or Afghanistan since 2001?

- 1

- 2

- 3

- $4+$

9. Since 2001, with which combat zones were you deployed?

- Afghanistan

- Iraq

- Both

- I did not deploy to either

10. Did you experience direct combat?

- Yes

- No

11. Do you currently use VA mental health services?

- Yes

- No 


\section{Appendix E: IRB Approval}

Approved IRB protocol number: $\underline{\text { 1902448880A001 }}$

Title: Morally Injurious Experiences of Combat Exposed Veterans of Iraq and Afghanistan: Moderating Effects of Self-Forgiveness on Feelings of Shame and Guilt

PI: Jeffrey A Daniels

The West Virginia University Institutional Review Board approved the above-referenced amendment on 15-May-2019. To access documents approved in this amendment, use the Dashboard to open the original protocol. They can be found in the Attachments section of the Protocol Summary page. Your approval correspondence concerning this action can be

found in the correspondence section of the Protocol Summary page HERE.

For more information, see the Viewing Correspondence quick reference guide. Any future protocol action requests can be completed through the WVU+kc system.

NEED HELP? The Office of Research Integrity and Compliance is here to assist you from initial submission of a protocol through approval and all subsequent actions. If you have any questions, please contact the Office of Research Integrity and Compliance at 304-2937073 or email IRB@mail.wvu.edu.

Thank you.

Please do not reply to this message. Replies to this message are routed to an unmonitored mailbox. If you have questions please use the contact information above. 
MORAL INJURY, SHAME, GUILT, AND SELF-FORGIVENESS

\section{Appendix F: Permission to Use the Moral Injury Questionnaire - Military Version}

September 13, 2018

Timothy Swiger

West Virginia University

Hello Dr. Currier,

I am Tim Swiger from West Virginia University. I am a combat Veteran of the United States

Marine Corps, and I am currently working on my dissertation. I am emailing you to request

permission to use the MIQ-M in my study of moral injury and feelings of shame and guilt among

combat exposed Veterans. Please feel free to contact me via email or phone (910) 787-6798.

Semper Fi,

Tim Swiger, M.S., C.R.C.

Reply on September 13, 2018:

Permission granted, Timothy! Here's a second scale that might also be helpful to you. Joe 


\section{Appendix G: Moral Injury Questionnaire - Military Version \\ MIQ-M}

Copyright $@ 2015$ * J.M. Currier, Ph.D.

Directions: Serving in the military can entail exposure to many stressful life events. Considering your possible war-zone deployment(s) and military service in general, please indicate how often you experienced the following types of events. Please read each statement carefully and note that for these statements, a response of 1 indicates that you "never" experienced the item and a response of 4 indicates that the item occurred "often" for you.

\begin{tabular}{|c|c|c|c|c|}
\hline & Never & Seldom & Sometimes & Often \\
\hline $\begin{array}{l}\text { (1) Things I saw/experienced left me feeling } \\
\text { betrayed or let-down by military/political leaders }\end{array}$ & 1 & 2 & 3 & 4 \\
\hline (2) I did things that betrayed my personal values & 1 & 2 & 3 & 4 \\
\hline $\begin{array}{l}\text { (3) There were times that I saw/engaged in } \\
\text { revenge/retribution for things that happened }\end{array}$ & 1 & 2 & 3 & 4 \\
\hline $\begin{array}{l}\text { (4) I had an encounter(s) with the enemy that } \\
\text { made } \\
\text { him/her seem more 'human' and made my job } \\
\text { more difficult }\end{array}$ & 1 & 2 & 3 & 4 \\
\hline $\begin{array}{l}\text { (5) I saw/was involved in violations of rules of } \\
\text { engagement }\end{array}$ & 1 & 2 & 3 & 4 \\
\hline $\begin{array}{l}\text { (6) I saw/was involved in the death(s) of an } \\
\text { innocent }\end{array}$ & 1 & 2 & 3 & 4 \\
\hline $\begin{array}{l}\text { (7) I feel guilt over failing to save the life of } \\
\text { someone }\end{array}$ & 1 & 2 & 3 & 4 \\
\hline $\begin{array}{l}\text { (8) I had to make decisions at times when I didn't } \\
\text { know the right thing to do }\end{array}$ & 1 & 2 & 3 & 4 \\
\hline (9) I feel guilt for surviving when others didn’t & 1 & 2 & 3 & 4 \\
\hline $\begin{array}{l}\text { (10) I saw/was involved in violence that was out } \\
\text { of proportion to the event }\end{array}$ & 1 & 2 & 3 & 4 \\
\hline $\begin{array}{l}\text { (11) I saw/was involved in the death(s) of } \\
\text { children }\end{array}$ & 1 & 2 & 3 & 4 \\
\hline $\begin{array}{l}\text { (12) I experienced tragic war-zone events that } \\
\text { were chaotic and beyond my control }\end{array}$ & 1 & 2 & 3 & 4 \\
\hline
\end{tabular}


MORAL INJURY, SHAME, GUILT, AND SELF-FORGIVENESS

\begin{tabular}{|l|l|l|l|l|}
\hline $\begin{array}{l}\text { (13) I sometimes treated civilians more harshly } \\
\text { than was necessary } \\
\text { (14) I felt betrayed or let-down by trusted } \\
\text { civilians }\end{array}$ & 1 & 2 & 3 & 4 \\
\hline $\begin{array}{l}\text { (15) I saw/was involved in a 'friendly-fire' } \\
\text { incident }\end{array}$ & 1 & 2 & 3 & 4 \\
\hline (16) I destroyed civilian property unnecessarily & 1 & 2 & 3 & 4 \\
\hline (17) Seeing so much death has changed me & 1 & 2 & 3 & 4 \\
\hline $\begin{array}{l}\text { (18) I made mistakes in the war zone that led to } \\
\text { injury or death }\end{array}$ & 1 & 2 & 3 & 4 \\
\hline (19) I came to realize that I enjoyed violence & 1 & 2 & 3 & 4 \\
\hline
\end{tabular}

Note. A sum of all items can be taken to compute a total score for the Moral Injury Questionnaire - Military Version (MIQ-M). This score will provide an estimated degree of "exposure" to potentially morally injurious stressors rather than gauging "symptoms" of a moral injury. At present, there are no established clinical thresholds for the MIQ-M or corresponding norms. The above instructions may be altered to make the measure applicable to different groups of interest and this numbering of items corresponds to the numbering used in the initial psychometric evaluation (Currier et al., 2013). In addition, an item assessing sexual trauma (i.e., "I was sexually assaulted") was omitted from this version based on Currier et al.'s (2013) findings. This lack of evidence was likely due to problems with the wording of the item and characteristics of the study samples (i.e., over-representation of male Veterans). Interested persons might consider revising the wording of this item to capture possible exposure to military sexual trauma.

This scale is published in the public domain to encourage its use by interested clinicians and researchers. No formal permission is required for its duplication and use beyond citation of its source and authorship. 


\section{Appendix H: Permission to Use the State Shame and Guilt Scale (SSGS)}

September 13, 2018

Timothy Swiger

West Virginia University

Greetings,

You are more than welcome to use our measures. I am attaching the SSGS (our most recent measure of state shame and guilt for adults) along with scoring instructions. You can also find some information on the reliability and validity of the SSGS in:

Tangney, JP \& Dearing, RL (2002). Shame and Guilt. NY: Guilford Press.

The book is available through www.guilford.com, www.amazon.com, and in some university libraries.

I should mention that I am not at all confident that the SSGS assesses shame and guilt as distinct constructs. These are very difficult emotions to assess and differentiate at the state level. If your research question and design pertains to shame-proneness and guilt-proneness as crosssituational dispositions, I'd suggest our TOSCA-3 measure.

Please do keep in touch and let us know how your research develops. I would be grateful for a summary of the results whenever they become available.

Best Wishes, June $\mathrm{T}$.

June Tangney, Ph.D.

University Professor

and Professor of Psychology

George Mason University

Department of Psychology

MSN 3F5

Fairfax VA 22030

7039931365 (Office)

7039931335 (Fax)

jtangney@gmu.edu 
MORAL INJURY, SHAME, GUILT, AND SELF-FORGIVENESS

\section{Appendix I: The State Shame and Guilt Scale (SSGS)}

\section{Copyright@ $2015 *$ Marschall, D.E., Sanftner, J.L., \& Tangney, J.P. (1994). SSGS}

The following are some statements which may or may not describe how you are feeling right now. Please rate each statement using the 5-point scale below. Remember to rate each statement based on how you are feeling right at this moment.

\begin{tabular}{|c|c|c|}
\hline $\begin{array}{l}\text { Not feeling } \\
\text { this way } \\
\text { at all }\end{array}$ & $\begin{array}{c}\text { Feeling } \\
\text { this way } \\
\text { somewhat }\end{array}$ & $\begin{array}{l}\text { Feeling } \\
\text { this way } \\
\text { very strongly }\end{array}$ \\
\hline
\end{tabular}

1. I feel good about myself. 1 ------- 2 ------- 3 ------- 4 ------- 5

2. I want to sink into the floor and disappear. 1 ------- 2 ------- 3 ------- 4 ------- 5

3. I feel remorse, regret. 1 ------- 2 ------- 3 ------- 4 ------- 5

4. I feel worthwhile, valuable. $\quad 1$------- 2 ------- 3 ------- 4 ------- 5

5. I feel small. 1 ------ 2 ------- 3 ------- 4 ------- 5

6. I feel tension about something I have done. 1 ------- 2 ------- 3 ------- 4 ------- 5

7. I feel capable, useful. 1 ------- 2 ------- 3 ------- 4 ------- 5

8. I feel like I am a bad person. 1 ------ 2 ------- 3 ------- 4 ------- 5

9. I cannot stop thinking about something bad I have done.

1 ------- 2 ------- 3 -------- 4 ------- 5

10. I feel proud.

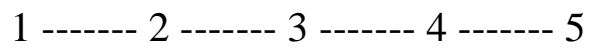

11. I feel humiliated, disgraced.

1 ------- 2 -------- 3 ------- 4 ------- 5

12. I feel like apologizing, confessing.

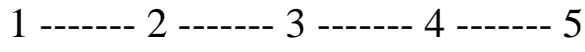

13. I feel pleased about something I have done. 1 ------- 2 ------- 3 ------- 4 ------- 5

14. I feel worthless, powerless. 1 ------- 2 ------- 3 ------- 4 ------- 5

15. I feel bad about something I have done. 1 ------- 2 ------- 3 ------- 4 ------- 5 


\section{Appendix J: The State Shame and Guilt Scale Scoring Rubric}

\section{State Shame and Guilt Scale (SSGS)}

The SSGS is a self-rating scale of in-the-moment (state) feelings of shame, guilt, and pride experiences. Fifteen items (five for each of the three subscales) are rated on a 5-point scale Likert scale.

Examples of shame items include: "I want to sink into the floor and disappear," and "I feel small." Examples of guilt items include: "I feel remorse, regret," and "I feel like apologizing, confessing." Examples of pride items include: "I feel good about myself," and "I feel capable, useful."

The SSGS was initially developed as a manipulation check for the shame induction in an experimental study of shame and empathy (Marschall, 1996). The items for each subscale were derived from the empirical and theoretical literature. Participants were asked to complete the questionnaire as a "mood check," immediately following the shame induction.

\section{Sample}

The sample was drawn from a large, east-coast university population. Students were enrolled in an introductory psychology class and were offered credit for their participation. The students ranged in age from 17 to $42(\underline{M}=21.1)$ and $69 \%$ were female. Seventy percent were White, 9\% Black, 11\% Asian, 4\% Hispanic, and 8\% Other.

\section{Results:}

\begin{tabular}{|l|c|c|c|}
\hline Scale & $\begin{array}{c}\text { Mean Sum (SD) } \\
\text { Control Participants } \\
\mathrm{n}=82\end{array}$ & $\begin{array}{c}\text { Mean Sum (SD) } \\
\text { Induced Shame } \\
\text { Participants } \\
\mathrm{n}=60\end{array}$ & $\begin{array}{c}\text { Inter-Item Reliability } \\
\text { (All participants) } \\
\mathrm{n}=142\end{array}$ \\
\hline Shame & $6.71(2.60)$ & $7.81(4.01)$ & .89 \\
\hline Guilt & $7.39(2.87)$ & $8.37(3.84)$ & .82 \\
\hline Pride & $16.83(4.05)$ & $15.90(4.90)$ & .87 \\
\hline
\end{tabular}

Participants reported higher levels of shame following the shame induction, as compared to nonshamed control participants $(\mathrm{t}=-1.89, \mathrm{p}<.05)$. Participants who were shamed also reported greater levels of guilt than did control participants $(\mathrm{t}=-1.69, \mathrm{p}<.05)$.

\section{Scoring}

Each scale consists of 5 items:

- Shame - Items 2, 5, 8, 11, 14

- Guilt - Items 3, 6, 9, 12, 15

- Pride - Items 1, 4, 7, 10, 13

All items are scored in a positive direction.

\section{References}

Marschall, D. E. (1996). Effects of induced shame on subsequent empathy and altruistic 
MORAL INJURY, SHAME, GUILT, AND SELF-FORGIVENESS

behavior. Unpublished master's thesis, George Mason University, Fairfax, VA.

Marschall, D. Saftner, J., \& Tangney, J. P. (1994). The State Shame and Guilt Scale. George Mason University, Fairfax, VA.

For additional information:

June Price Tangney, Ph.D.

Department of Psychology

George Mason University

Fairfax, VA 22031 
MORAL INJURY, SHAME, GUILT, AND SELF-FORGIVENESS

\section{Appendix K: Permission to Use the Heartland Forgiveness Scale (HFS)}

On Thu, Sep 13, 2018 at 7:37 AM Squarespace<no-reply@squarespace.info> wrote:

Name: Timothy Swiger

Email Address: tswiger2@mix.wvu.edu

Subject: HFS

Message: Hello,

I am emailing you for permission to use the Heartland Forgiveness Scale. I am also inquiring if it would be possible for me to use just the self-forgiveness subscale. I am examining combat

Veterans who struggle with shame and guilt and would like to use the HFS, as the HFS has been used in multiple studies with Veterans. Thank you for your time.

Respectfully,

Tim Swiger, M.S., C.R.C.

West Virginia University

United States Marine Corps

(910)787-6798

Dear Timothy Swiger,

You may use the Heartland Forgiveness Scale for your research.

Regards,

Laura

(Sent via H.F.S.)

Yes, it is appropriate to report the self-forgiveness subscale score alone. 
MORAL INJURY, SHAME, GUILT, AND SELF-FORGIVENESS

Here is an excerpt about the factor structure of the HFS that will be included in an upcoming chapter about measuring forgiveness.

"Confirmatory factor analyses of the HFS items indicated that a three-factor solution corresponding only to type of forgiveness (i.e., self, other, and situation) did not fit adequately. Adding uncorrelated method factors related to item wording (i.e., positive and negative wording) did result in an acceptably fitting model, and factor loadings related to forgiveness type were greater than those related to wording (Thompson et al., 2005). Thus, the HFS measures three aspects of forgiveness through two methods of wording. It is therefore recommended that HFS subscale scores be reported. This finding also suggests that it may be important for forgiveness measures to contain items worded in both a forgiving and an unforgiving manner. The HFS has been translated into at least 17 languages (see: http://www.heartlandforgiveness.com).” 


\title{
Appendix L: Permission to Use the Heartland Forgiveness Scale (HFS)
}

\author{
Laura Thompson and C.R. Snyder (C) August 1, 1999
}

\section{HFS}

Directions: In the course of our lives negative things may occur because of our own actions, the actions of others, or circumstances beyond our control. For some time after these events, we may have negative thoughts or feelings about ourselves, others, or the situation. Think about how you typically respond to such negative events. Next to each of the following items write the number (from the 7-point scale below) that best describes how you typically respond to the type of negative situation described. There are no right or wrong answers. Please be as open as possible in your answers.

$\begin{array}{llllllll}1 & 2 & 3 & 4 & 5 & 6 & 7\end{array}$

$\begin{array}{cccc}\text { Almost Always } & \text { More Often } & \text { More Often } & \text { Almost Always } \\ \text { False of Me } & \text { False of Me } & \text { True of Me } & \text { True of Me }\end{array}$

1. Although I feel badly at first when I mess up, over time I can give myself some slack.

2. I hold grudges against myself for negative things I've done.

3. Learning from bad things that I've done helps me get over them.

4. It is really hard for me to accept myself once I've messed up.

5. With time I am understanding of myself for mistakes I've made.

6. I don't stop criticizing myself for negative things I've felt, thought, said, or done.

7. I continue to punish a person who has done something that I think is wrong.

8. With time I am understanding of others for the mistakes they've made.

9. I continue to be hard on others who have hurt me.

10. Although others have hurt me in the past, I have eventually been able to see them as good people.

11. If others mistreat me, I continue to think badly of them.

12. When someone disappoints me, I can eventually move past it.

13. When things go wrong for reasons that can't be controlled, I get stuck in negative thoughts about it. 
MORAL INJURY, SHAME, GUILT, AND SELF-FORGIVENESS

14. With time I can be understanding of bad circumstances in my life.

15. If I am disappointed by uncontrollable circumstances in my life, I continue to think negatively about them.

16. I eventually make peace with bad situations in my life.

17. It's really hard for me to accept negative situations that aren't anybody's fault.

18. Eventually I let go of negative thoughts about bad circumstances that are beyond anyone's control.

\section{HFS Scoring Instructions}

Four scores are calculated for the Heartland Forgiveness Scale (HFS):

Total HFS (items 1-18) HFS Forgiveness of Self subscale (items 1-6) HFS Forgiveness of Others subscale (items 7-12) HFS Forgiveness of Situations subscale (items 13-18)

To score the HFS:

1. Scores for items $1,3,5,8,10,12,14,16, \& 18$ are the same as the answer written by the person taking the HFS. Scores for items 2, 4, 6, 7, 9, 11, 13, 15, and 17 are reversed. For example, an answer of 1 is given a score of 7 and an answer of 7 is given a score of 1 . Refer to the tables below for more information about scoring individual items.

2. To calculate the Total HFS, HFS Forgiveness of Self, HFS Forgiveness of Others, and HFS Forgiveness of Situations, sum the values for the items that compose each scale or subscale (with appropriate items being reverse scored). Scores for the Total HFS can range from 18 to 126. Scores for each of the three HFS subscales can range from 6 to 42.

Scoring

Scoring Items 1, 3, 5, 8, 10, 12, 14, 16, \& 18

Person's Answer Item Score

\begin{tabular}{|l|l|}
\hline 1 & 1 \\
\hline 2 & 2 \\
\hline 3 & 3 \\
\hline 4 & 4 \\
\hline 5 & 5 \\
\hline 6 & 6 \\
\hline 7 & 7 \\
\hline
\end{tabular}

Reverse-Scoring

Items 2, 4, 6, 7, 9, 11, 13, 15, \& 17

Person's Answer Item Score

\begin{tabular}{|l|l|}
\hline 1 & 7 \\
\hline
\end{tabular}




\begin{tabular}{|l|l|}
\hline 2 & 6 \\
\hline 3 & 5 \\
\hline 4 & 4 \\
\hline 5 & 3 \\
\hline 6 & 2 \\
\hline 7 & 1 \\
\hline
\end{tabular}

\section{Interpreting HFS Scores}

The Heartland Forgiveness Scale (HFS) is an 18-item, self-report questionnaire designed to assess a person's dispositional forgiveness (i.e., one's general tendency to be forgiving), rather than forgiveness of a particular event or person. The HFS consists of items that reflect a person's tendency to forgive him or herself, other people, and situations that are beyond anyone's control (e.g., a natural disaster).

Four scores are calculated for the HFS. There is a score for the Total HFS and a score for each of the three HFS subscales (HFS Forgiveness of Self subscale, HFS Forgiveness of Others subscale, and HFS Forgiveness of Situations). Scores for the Total HFS can range from 18 to 126. Scores for the three HFS subscales can range from 6 to 42 .

\section{Total HFS}

One's score on the Total HFS indicates how forgiving a person tends to be of oneself, other people, and uncontrollable situations. Higher scores indicate higher levels of forgiveness, and lower scores indicate lower levels of forgiveness.

- A score of 18 to 54 on the Total HFS indicates that one is usually unforgiving of oneself, others, and uncontrollable situations. •

- A score of 55 to 89 on the Total HFS indicates that one is about as likely to forgive, as one is not to forgive oneself, others, and uncontrollable situations.

- A score of 90 to 126 on the Total HFS indicates that one is usually forgiving of oneself, others, and uncontrollable situations.

\section{HFS Subscales}

One's score on the three HFS subscales indicate how forgiving a person tends to be of oneself (HFS Forgiveness of Self), other people (HFS Forgiveness of Others), or situations beyond anyone's control (HFS Forgiveness of Situations). Higher scores indicate higher levels of forgiveness, and lower scores indicating lower levels of forgiveness.

- A score of 6 to 18 on HFS Forgiveness of Self, HFS Forgiveness of Others, or HFS Forgiveness of Situations indicates that one is usually unforgiving of oneself, other people, or uncontrollable situations, respectively.

- A score of 19 to 29 indicates that one is about as likely to forgive as to not forgive oneself, other people, or uncontrollable situations, respectively.

- A score of 30 to 42 indicates that one is usually forgiving of oneself, other people, or uncontrollable situations, respectively. 


\section{Appendix M: Statistical Assumptions}

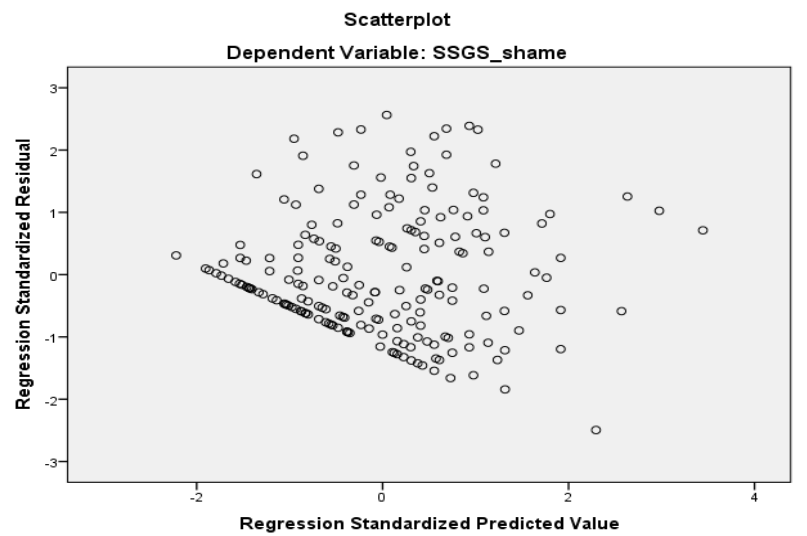

Figure 1. Scatterplot Testing Linearity and Homoscedasticity for Shame Alone.

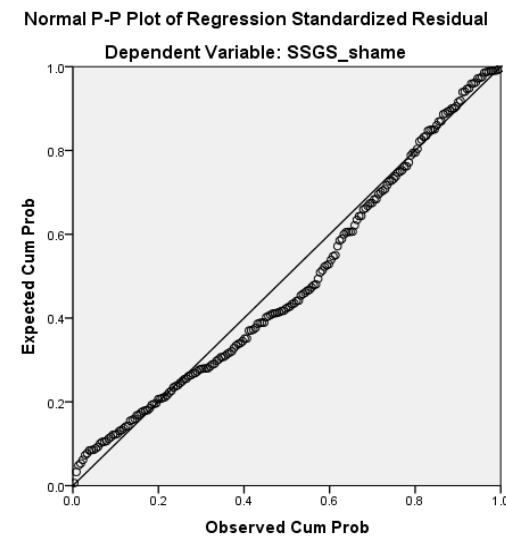

Figure 3. Normal P-P Plot Testing Normality for Shame Alone.

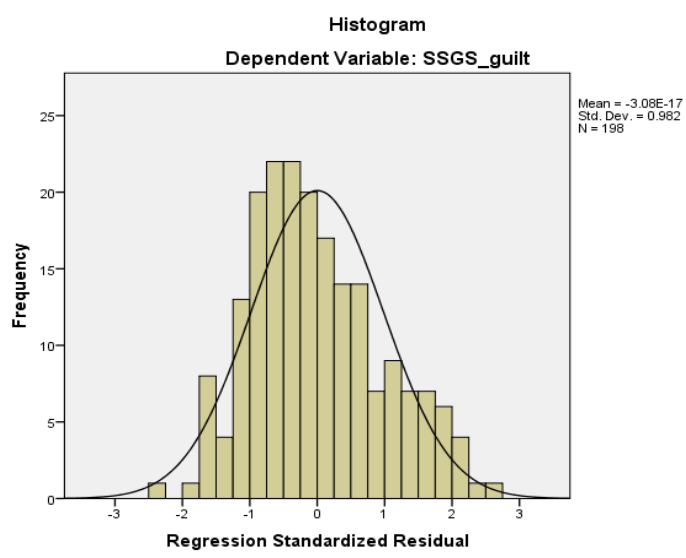

Figure 5. Histogram Testing Normality for Guilt Alone.

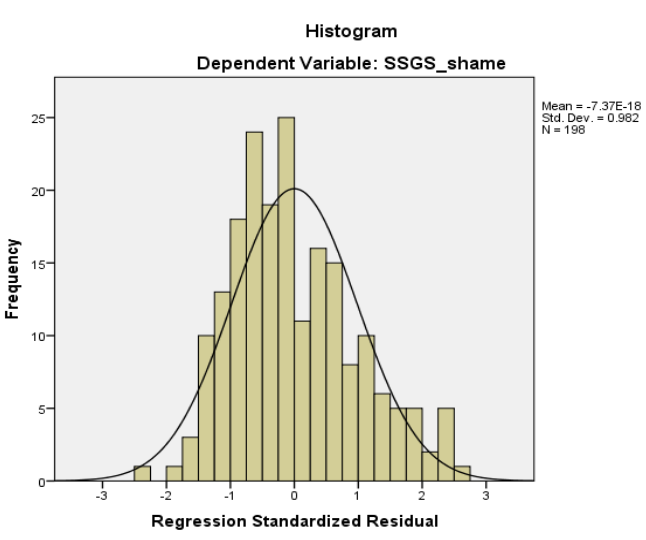

Figure 2. Histogram Testing Normality for Shame Alone.

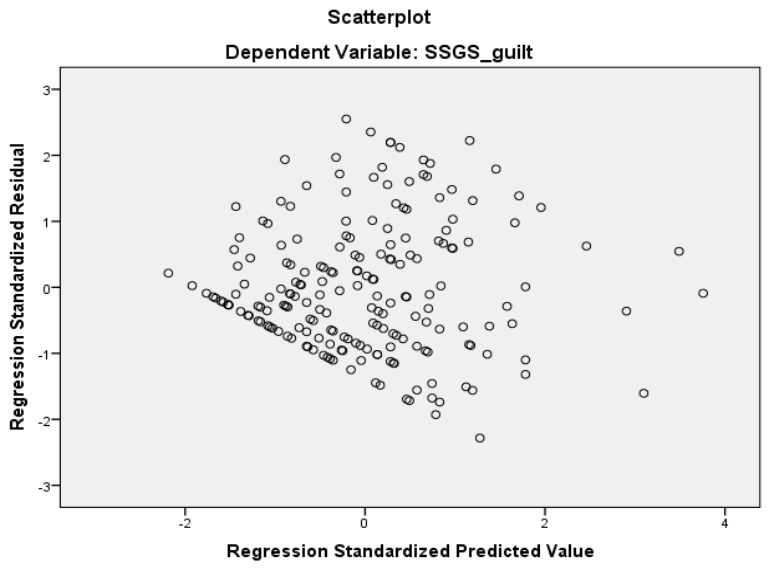

Figure 4. Scatterplot Testing Linearity and Homoscedasticity for Hypothesis Guilt Alone

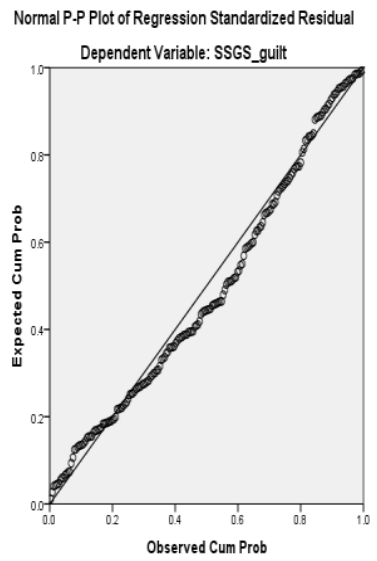

Figure 6. Normal P-P Plot Testing Normality for Hypotheses Guilt Alone. 


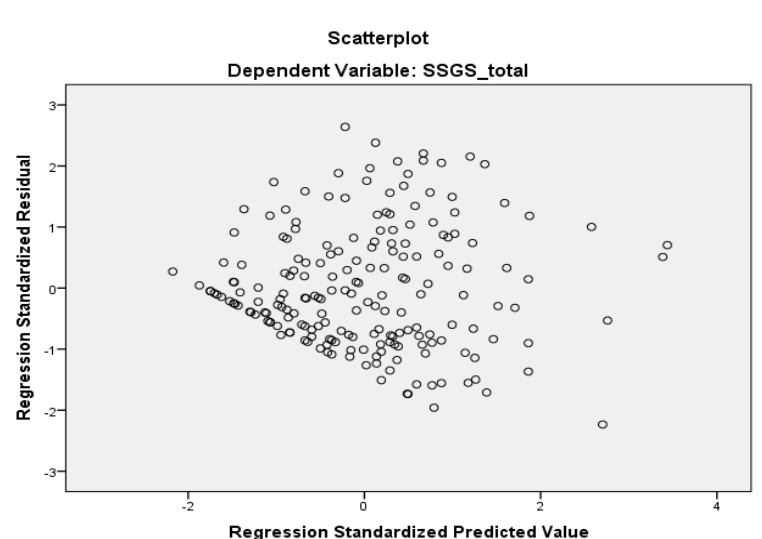

Figure 7. Scatterplot Testing Linearity Homoscedasticity for Shame and Guilt Combined.

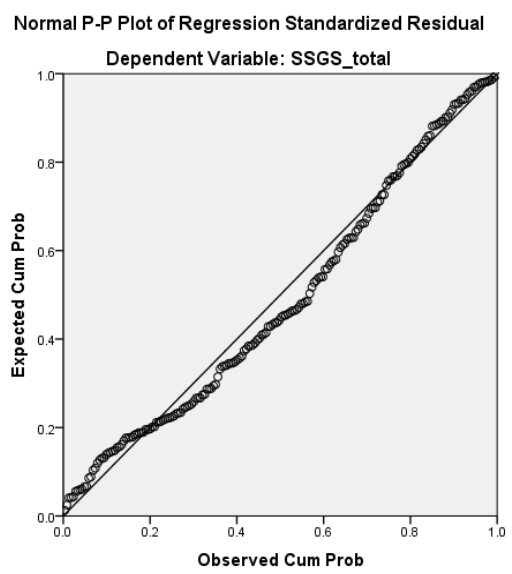

Figure 9. Normal P-P Plot Testing Normality for Shame and Guilt Combined.

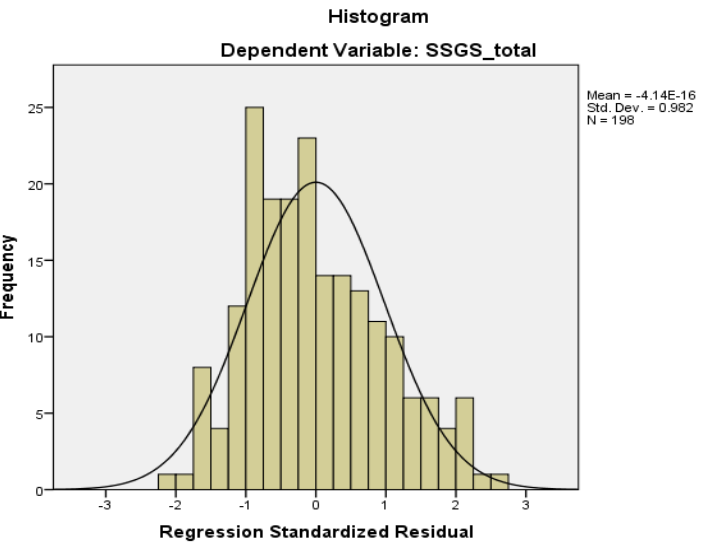

Figure 8. Histogram Testing Normality for and Shame and Guilt Combined. 
EDUCATION

\section{CURRICULUM VITAE}

Timothy A Swiger, M.S., C.R.C.

West Virginia University

Doctorate in Counseling Psychology

Advisor: Jeffrey Daniels, Ph.D.

West Virginia University

Masters in Rehabilitation Counseling

August 2013 - May 2015

Advisor: Margret Glenn, Ph.D.

Glenville State College

August 2010 - May 2013

Bachelor of Science in Psychology and Sociology

Minor: Non-Profit Business Management

\section{CLINICAL}

EXPERIENCE

Psychology Intern

July 2018 - Present

Lexington VA Medical Center

U.S. Department of Veterans Affairs

Supervisor: Dr. Joshua Phillips

- Completed 6-month major rotation with the Residential Rehabilitation Program

- Provided Individual Substance Abuse Treatment and Case Management

- Developed and Implemented Acceptance and Commitment Therapy Group

○ Provided Cognitive Processing Therapy for PTSD

- Conducted psychodiagnostic assessments, scored and wrote integrated reports, and provided feedback to Veterans.

- Completed 6-month minor rotation with Home-Based Primary Care

- Provided individual and family therapy to Veterans and their Caregivers

- Completed REACH VA protocol for Caregiver Support

- Conducted cognitive, mood, and capacity assessments.

- Attended Didactic presentations and clinical training.

- Completed appropriate paperwork (e.g. progress notes, intake forms, termination reports, continuation plans, etc.) in a timely manner.

- Participated in weekly individual and group supervision with licensed supervisor and doctoral trainees.

- Facilitated appropriate referrals within the VA medical center and supported continuity of care via referrals to other VA medical centers for longer-term treatment.

Advanced Clinical Practicum Student

August 2018 - May 2019

Louis A. Johnson VA Medical Center

U.S. Department of Veterans Affairs

Supervisor: Dr. Charlton-Fryer

- Provided individual and group structured psychological services through the Mental

Health Residential Rehabilitation Treatment Program.

- Implemented Cognitive-Processing Therapy. 
- Attended Didactic presentations and clinical training.

- Conducted intake interviews, psychological assessments, and compose comprehensive report writing.

Advanced Clinical Practicum Student

August 2017 - May 2018

VA Pittsburgh Healthcare System

U.S. Department of Veterans Affairs

Supervisor: Dr. Stephen Huegel

- Provided individual and group structured mental health services through the schizophrenia specialty outpatient clinic.

- Conducted clinical interviews and psychological testing in the short-term inpatient unit.

- Participated in individual supervision and treatment team meetings to address client concerns and evidenced-based practices.

Advanced Clinical Practicum Student

William R. Sharpe Jr. Hospital

May 2016 - May 2017

West Virginia Department of Health and Human Resources

Supervisors: Theodor Glance, M.S., Wilda Posey, M.S., \& Thomas Bell, Ph.D.

- Conduct clinical interviews, and administer psychological testing batteries to forensic patients. Score assessment measures using the appropriate software. Compose comprehensive reports, including background history, test results, summary and diagnoses, and recommendations. Provide feedback sessions with clients regarding testing results.

- Participate in individual and group supervision to provide case conceptualizations and discuss client concerns with licensed psychologists and other mental health professionals. Attend educational presentations regarding relevant clinical care services.

- Conduct triage assessments and intakes, and provide individual counseling sessions with a diverse forensic inpatient population. Provide crisis intervention services when necessary. Complete appropriate paperwork (e.g., progress notes and intake paperwork) within the CareVue software. Completed continuation of treatment forms, as appropriate.

- Participate as a member of the facility interdisciplinary team.

- Develop, organize, and lead emotion regulation groups for patients relating to mental health concerns (e.g., stress and anger management).

- Developed, organized, and co-led weekly medication and diagnosis education drop-in groups for patients.

- Observed and co-led competency restoration groups.

Master's Level Practicum Student

August 2014 - May 2015

Louis A. Johnson VA Medical Center

U.S. Department of Veteran Affairs

Clarksburg, WV

Total Clinical Hours: 750+

Supervisors: Heather Brown, PhD. \& Kara Tustin, M.S., CRC

- Conducted intake interviews with Veterans for the Compensated Work Therapy (CWT) program, implemented CWT plans on an individualized basis and conducted annual plan reviews. 
- Co-facilitated psychoeducational groups for Veterans experiencing anger and substance abuse.

- Performed work site and job analysis, and provided vocational counseling.

- Developed curriculum for weekly sessions including topics relating to social norms, overcoming challenges, goals, community, and family influences.

- Composed initial assessment reports, case notes, treatment plans, crisis response plans, transfer reports, and termination letters and reports. Maintained an accurate record of contact with clients.

- Participated in weekly individual supervision with a licensed psychologist and obtained feedback. Presented case conceptualizations for supervisors.

\section{RELATED}

\section{EMPLOYMENT}

Graduate Research Assistantship

August 2016 - May 2017

College of Education \& Human Services

West Virginia University

- Complete literature reviews, as needed, for research articles.

- Performed data entry of assigned research project for statistical analysis.

- Concerning Veterans Area of Emphasis (AOE), assisted the supervisor in developing and editing course rubrics; revising course syllabi; organizing and finalizing documents for proposed focus.

- Participated in meetings with faculty and community health providers from VA medical centers to determine training goals and initiatives.

\section{Provost Fellow}

May 2016 - August 2016

College of Education \& Human Services

West Virginia University

- Reviewed literature related to female Veterans' access to transitional programs and biopsychosocial needs. Collected strategic learning data, and composed document draft addressing transitional programming needs.

- Assisted in compiling data for a proposed Veterans Area of Emphasis.

- Participated in meetings with related faculty to determine program goals and initiatives.

Graduate Research Assistantship

August 2014 - May 2015

College of Education \& Human Services

West Virginia University

- $\quad$ Acted as a liaison between the research assistants and department faculty to manage and organize data, distribute related information, and schedule meetings.

- $\quad$ Assisted other department faculty with research duties, as needed.

- Developed and organized presentation material utilizing interactive media for research conferences.

- $\quad$ Abetted program assistant with clerical admissions of new applicants.

- Selected as a student representative for a search committee for the incoming faculty member(s). Student interviewer for incoming doctoral candidates.

- Contributed to the completion of the 2013-2014 grant report. 
Rifleman

United States Marine Corp, Camp Lejeune, N.C.

- $\quad$ Achieved the rank of Corporal

- $\quad$ Supervised a squad of fifteen military personnel during combat operations.

- $\quad$ Completed two decorated combat tours in Afghanistan (2007-2008; 2008-2009)

- $\quad$ Earned the Navy-Marine Corps Achievement Medal for a medical application that resulted in saving 3 Afghan national lives.

\section{TEACHING \& ACADEMIC COACHING}

\section{EXPERIENCE}

Instructor

August 2018 - August 2019

Counseling 405 Career and Lifespan Development

West Virginia University

- Implemented course material for two sections of 405 focused on the human service profession, multiculturalism and diversity for aspiring social service and mental health professionals.

Instructor

August 2017 - August 2018

Counseling 303 Introduction to the Helping Profession and

Counseling 405 Career and Lifespan Development

West Virginia University

- Designed and implemented course material for section 405 focused on the human service profession, multiculturalism, and diversity for aspiring social service and mental health professionals.

- Graded student assignments (e.g., discussion posts, participation, and papers) and uploaded grades.

- Maintain online database deadlines and technical troubleshooting for students.

- Responsible for answering student questions about assignments or technical problems promptly.

Instructor

August 2015 - May 2016

First-Year Seminar 191

West Virginia University

- Maintain online database deadlines and technical troubleshooting for students.

Responsible for answering student questions about assignments or technical problems promptly.

- Graded student assignments (e.g., discussion posts, participation, and papers) and uploaded grades.

- Prepared and executed lecture materials for five sections of First-Year Seminar courses through the fall semester of 2015.

- Created individualized academic success plans for students throughout the spring semester of 2016.

- Provided individual success coaching with students. 


\section{PROFESSIONAL} PRESENTATIONS

Swiger, T., Molder, A., \& Fais, C. (2018, April). The Opioid Epidemic: Counseling

Psychology's Role in Prevention and Recovery. Round table discussion presented at the 2018 Great Lakes Regional Conference.

Swiger, T., \& Bridendolph, N. (2017, October). Do Opioid Prevalence Rates in Geographic Regions Correlate with High-Risk Opioid Use among Iraq and Afghanistan Veterans? Poster session presented at the 2017 West Virginia Psychology Association Conference.

Swiger, T., \& Daniels, J. (2017, August). What do counseling psychology students need to know when working with Veterans? Poster session presented at the 2017 APA National Convention, Washington, D.C.

Swiger, T. (2017, May). West Virginia Veterans and counseling psychology: A testimonial. Talk session presented at the spring 2017 Advisory Committee to the Dean of the College of Education and Human Services, Morgantown, WV.

Swiger, T. (2017, April). Veterans and Mental Health Consequences: Moral Injury. Talk session presented at the 2017 West Virginia University Mountaineer Talk Series, Morgantown, WV.

Swiger, T. (2017, April). Moral Injury: A conceptual model for healing. Poster session presented at the 2017 West Virginia University Celebration of Scholars Event, Morgantown, WV.

Latorre, C., \& Swiger, T. (2017, March). Recognizing racial trauma: Raising awareness and advocacy implementation. Symposium presented at the 2017 Great Lakes Regional Counseling Psychology Conference, Muncie, IN.

Swiger, T. (2017, March). Hope and self-forgiveness among morally injured combat Veterans. Poster session presented at the 2017 Great Lakes Regional Counseling Psychology Conference, Muncie, IN.

Swiger, T. (2016, October). Moral injury construct relevance among Operation Enduring Freedom $(\mathrm{OEF})$ and Operation Iraqi Freedom (OIF) Veterans: A literature review. Poster session presented at the 2016 West Virginia Psychological Association Fall Conference, Roanoke, WV.

Fais, C., \& Swiger, T. (2016, April). Forgiveness and Hope as a Pathway to Anger Reduction. In S. B. Milam (Chair), Forgiveness and hope as pathways to decrease prejudice and increase inclusivity in a multicultural society following terrorism. Symposium presented at the 2016 Great Lakes Regional Counseling Psychology Conference, Bloomington, IN.

Swiger, T. (2014, July). Military transitioning to civilian life: A Veteran's perspective. Poster session presented at National Association of Multicultural Rehabilitation Concerns, St. Louis, MO. 


\section{SOCIAL JUSTICE \& OUTREACH INITIATIVES}

Hurricane Harvey Flood Relief

August 2017

- Organized and collected food and cleaning materials

- Collected funds for postal shipping and prearranged donation transport

VFW Post 5469 Veterans Golf Tournament

June 2017

- Organized and support logistics and sought community resources to benefit West Virginia Veterans nursing facilities and Cruz Strong (i.e., cancer expenses for a local child).

SORO Food Drive

November 2016

- Collected and distributed food for homeless Veterans.

Jobs4Life March 2016

- Presented on effective communication and interviewing skills for individuals participating in Jobs4Life programming.

VFW Post 5469 Veterans Golf Tournament May 2015 \& 2016

- Organized and support tournament proceedings and donated raised funds to Wounded Warrior Project and Clarksburg, WV VAMC.

Winter Weather Posse

October $2014 \& 2015$

- Weatherized homes for the elderly of Morgantown, WV

\section{PROFESSIONAL}

\section{MEMBERSHIPS}

American Counseling Association

2013 - Present

American Psychological Association (APA) of Graduate Students (APAGS)

2015 - Present

APA Division 17

2015 - Present

APA Division 19

2015 - Present

American Red Cross

2011 - Present

(Recipient, American Red Cross Humanitarian Award, March 2011)

Veterans of Foreign Wars (VFW)

2013 - Present

(Served as Secretary 2013-2014)

Veterans of West Virginia University

2015 - Present

West Virginia Psychological Association (WVPA)

$2016-2018$

Association of Military Psychology (AMP)

$2014-2017$ 
MORAL INJURY, SHAME, GUILT, AND SELF-FORGIVENESS

(Served as Vice President 2014 - 2016)

Chi Sigma Iota

$2013-2015$

Speak Out Reach Out (SORO)

$2016-2018$

Student Veterans Association (SVA)

$2011-2013$

(Served as Vice-President 2012-2013) 